\title{
The Central Area of a" Square" from the Time of Turdaș Culture Turdaș-Luncă. 2011 Campaign. Sector C The Architectural Horizon before the great Migration from Turdaș
}

\begin{abstract}
The preventive excavation from 2011, at Turdaş-Luncă, led to the discovery of over 2000 archaeological features. Among them is feature 959. Through this article we want to continue the series of publications related to the preventive excavation of 2011 and highlight certain aspects related to a possible organization of the communities that lived here.
\end{abstract}

Keywords: preventive research, Turdaş-Luncă, feature 959, Transylvania, Romania.

As we already know, in Hunedoara county a multitude of settlements are located on the terraces dug by the rivers over time. Among them is the site from Turdaș ${ }^{1}$. Turdaș commune was attested in $1332^{2}$, but - as an area - it was inhabited long before. In its south-west side, on the left bank of the Muress river, is the site of Turdaș-Luncă (Map 1-2), a site that became known since 1860, but which benefited from a first mention a few years later, in $1866^{3}$.

From now on, a series of surface investigations/research would follow ${ }^{4}$ some with published results ${ }^{5}$. All these were to materialize starting with 1992 in the form of systematic field research, led by Sabin Adrian Luca, concluded in $1998^{6}$.

* "Lucian Blaga" University of Sibiu, Brukenthal National Museum, Sibiu,
florentin_florentin13@yahoo.com

${ }^{1}$ Sabin Adrian Luca," Descoperiri preistorice din judetul Hunedoara - din Paleolitic până la începutul civilizației dacice", în SUC.SH, II, 2005, p. 7-51, 38, Point 187; A.T. Marc," Contribuții la repertoriul arheologic al județului Hunedoara. Descoperiri recente pe raza comunei Turdaș", în Sargetia (SN), I, 2010, p. 38-63, 38-41.

2 Ghinea Enciclopedia Geografică a României, Vol. III (R-Z), (Bucuresti: Editura Enciclopedică, 1998), 320; Sabin Adrian Luca, Cercetarile arheologice preventive de la Turdass-Lunca (jud. Hunedoara). Campania 2011, în BB, LIX, (Sibiu: Editura Muzeului Naţional Brukenthal, 2012), 7.

${ }^{3}$ Carl Gooss, "Skizzen zur vorrömischen Kulturgeschichte der mittleren Donaugegenden", in $A V S L, 14,1,1877$, p. 47-175, 103

${ }^{4}$ Sabin Adrian Luca, Cercetările arheologice preventive de la Turdaș-Luncă, 11-18.

${ }^{5}$ We mention a few: Marton Roska, Die Sammlung Zsófia von Torma, (Cluj, 1941); Florin Drașovean, T. Mariş," Cercetări arheologice de suprafață în așezarea neolitică de la Turdaş (jud. Hunedoara)", în Sargetia, XVI-XVII, 1982-1983, p. 89-94; Zoia Kalmar, Turdaş, (Cluj-Napoca, 1991).

${ }^{6}$ Results published in: Sabin Adrian Luca," Așezarea de la Turdaş - situaţia actuală a sitului arheologic (II)", în AICSU, 3, 1996, p. 27-30; Sabin Adrian Luca, Aşezări neolitice pe valea Mureşului (II). Noi cercetări arheologice de la Turdaş-Luncă. I. Campaniile anilor 1992-1995, în BMA, XVII, (București: Editura Economică, 2001); Sabin Adrian Luca (cu contribuții de: Dragoș Diaconescu, Cristian Roman, 
In 2007-2008, a magnetometric research was carried out ${ }^{7}$ in Turdaș-Luncă and one in $2011^{8}$. The AFCN project entitled Primul oraș preistoric datat cu mijloace moderne din România was also carried out and the series of large-scale preventive research was opened, concluded in 2019 with impressive results ${ }^{9}$, and contradictory discussions appeared, discussions we distance ourselves from ${ }^{10}$.

The plateau on which the settlement is located has been conventionally divided into systematic research, in three large areas ${ }^{11}$, in order to follow the horizontal stratigraphy of the Neolithic and Eneolithic settlements from the perimeter of the site.

As a result of the preventive excavation carried out in 2011, the sectors in which the surface of the site was divided are the following: area A $(\mathrm{km} 11+200-$

Georgeta El Susi, Florentin Perianu, Adrian Luca), Așezări neolitice pe valea Mureșului (III). Campaniile anilor 1996-1998, în BS, XXV, (Sibiu: Editura Universității” Lucian Blaga", 2018)

7 C. Mischka," Geomagnetische Prospektion neolithischer und kupferzeitlicher Siedlungen in Rumänien”. In Eurasia Antiqua, 14, 2008, p. 105-106.

${ }^{8}$ Some of the results have already been printed - we mention Sabin Adrian Luca, Cercetările arheologice preventive de la Turdaș-Luncă (jud. Hunedoara). Campania 2011; S.A. Luca (coordonator), Fl. Dumitrescu-Chioar, Gh.V. Natea, Fl/M. Niţu, M.-R. Teodorescu, V. Palaghie, A. Tudorie, C. Beldiman, M.C. Căstăian, V.C. Sava, C.I. Suciu, S. Tincu, "Şantierul arheologic TurdaşLuncă, campania anului 2011". In: CCA, 2012, p. 292-293; Sabin Adrian Luca; Adrian Georgescu; Gheorghe V. Natea; Raluca Maria Teodorescu; Claudia Urduzia; Claudiu I. Munteanu; Vasile Palaghie; Adrian Luca, Cercetarea preventivă. Provocarea arheologică a zilelor noastre, în $B B$, LXV, (Sibiu: Editura Muzeului Național Brukenthal, 2013), 9-32; Sabin Adrian Luca, Cosmin I. Suciu," The eneolithic fortification system of Turdaș-Luncă, Hunedoara County, Romania".In Pradziejowe osady obronne w Karpatach, 2015, p. 43-60; Sabin Adrian Luca, Florentin Perianu, Sergiu Chideșa, "Câteva amănunte despre complexele arheologice C32-33 din situl de la Turdaș-Luncă, jud. Hunedoara (I). Săpăturile preventive ale anului 2011". In Studia in Honorem Florea Costea, 2017, p. 32-50; Sabin Adrian Luca, Florentin Perianu, Sergiu Chideșa," Some details regarding the archaeological feature $\mathrm{C}_{23}$ from Turdaş-Luncă site, Hunedoara County (II). The preventive excavations from 2011" în ActaTS, XVI, 2017, p. 21-59; Sabin Adrian Luca, Florian Dumitrescu-Chioar, Tiberiu B. Sava, Doru Păceșilă, Oana Gaza, Iuliana Stanciu, G. Sava, B. Ștefan, Florentin Perianu," Radiocarbon data from the TurdașLuncă archaeological site. Petrești culture. (Preventive research of 2011) (II)". In: ActaTS, XVII, 2018, p. 115-120; Sabin Adrian Luca," Some details about the $\mathrm{C}_{403}$ archaeological feature from the site of Turdaș-Luncă, Hunedoara County (III). Petrești culture. Preventive excavations of the year 2011”. In: ActaTS, 2018, p. 121-131; Sabin Adrian Luca (cu contribuții de: Fl. Perianu), Un oraș preistoric din Europa. Turdaș-Luncă. Sectorul A. I.1, în BS, XXVI, (Sibiu: Editura Universității” Lucian Blaga”, 2019); S.A. Luca (cu contribuții de: Vasile Palaghie, Florentin Perianu), Un oraș preistoric din Europa. Turdaș-Luncă. Sector B. II.1 în BS, XXVII, (Sibiu Editura Universității” Lucian Blaga", 2019); Sabin Adrian Luca, Florentin Perianu, "Turdaș-Luncă. 2011 preventive campaign. Sector B. Feature 341-2. A ritual pit? Turdaș culture, phase III". In: ActaTS, XVIII, 2019, p. 5-21; Sabin Adrian Luca, Tiberiu B. Sava, M. Ilie, A. Dima, D. Pascal, G. Sava, C. Mănăilescu, Floretin Perianu, Raluca Maria Teodorescu," Radiocarbon data from the archaeological site of Turdaș-Luncă (preventive research of 2011) (IV)". In: ActaTS, XVIII, 2019, p. 93-112.

${ }^{9}$ Sabin Adrian Luca, Gheorghe Natea, Vasile Palaghie," Data about stylized bull/calf heads from Turdaş excavations". In: Annales d'Université Valahia, XXI, 2019, p. 29-37.

${ }^{10}$ Dragoș Diaconescu," Despre cultura Turdaș și poziția sa cronologică”. In: AB, S.N., XXII, 2014, p. 67-88.

${ }^{11}$ Sabin Adrian Luca, Aşezări neolitice pe valea Mureşului (II). Noi cercetări arheologice de la TurdaşLuncă. I. Campaniile anilor 1992-1995, în BMA, XVII, (București: Editura Economică, 2001), Plan 1. 
$11+400$; in the east of the site), area B ( $\mathrm{km} \mathrm{11+400} \mathrm{-} \mathrm{11+900;} \mathrm{central} \mathrm{area),} \mathrm{which}$ in turn was subdivided into area B east and B west and area C (km 11+900-12+450; west part; Plan 1$)^{12}$.

Focusing on the area that is the subject of this study, namely (area) sector C, mention the presence of the following stratigraphy:

- 0-0,4 $\mathrm{m}$ - the greyish-yellowish arable layer appears.

- 0,4-0,8 $\mathrm{m}$ - clayey black layer, with traces of burnt platforms in the west zone, from here starting in sterile soil most of the archaeological features.

- 0,8-1,2/1,3 m - light brown soil with rare ceramic fragments.

- Under 1,2/1,3 m - sterile, geological, clayey, brown layer appears.

- In sterile soil appears archaeological features (black color with yellow clay inserts, black with ceramic pigment) that reach up to $3,5 \mathrm{~m}$ depth.

Following the preventive excavation from 2011, a number of approximately 2000 features resulted, including feature 959. It consisted of approximately 4000 ceramic fragments outside the lithic and osteological material.

Feature 959 was identified in sector C, in the N-E part of it (Plan 2), being surrounded by several dwelling structures. It is noted that in the $\mathrm{S}-\mathrm{V}^{13}$ and the central-eastern part of this sector, are other agglomerations of structures, similar to those from N-E.

Feature 959 (I want to thank S.A. Luca for the archaeological materials offered to carry out this work and colleague V. Palaghie for the adjacent information) is represented by a large deep dwelling, with an approximately quadrilateral shape, belonging to the Turdaș culture. It has a filling with several layers and after abandonment it is transformed into a possible household pit. The filling has several layers (Drawing 2, Photo 1):

- black greyish with adobe pigments and ceramic fragments.

- black greyish with rare ceramic fragments.

- agglomeration of ceramic and osteological materials mixed with black soil.

- black soil mixed with ceramic materials.

- black with yellow pigment, adobe, ceramic fragments and osteological material.

- black mixed with yellow, adobe pigment and ceramic materials.

- black soil lenses alternating with yellow lenses.

This feature has many fragments of adobe with traces of beams and poles, thrown in, many ceramic fragments but also whole vessels (Luca et al 2013, 16-17).

In the upper part the ceramic material is very fragmentated and in the lower part material is much better preserved and belongs to the moment of abandonment

\footnotetext{
${ }^{12}$ Sabin Adrian Luca, Cercetările arheologice preventive de la Turdaş-Luncă, 20.

${ }^{13}$ For Structure 29, see Gheorghe Lazarovici, Sabin Adrian Luca, Gheorghe Natea, Cosmin Suciu, Mihai Căstăian, "Turdaș, C sector, reconstruction of feature or St. 29 based on ethno-archeological studies". In: Acta TS, XIII, 2014, p. 73-111, 73-111; for structure 28, see Sabin Adrian Luca, Cercetările arheologice preventive de la Turdaș-Luncă, 77-100.
} 
of the feature. The feature also had a rich lithic inventory which will be presented with another occasion.

The depth of the feature is $2,40 \mathrm{~m}$ from the contour level of the pit, the length is 4,90 $\mathrm{m}$ and the width is 4,80 $\mathrm{m}$ (Drawing 1 , Photo 2).

Technological aspects of ceramics from the feature 959

As mentioned above, the 959 features provided a fairly rich archaeological inventory. From this inventory, most was represented by pottery (approximately 4000 fragments), which we will deal with in the following rows.

From the point of view of the technology of making ceramic, we find, as can be seen from Graphic 1, below, that all 3 categories are somewhat balanced represented, $39 \%$ being the percentage of rough ceramics, $26 \%$ semi-fine ceramics and $35 \%$ fine ceramics. The categories are distributed as follows:

Category

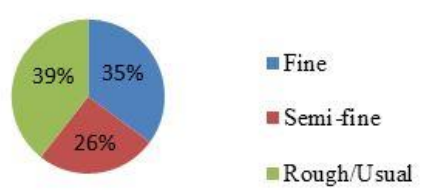

Graphic 1. Turdaș-Luncă. 2011 campaign. Sector C. Feature 959. Turdaş culture, phase III. Graphic with percentage analysis of ceramic categories.
Firing

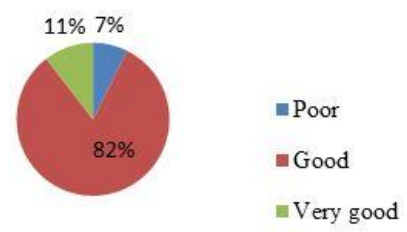

Graphic 2. Turdaş-Luncă. 2011 campaign. Sector C. Feature 959. Turdaş culture, phase III. Graphic with percentage analysis of firing categories.

- fine - Pl. I/1,3,4; Pl. II/1-6,8; Pl. III/2-6; Pl. IV/1-5; Pl. V/1-7,9; Pl. VI/1-6; Pl. VII/1-3; Pl. VIII/2, 3; Pl. XIV/1; P1. XVI/2; P1. XVIII/2; Pl. XXI/2; Pl. XXII/6; Pl. XXIII/6; Pl. XXIV/3; Pl. XXV/5; Pl. XXVI/2, 4, 5, 7; Pl. XXVII/3, 5, 6; Pl. XXVIII/7; Pl. XXIX/2, 4, 6, 8, 9; Pl. XXX/2, 3, 5; Pl. XXXI/2, 4, 8, 9-12, 15, 17 ; Pl. XXXII/1, 2, 4, 5, 7; Pl. XXXIII/2, 5-7.

- semi-fine - Pl. I/5, 6; Pl. II/7; Pl. III/1; Pl. V/8; Pl. VIII/5; Pl. IX/1, 2, 4; Pl. XV/1, 3, 4; Pl. XVII/2, 3, 7, 9; Pl. XVIII/6, 8; Pl. XIX/4; Pl. XX/2; Pl. XXI/5; Pl. XXII/1, 4; Pl. XXVI/1, 6; Pl. XXVII/1, 2, 4; Pl. XXVIII/1-5; Pl. XXIX/1, 3, 5, 7; P1. XXX/1, 4; Pl. XXXI/1, 3, 5-7, 14; Pl. XXXII/1, 2, 4, 5, 7; Pl. XXXIII/1, 4, 8.

- rough/usual - Pl. XIV/2-6; Pl. XV/2, 5, 6; Pl. XVI/1, 3, 4; Pl. XVII/1, 4, 5, 6, 8, 10; Pl. XVIII/1, 3-5, 7; Pl. XIX/1, 2, 3, 5; Pl. XX/1, 3-5; P1. XXI/1, 3, 4; P1. XXII/2, 3, 5, 7; Pl. XXIII/1-5, 8-10; Pl. XXIV/1, 2, 4, 5; Pl. XXV/1-4, 6-8; P1. XXVI/3, 8; Pl. XXVIII/6, 8, 9; Pl. XXXI/13, 16.

Another aspect analyzed in terms of ceramic production technology refers to firing (Graphic 2). From this point of view, $82 \%$ of the total material have good firing, $11 \%$ is very good fired and only $7 \%$ of the material present in this feature has poor firing. From the point of view of firing, the archaeological material presented in the plates is as follows: 
- very good - Pl. II/2, 3; Pl. III/2-6; Pl. IV/2, 4, 5; Pl. V/2, 4, 7; Pl. VI/3, 4; Pl. $\mathrm{XXVI} / 4,5,7 ; \mathrm{Pl}$. XXXII/7;

\title{
Exterior color
}

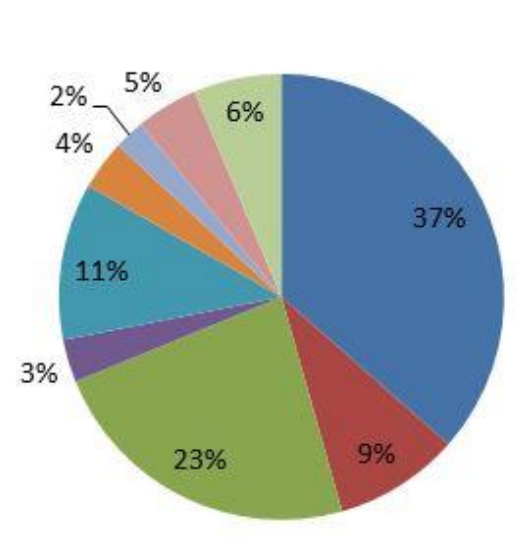

\author{
- Brick-like \\ - Coffee-like \\ - Light-brown \\ n Dark-brown \\ - Reddish-brown \\ - Greyish-brown \\ - Greyish \\ Black-greyish \\ - Blacktopped
}

Graphic 3. Turdaș-Luncă. 2011 campaign. Sector C. Feature 959. Turdaș culture, phase III. Graphic with percentage analysis of exterior color of the ceramic materials.

- good - Pl. I/1, 3-6; Pl. II/1, 4-8; Pl. III/1; Pl. IV/1, 3; Pl. V/1, 3, 5, 6, 8, 9; Pl. VI/1, 2, 5, 6; Pl. VII/1-3; Pl. VIII/1-5; Pl. IX/1-4; Pl. X/1, 2, 4; Pl. XI/1-4; Pl. XII/1-7; Pl. XIII/1-4; Pl. XIV/1-6; Pl. XV/1-6; Pl. XVI/1-4; Pl. XVII/2, 4-10; Pl. XVIII/1-3, 68; Pl. XIX/1-5; Pl. XX/1, 3-5; Pl. XXI/1-5; Pl. XXII/1, 3, 4-7; Pl. XXIII/1-10; Pl. XXIV/1-5; Pl. XXV/1, 3-8; Pl. XXVI/1, 2, 6; Pl. XXVII/1-6; Pl. XXVIII/1-7, 9; Pl. XXIX/1-9; Pl. XXX/1, 2, 4, 5; Pl. XXXI/1, 3-12, 14-17; Pl. XXXII/1-6, 8; Pl. $\mathrm{XXXIII/1-3;} \mathrm{5-7;}$

- poor - Pl. I/2; Pl. V/10; Pl. X/3; Pl. XVII/1, 3, 7; Pl. XVIII/4, 5; Pl. XX/2; Pl. XXII/2; Pl. XXV/2; Pl. XXVI/3, 8; Pl. XXVIII/8; Pl. XXX/3; Pl. XXXI/2, 13; Pl. XXXIII/4.

Referring to this aspect, we can also specify that the vast majority of the material has an oxidizing firing and only a small part has a reducing firing.

Regarding the exterior color, there is a majority of $37 \%$ represented by the brick-like color $37 \%$, followed by the light brown color $23 \%$, reddish-brown color $11 \%$ and coffee-like $9 \%$. Less represented are the colors/effects: blacktopped 6\%, black greyish $5 \%$, greyish brown $4 \%$, dark brown $3 \%$ and greyish $2 \%$. 

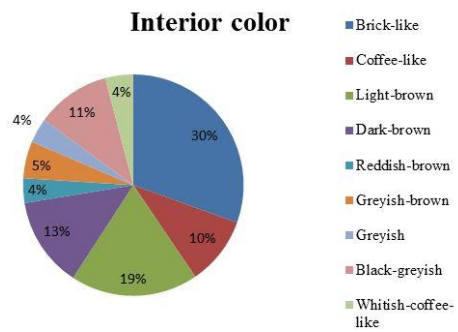

Graphic 4. Turdaș-Luncă. 2011 campaign. Sector C. Feature 959. Turdaș culture, phase III. Graphic with percentage analysis of interior color of the ceramic materials.

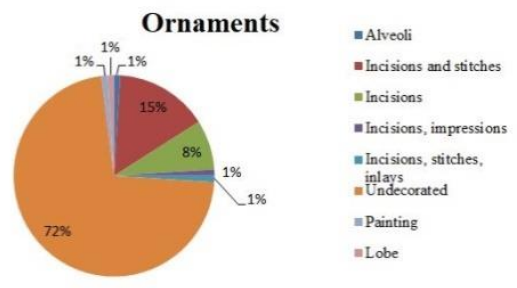

Graphic 5. Turdaș-Luncă. 2011 campaign. Sector C. Feature 959. Turdaș culture, phase III. Graphic with percentage analysis of decoration of the ceramic materials.

\section{Exterior color:}

- brick-like - Pl. I/1, 2; Pl.II/4, 8; Pl. III/1-3; Pl. V/4, 7; Pl. VIII/1, 3; Pl. IX/1, 2; Pl. XI/1-4; Pl. XII/1, 2; Pl. XIII/1, 4; Pl. XIV/2; Pl. XVI/2, 4; Pl. XVII/1, 7; Pl. XVIII/1; Pl. XIX/2, 4, 5; Pl. XX/1, 4, 5; Pl. XXI/2, 4; Pl. XXII/4; Pl. XXIII/2; Pl. XXIV/3; Pl. XXV/1, 3, 4, 8; Pl. XXVI/2, 4, 6-8; Pl. XXVII/2, 5; Pl. XXVIII/1, 3, 7-9; Pl. XXIX/2, 7; Pl. XXX/1-3, 5; Pl. XXXI/1, 3, 6, 8, 13, 17; Pl. XXXII/1-7; Pl. $\mathrm{XXXIII/1-4,} \mathrm{7,} \mathrm{8;}$

- coffee-like - Pl. I/5; Pl. II/3, 5; Pl. V/2; Pl. VIII/5; Pl. XII/4; Pl. XIV/1; Pl. XVII/2, 5; Pl. XVIII/3; Pl. XXIII/5; Pl. XXV/5; Pl. XXVI/5; Pl. XXVIII/4; Pl. XXIX/5; Pl. $\mathrm{XXXI} / 2,7,9,12 ; \mathrm{Pl}$. XXXII/8; Pl. XXXIII/5;

- light brown - Pl. I/3, 4, 6; Pl. V/5, 6; Pl. IX/3, 4; Pl. X/1-3; Pl. XII/3; Pl. XIII/3; Pl. XIV/3, 5, 6; Pl. XV/1-6; Pl. XVI/3; Pl. XVII/4, 10; Pl. XVIII/2; Pl. XIX/3; Pl. XX/2, 3; Pl. XXII/5, 7; Pl. XXIII/3, 6-10; Pl. XXIV/2, 4, 5; Pl. XXV/6; Pl. XXVI/3; Pl. XXVII/1, 4; Pl. XXVIII/2, 5, 6; Pl. XXIX/1, 3, 6; Pl. XXXI/4, 5, 11, 16; Pl. $\mathrm{XXXIII/6;}$

- dark brown - Pl. VIII/2, 4; Pl. X/4; Pl. XVII/3; Pl. XXVII/3; Pl. XXIX/8, 9;

- reddish-brown - Pl. II/1, 7; Pl. V/10; Pl. XVII/9; Pl. XVIII/4, 5, 7, 8; Pl. XIX/1; Pl. XXI/3; Pl. XXII/1; Pl. XXIII/1, 4; Pl. XXV/2, 7; Pl. XXVI/1; Pl. XXVII/6; Pl. $\mathrm{XXX} / 4 ; \mathrm{Pl} . \mathrm{XXXI} / 15$;

- greyish brown - Pl. II/2; Pl. V/ 1, 3, 8, 9; Pl. XII/5-7; Pl. XIII/2; Pl. XVI/1; Pl. XVII/6, 8; Pl. XXI/1; Pl. XXII/2; Pl. XXIV/1; Pl. XXIX/4;

- greyish - Pl. XXI/5; Pl. XXII/3; Pl. XXXI/4, 10;

- black greyish - Pl. II/6; Pl. VI/1-6; Pl. VII/1-3;

- blacktopped - Pl. III/4-6; Pl. IV/1-5; Pl. XIV/4; Pl. XVIII/6; Pl. XXII/6. 


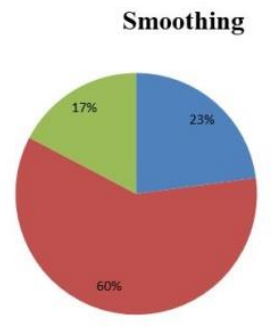

Graphic 6. Turdaș-Luncă. 2011 campaign. Sector C. Feature 959. Turdaș culture, phase III. Graphic with percentage analysis of smoothing of the ceramic materials.

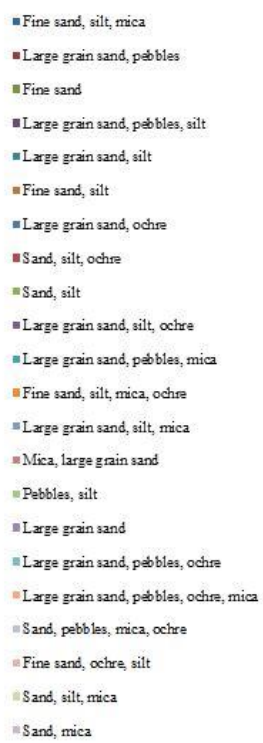

Graphic 7. Turdaș-Luncă. 2011 campaign. Sector C. Feature 959. Turdaș culture, phase III. Graphic with percentage analysis of temper.

Regarding ornamentation, we notice an overwhelming majority of unornamented material (72\%). The ornamented material is divided as follows, in big categories: incisions and stitches (short stitches, elongated or which together form the dotted-incised strip) $15 \%$, incisions $8 \%$, alveoli $1 \%$, incisions and impressions (with fingertip or different objects) $1 \%$, incisions, stitches and inlays $1 \%$, painting $1 \%$ and lobes $1 \%$ with many combinations.

Ornaments register in the plates are as follows:

-" bitumen" black painting - Pl. II/2.

- reddish-brown painting associated with incisions (small altar fragment) - $\mathrm{Pl}$. $\mathrm{XXX} / 4$.

- alveoli - Pl. IX/4 (on the lip of the vessel); Pl. XV/5.

- lobe on the lip of the vessel - Pl. XVIII/2; associated with 3 impressions under the lip - Pl. XXII/6.

- incisions - Pl. XXVII/1; Pl. XXVIII/3; Pl. XXIX/4; Pl. XXXI/5, 13, 16; Pl. XXXII/1; Pl. XXXIII/2, 4.

- short incisions - Pl. XXIX/2; Pl. XXXI/9; P1. XXXIII/5;

- stitches - Pl. XXVIII/1.

- incisions and stitches - Pl. XXVI/6; Pl. XXVIII/2; Pl. XXXI/1-3.

- incisions, stitches and impressions made with and object - Pl. XXVII/3; Pl. $\mathrm{XXIX/3.}$ 
- incised strips filled with stitches in Turdaș style - Pl. XXVII/6; Pl. XXVIII/4, 9; Pl. XXX/1, 3 (fragment altăraş); Pl. XXXI/4, 7, 10, 12, 14, 15, 17; Pl. XXXII/3, 7, 8; Pl. XXX/3.

- incised strips filled with elongated stitches in Turdaș style - Pl. XXVII/5.

- incised strips filled with short incisions in Turdaș style - Pl. XXVIII/7; Pl. XXXI/6, 11; Pl. XXXII/2, 4, 5; Pl. XXXIII/6, 7, 8.

- incised strips filled with short incisions inlays with white - Pl. XXVII/4.

- incised strips filled with elongated stitches and impressions made with an object Pl. XXVII/2.

- incised strips filled with stitches and oblique incisions/parallel with the lip of the vessel - Pl. XXIX/5, 6, 7 (quadrilateral vessel), 8, 9; Pl. XXXI/8; Pl. XXXII/6; Pl. XXXIII/1.

Regarding the smoothing of the ceramic material, more than half of the analyzed material has a good smoothing (60\%), being followed at a great distance by the poor smoothed material (23\%) and an even smaller part of very good smoothed material $(17 \%)$.

In the plates we have the following situation regarding the smoothing of the material:

- very good - Pl. I/3, 4; Pl. II/1-6; Pl. III/2-6; Pl. IV/1-5; Pl. VI/3-5; Pl. VII/2; Pl. XIV/1; Pl. XXI/2, 5; Pl. XXVI/4, 5, 7; Pl. XXXI/12; Pl. XXXII/3, 8; Pl. XXX/5-7; - good - Pl. I/1, 2, 5, 6; Pl. II/7, 8; Pl. III/1; Pl. V/1, 3, 5-8; Pl. VI/1, 2, 6; Pl. VII/1, 3; Pl. VIII/1-5; Pl. IX/1, 2, 4; Pl. X/1-4; Pl. XI/1-3; Pl. XII/1-5, 7; Pl. XIII/1, 2, 4; Pl. XIV/2, 5, 6; Pl. XV/1, 3, 4, 6; Pl. XVI/1-4; Pl. XVII/2, 4, 6; Pl. XVIII/1, 2, 7; Pl. XIX/2-5; Pl. XX/1, 3, 4; Pl. XXI/1, 4; Pl. XXII/1, 3, 4, 7; Pl. XXIII/2, 4, 7, 9, 10; Pl. XXIV/1, 2, 4; Pl. XXV/1, 3, 6, 7; Pl. XXVI/1, 2; Pl. XXVII/1-3, 5, 6; Pl. XXVIII/13, 5, 7; Pl. XXIX/1-9; Pl. XXX/1, 2, 4, 5; Pl. XXXI/1-11, 14, 15, 17; Pl. XXXII/1, 2, 4-7; Pl. XXXIII/1-4, 8;

- poor - Pl. V/10; Pl. IX/3; Pl. XI/4; Pl. XII/6; Pl. XIII/3; Pl. XIV/3, 4; Pl. XV/2, 5; Pl. XVII/1, 3, 5, 7-10; Pl. XVIII/3-6, 8; Pl. XIX/1; Pl. XX/2, 5; Pl. XXI/3; Pl. XXII/2, 5, 6; Pl. XXIII/1, 3, 5, 6, 8; Pl. XXIV/3, 5; Pl. XXV/2, 4, 5, 8; Pl. XXVI/3, 6, 8; Pl. XXVII/4; Pl. XXVIII/4, 6, 8, 9; Pl. XXX/3; Pl. XXXI/13, 16.

Making an analysis of the temper from which the materials were made, we notice a great diversity: sand, silt (15\%), fine sand, silt, mica (12\%), large grain sand, pebbles, silt (9\%), large grain sand, silt (8\%), sand, silt and mica (7\%), large grain sand, pebbles and large grain sand, silt and ochre (each combination with 6\%), fine sand, silt and sand, silt and ochre (each combination with 5\%), sand, mica (4\%), fine sand and large grain sand, pebbles, ochre (each combination with 3\%) and some combinations with $2 \%$ and $1 \%$, represented in Graphic 7.

The temper present in plates I-XXXIII is following:

- fine sand - Pl. I/4; Pl. II/5; Pl. VI/3, 4;

- fine sand and silt - Pl. II/1, 4, 6; Pl. III/2; Pl. IV/1; Pl. V/3, 7, 9; Pl. VI/6; Pl. VII/2; Pl. XXV/5; Pl. XXVII/6; Pl. XXVIII/7; Pl. XXIX/1; Pl. XXX/3, 5; Pl. XXXI/ 1, 2, $4,9,12,15 ; \mathrm{Pl} . \mathrm{XXXIII} / 2,7$; 
- fine sand, silt, and mica - Pl. I/1, 3; Pl. II/2, 3; Pl. III/6; Pl. IV/4, 5; Pl. VIII/2; Pl. XIV/1; Pl. XVIII/2; Pl. XXI/2; Pl. XXIV/3; Pl. XXVI/4, 5; Pl. XXVII/5; Pl. XXIX/2, 8, 9; Pl. XXX/2; Pl. XXXI/10, 11; Pl. XXXII/3; Pl. XXXIII/5.

- fine sand, ochre, and silt - Pl. V/2; Pl. VIII/3; Pl. XVI/2, Pl. XXVI/7; Pl. XXXII/6, 8.

- fine sand, silt, mica and ochre - Pl. IV/2; Pl. V/4, 6; Pl. XXXIII/3.

- sand and mica - Pl. III/3; Pl. VI/1, 2; Pl. VII/1, 3; Pl. VIII/5; Pl. IX/2; Pl. XXXI/14. - sand and silt - Pl. III/1, 4, 5; Pl. V/5; Pl. VI/5; Pl. XXIII/7, Pl. XXVI/1, 6; Pl. XXVII/ 1, 3; Pl. XXVIII/1-4; Pl. XXIX/3; Pl. XXX/4; Pl. XXXI/3, 6; Pl. XXXIII/1, 6.

- sand, silt, and mica - Pl. XV/4; Pl. XVII/1, 2; Pl. XIX/4; Pl. XXI/5, Pl. XXIII/10; Pl. XXVI/2; Pl. XXVII/2, 4; Pl. XXIX/4-6; Pl. XXXI/8, 17; Pl. XXXII/1, 2, 4, 5, 7; Pl. XXXIII/8.

- sand, silt, and ochre - Pl. II/8; Pl. V/1; Pl. XVII/3, 9; Pl. XX/1, 6; Pl. XXXI/ 5.

- sand, pebbles, silt, and ochre - Pl. IX/3; Pl. XII/5, 7; Pl. XIII/3; Pl. XVIII/8.

- large grain sand - Pl. V/8; Pl. XII/3; Pl. XXI/3; Pl. XXII/4; Pl. XXIV/1.

- large grain sand, pebbles, ochre, and mica - Pl. VIII/1; Pl. XII/6; Pl. XX/4.

- large grain sand, pebbles, and ochre - Pl. V/10; Pl. IX/4; Pl. XI/2; Pl. XV/5; Pl.

XVI/3; Pl. XVIII/3, 4; Pl. XIX/1, 3; Pl. XX/5; Pl. XXII/3, 9; Pl. XXIV/4; Pl. XXV/1; Pl. XXXI/16.

- large grain sand, silt, and mica - Pl. XI/1; Pl. XXX/1.

- large grain sand, pebbles, and mica - Pl. X/4; Pl. XIII/2; XIV/4; Pl. XX/2.

- large grain sand, silt, and ochre - Pl. XI/3; Pl. XIII/4; Pl. XVI/4; Pl. XVII/10; Pl. XXIII/5.

- large grain sand and ochre-Pl. II/7; Pl. XIV/2; Pl. XVII/4; Pl. XXIII/6; Pl. XXV/6; Pl. XXVIII/8;

- large grain sand and silt - Pl. I/6; Pl. IX/1; Pl. XII/2; Pl. XIII/1; Pl. XVIII/1; Pl. XIX/5; Pl. XXI/1; Pl. XXII/5; Pl. XXIII/2, 4, 8; Pl. XXIV/2, 5; Pl. XXV/3, 4; Pl. XXVI/8; Pl. XXVIII/5; Pl. XXXI/7, 17; Pl. XXXIII/4.

- large grain sand, pebbles and silt - Pl. I/5; Pl. X/1, 2; Pl. XI/4; Pl. XII/1, 4; Pl. XIV/3, 6; Pl. XV/2, 6; Pl. XVI/1; Pl. XVII/7, 8; Pl. XVIII/5; Pl. XIX/2; Pl. XXI/4; Pl. XXIII/1; Pl. XXV/8; Pl. XXVI/3; Pl. XXVIII/9.

- large grain sand and pebbles - Pl. I/2; Pl. X/3; Pl. XIV/5; Pl. XVII/5, 6; Pl. XVIII/7; Pl. XX/1, 3; Pl. XX/7; Pl. XXIII/3; Pl. XXV/2; Pl. XXVIII/6.

- mica and large grain sand - Pl. IV/3; Pl. VIII/4; Pl. XX/2; Pl. XXV/7.

- pebbles and silt - Pl. XV/1, 3; Pl. XVIII/6.

Also, from the graphic we notice that the fine sand can be found in combination with mica, ochre and silt and that it predominates in these combinations that we can see especially in fine ceramics.

We also notice that the large grain sand is found in most combinations together with pebbles, silt and ochre, combinations rendered in rough pottery that has a rough texture. In our analysis, sand - simple (it has a texture between fine sand and large grain sand) is most often found in combination with pebbles, silt and ochre. 
From this combination results, most of the times, a ceramic that we classified in the semi-fine category, from our observations being somewhat close to the fine one, the difference in classification consisting in the fact that the semi-fine ceramic has a more textured porous than the texture of the fine.

\section{Morphological aspects of the ceramics from feature 959}

In the following, we will present some of the material discovered in this feature, not being able to be presented at all, due to its richness.

Repertoire of the forms:

- circular button - Pl. XXX/1.

- unperforated handles:

- simple handle - Pl. V/7; Pl. VIII/1, 2; Pl. XII/1; Pl. XVIII/3, 5; Pl. XXII/4, 5, 7; Pl. XXIII/ 10; Pl. XXV/7; Pl. XXVII/4, 5; Pl. XXIX/ 8; Pl. XXXI/9.

- wavy handle, narrow - Pl. IX/1; Pl. XII/5, 6, 7; Pl. XV/6; Pl. $\mathrm{XXV} / 2,3,4,5,6,7,8$.

- narrow handle with an impression made with an object, under it Pl. XVII/6.

- narrow handle with an impression made with an object, in her - Pl. $\mathrm{XXV} / 5$.

- simple handle, conical, wavy, with the tip up - Pl. XII/ 2, 3, 4; Pl. $\mathrm{XV} / 2,4 ; \mathrm{Pl}$. XVII/6.

- simple handle, conical, wavy, with the tip down $-\mathrm{Pl}$. XV/1; Pl. XVIII/7; Pl. XXXII/7.

- perforated handles:

- beaked handle, horizontally perforated - Pl. III/1.

- handle with one horizontally perforation - Pl. VI/1; Pl. XXI/5; Pl.

$\mathrm{XXIX/7.}$

$\mathrm{XXI} / 2$.

- handle with one vertical perforation - Pl. XXVII/3; Pl. XXX/2.

- handle with two vertical perforations - Pl. III/3; Pl. VI/2; Pl.

- small altar with two legs, unornamented - Pl. XXX/5.

- small altar with four legs (probably), decorated with oblique incised strips, filled with stitches $-\mathrm{Pl}$. XXX/3.

- $\mathrm{A}_{1}$ - bowl with walls at an angle of $45^{\circ}-\mathrm{Pl}$. XXVII/5.

- $\mathrm{A}_{1 \mathrm{a}}$ - bowl with walls at an angle of $45^{\circ}$, quadrilateral - Pl. I/1; Pl. XVIII/2 (with lobe on the lip); Pl. XXIX/3.

- $\mathrm{A}_{1 \mathrm{~b}}$ - bowl with walls at an angle of $45^{\circ}$ with four alveolar protomes $-\mathrm{Pl}$. $\mathrm{XXX} / 4$.

- $\mathrm{A}_{1 \mathrm{~d}}$ - bowl with walls at an angle of $45^{\circ}$ with handle under the lip - Pl. V/7.

- $\mathrm{A}_{2}$ - bowl with walls at an angle greater then $45^{\circ}-\mathrm{Pl}$. II/7, 8; Pl. III/5; Pl.

IV/3-5; Pl. V/1, 6; Pl. IX/4; Pl. XIV/6; Pl. XVII/7; Pl. XXIII/6-8; Pl. $\mathrm{XXVII} / 2$. 
- $\mathrm{A}_{2 \mathrm{a}}$ - bowl with walls at an angle greater then $45^{\circ}$, quadrilateral - Pl. XXIX/7.

- $\mathrm{A}_{2 \mathrm{~b}}$ - bowl with walls at an angle greater then $45^{\circ}-\mathrm{Pl}$. XXII/6 (lobe on the lip).

- $\mathrm{A}_{4}$ - bowl with flared walls and arched inwards - Pl. XIV/5; Pl. XV/3, 4, 6; Pl. XVIII/3, 5, 7, 8; Pl. XIX/1; Pl. XX/1; Pl. XXII/3, 5, 7; Pl. XXV/1, 36,8 .

- $\mathrm{A}_{4 \mathrm{a}}$ - bowl with flared walls and arched inwards, with lobe - Pl. II/1.

- $\mathrm{A}_{4 b}$ - bowl with flared walls and arched inwards, flat - Pl. III/6; Pl. V/2; $\mathrm{Pl}$. XVII/5.

- $\mathrm{A}_{5}$ - bowl with walls arched inwards - Pl. IV/2; Pl. XXVII/1, 4, 6.

- A 7 - bowl - Pl. IX/1; Pl. XII/5; Pl. XVII/6; Pl. XXIII/9; Pl. XXIV/1,4; Pl. $\mathrm{XXV} / 2$.

- $\mathrm{B}_{2}$ - deep bowl with slightly arched walls $-\mathrm{Pl}$. XV/1 (with handles), 5; Pl. XVI/1, 3, 4; Pl. XVII/9; Pl. XVIII/4; Pl. XXIII/2-4; Pl. XXIX/4-6, 8, 9.

- $\mathrm{B}_{3}$ - deep bowl with arched walls - Pl. XII/1, 6; Pl. XIV/4; Pl. XV/2; Pl. XVIII/1; Pl. XXI/3.

- $\mathrm{B}_{4}$ - deep bowl with arched walls making transition to globular forms $-\mathrm{Pl}$. X/4; Pl. XII/7; Pl. XIII/1-3; Pl. XXI/4.

- $\mathrm{D}_{1}$ - globular pot - Pl. III/4; Pl. XI/3, 4; Pl. XII/3, 4; Pl. XVII/8; Pl. $\mathrm{XXIV} / 2,3,5$.

- $\mathrm{D}_{2}$ - globular pot with slightly arched lip - Pl. II/6; Pl. III/2; Pl. V/9; Pl. $\mathrm{X} / 2$; Pl. XI/2; Pl. XVII/4, 10; Pl. XIX/5; Pl. XX/3; Pl. XXI/1.

- $\mathrm{D}_{3}$ - globular pot with slightly profiled lip and slightly elongated body Pl. IV/1; Pl. IX/2; Pl. XXV/7.

- $\mathrm{D}_{4}$ - globular pot with straight lip - Pl. I/3, 5; Pl. V/10; Pl. VI/3.

- $\mathrm{E}_{2}-$ tall pot with domed belly and flared lip - Pl. XXIX/1 (miniatured vessel);

- $\mathrm{F}_{1}$ - amphora with elongated walls and straight lip - Pl. XIV/2, 3; Pl. $\mathrm{XVII} / 2$.

- $\mathrm{F}_{2}$ - amphora with elongated walls and profiled lip - Pl. II/3-5; Pl. XIII/4; Pl. XIV/1; Pl. XX/2-4;

- $\mathrm{G}_{1}$-,fish tray”, oval, with oblique walls - Pl. VIII/3, 4 (with drain or wick mouth), 5 .

- G - ,fish tray”, oval, with arched walls and handles - Pl. VIII/1, 2; Pl. IX/3; Pl. XXIII/10.

- $\mathrm{H}_{1}$ - plate with slightly sloping walls $-\mathrm{Pl}$. V/3; Pl. VII/2, 3; Pl. XXIII/5.

- $\mathrm{H}_{2}$ - plate with flared walls, slightly arched and profiled bottom $-\mathrm{Pl}$. V/4; $\mathrm{Pl} . \mathrm{XVI} / 2$.

- $\mathrm{I}_{1 \mathrm{~b}}-$ leg with very short spindle- $\mathrm{Pl}$. XXVI/1, 8 .

- $\mathrm{I}_{2}$-massive vessel foot with arched pedestal inwards - Pl. XXVI/5.

- $\mathrm{I}_{4 \mathrm{a}}$ - foot with widened pedestal - Pl. XXVI/4. 
- $\mathrm{I}_{5}-$ leg with circular pedestal and slightly pronounced hollow $-\mathrm{Pl}$. XXVI/2, 7.

- $\mathrm{K}_{2}$ - miniatured vessel, bowl type $\mathrm{A}_{1}-\mathrm{Pl}$. V/5; Pl. XXIII/1.

- $\mathrm{K}_{3}-$ miniatured vessel, bowl type $\mathrm{A}_{2}-\mathrm{Pl}$. XXII/1, 2.

We consider it necessary to mention the fact that one of the" fish trays" has a band of soot around the lip (inside) and the drain (Plate VIII/4), which may lead us to think of a used vessel to the lighting, which, in the area of the drain, had a burning wick.

Plates XXXI, XXXII, XXXIII, contain largely ornamented ceramic fragments that could not help us determine the exact shape of the vessel of which they were part.

The materials belonging to the Turdaş culture presented can be partially included in the catalog made in the doctoral thesis of our late colleague Nițu Florina Maria, entitled Aspecte tehnologice privind ceramica culturii Vinča din Transilvania, built under the coordination of S.A. Luca ${ }^{14}$ but also in other typologies that we used in this paper ${ }^{15}$.

The author mentioned above is the one who also took care of other features belonging to the Turdaș culture, from this site, analyzing approximately 27000 ceramic fragments ${ }^{16}$.

\footnotetext{
${ }^{14}$ For ceramic typology see Sabin Adrian Luca, Aşezări neolitice pe valea Mureşului (II), Pl. I-V.

${ }^{15}$ Sabin Adrian Luca, Aşezări neolitice pe valea Mureşului (II), Pl. 1-5

${ }^{16}$ Florentina M. Nițu, Aspecte tehnologice privind ceramica culturii Vinča din Transilvania, $(\mathrm{PhD}$ Thesis), (Sibiu: Universitatea "Lucian Blaga" din Sibiu, 2012), 57-84; Sabin Adrian Luca, Cercetările arheologice preventive de la Turdaș-Luncă, 55-73.
} 


\section{Description of the ceramic material}

\section{Plate I}

1. Fine category; exterior color: brick-like; interior color: light brown; temper: fine sand, silt, mica; good smoothing; good firing; quadrilateral pot.

2. Rough category; exterior color: brick-like; interior color: brick-like; temper: large grain sand, pebbles; good smoothing; poor firing.

3. Fine category; exterior color: light brown; interior color: greyish; temper: fine sand, silt, mica; very good smoothing (polishing traces); good firing.

4. Fine category; exterior color: light brown; interior color: dark brown; temper: fine sand; very good smoothing; very good firing.

5. Semi-fine category; exterior color: coffee-like; interior color: brick-like; temper: large grain sand, pebbles, silt; good smoothing; good firing.

6. Semi-fine category; exterior color: light brown; interior color: greyish; temper: large grain sand, silt; good smoothing; good firing.

\section{Plate II}

1. Fine category; exterior color: reddish-brown; interior color: reddish-brown; temper: fine sand, silt; very good smoothing; good firing.

2. Fine category; exterior color: greyish brown; interior color: greyish brown; temper: fine sand, silt, mica; very good smoothing (slip traces); very good firing; decoration: traces of bitumen painting.

3. Fine category; exterior color: coffee-like; interior color: coffee-like; temper: fine sand, silt, mica; very good smoothing; very good firing.

4. Fine category; exterior color: brick-like; interior color: brick-like; temper: fine sand, silt; very good smoothing; good firing.

5. Fine category; exterior color: coffee-like; interior color: whitish-coffee-like; temper: fine sand; very good smoothing; good firing.

6. Fine category; exterior color: black greyish; interior color: black greyish; temper: fine sand, silt; very good smoothing (polishing traces); good firing.

7. Semi-fine category; exterior color: reddish-brown; interior color: light brown; temper: large grain sand, ochre; good smoothing; good firing.

8. Fine category; exterior color: brick-like; interior color: brick-like; temper: sand, silt, ochre; good smoothing; good firing.

\section{Plate III}

1. Semi-fine category; exterior color: brick-like in the lower part with black greyish in the upper part (blacktopped); interior color: whitish-coffee-like; temper: sand, silt; good smoothing; good firing.

2. Fine category; exterior color: brick-like in the lower part with black greyish in the upper part (blacktopped); interior color: black greyish; temper: fine sand, silt; very good smoothing; very good firing. 
3. Fine category; exterior color: brick-like in the lower part with black greyish in the upper part (blacktopped); interior color: black greyish; temper: sand, mica; very good smoothing (polishing traces in the upper part); very good firing.

4. Fine category; exterior color: coffee-like in the lower part with greyish in upper part (blacktopped); interior color: greyish; temper: sand, silt; very good smoothing; very good firing.

5. Fine category; exterior color: brick-like in the lower part with black greyish in upper part (blacktopped); interior color: black greyish; temper: sand, silt; very good smoothing; very good firing.

6. Fine category; exterior color: coffee-like in the lower part with black greyish in the upper part (blacktopped); interior color: black greyish; temper: fine sand, silt, mica; very good smoothing; very good firing.

\section{Plate IV}

1. Fine category; exterior color: brick-like in the lower part with dark greyish in the upper part (blacktopped); interior color: black greyish; temper: fine sand, silt; very good smoothing; good firing.

2. Fine category; exterior color: coffee-like in the lower part with black greyish in the upper part (blacktopped); interior color: coffee-like; temper: fine sand, silt, mica, ochre; very good smoothing; very good firing.

3. Fine category; exterior color: light brown in the lower part with black greyish in the upper part (blacktopped); interior color: black greyish; temper: mica, large grain sand; very good smoothing; good firing.

4. Fine category; exterior color: brick-like in the lower part with black greyish in the upper part (blacktopped); interior color: black greyish; temper: fine sand, silt, mica; very good smoothing; very good firing.

5. Fine category; exterior color: brick-like in the lower part with black greyish in the upper part (blacktopped); interior color: black greyish; temper: fine sand, silt, mica; very good smoothing; very good firing.

\section{Plate V}

1. Fine category; exterior color: greyish brown; interior color: brick-like; temper: sand, silt, ochre; good smoothing; good firing.

2. Fine category; exterior color: coffee-like; interior color: coffee-like; temper: fine sand, ochre. silt; very good smoothing; very good firing.

3. Fine category; exterior color: greyish brown; interior color: dark brown; temper: fine sand, silt; good smoothing; good firing.

4.Fine category; exterior color: brick-like; interior color: brick-like; temper: fine sand, silt, mica, ochre; very good smoothing; very good firing.

5. Fine category; exterior color: light brown; interior color: brick-like; temper: sand, silt; good smoothing; good firing.

6 . Fine category; exterior color: light brown; interior color: light brown; temper: fine sand, silt, mica, ochre; good smoothing; good firing. 
7. Fine category; exterior color: brick-like; interior color: brick-like; temper: fine sand, silt; good smoothing; very good firing.

8. Semi-fine category; exterior color: greyish brown; interior color: greyish brown; temper: large grain sand; good smoothing; good firing; decoration: impressions made with nail and finger on the rim.

9. Fine category; exterior color: greyish brown; interior color: light brown; temper: fine sand, silt; very good smoothing; very good firing.

10. Rough category; exterior color: reddish-brown; interior color: brick-like; temper: large grain sand, pebbles, ochre; poor smoothing; poor firing.

\section{Plate VI}

1. Fine category; exterior color: black greyish; interior color: black greyish; temper: sand, mica; good smoothing; good firing.

2. Fine category; exterior color: black greyish; interior color: black greyish; temper: sand, mica; good smoothing; good firing.

3. Fine category; exterior color: black greyish; interior color: black greyish; temper: fine sand; very good smoothing (polished); very good firing.

4. Fine category; exterior color: black greyish; interior color: black greyish; temper: fine sand; very good smoothing (polished); very good firing.

5. Fine category; exterior color: black greyish; interior color: black greyish; temper: sand, silt; very good smoothing; good firing.

6. Fine category; exterior color: black greyish; interior color: black greyish; temper: fine sand, silt; good smoothing; good firing.

\section{Plate VII}

1. Fine category; exterior color: black greyish; interior color: black greyish; temper: sand, mica; good smoothing; good firing.

2. Fine category; exterior color: black greyish; interior color: black greyish; temper: fine sand, silt; very good smoothing (polished); good firing.

3. Fine category; exterior color: black greyish; interior color: light brown; temper: sand, mica; good smoothing; good firing.

\section{Plate VIII}

1. Rough category; exterior color: brick-like; interior color: brick-like; temper: large grain sand, pebbles, ochre, mica; good smoothing; good firing.

2. Fine category; exterior color: light brown; interior color: greyish; temper: fine sand, silt, mica; very good smoothing; good firing.

3. Fine category; exterior color: brick-like; interior color: brick-like; temper: fine sand, ochre, silt; good smoothing; good firing.

4. Rough category; exterior color: dark brown; interior color: dark brown; temper: large grain sand, mica; good smoothing; good firing (inside is a soot band, in the upper part). 
5. Semi-fine category; exterior color: coffee-like; interior color: dark brown; temper: sand, mica; good smoothing; good firing.

\section{Plate IX}

1. Semi-fine category; exterior color: brick-like; interior color: brick-like; temper: large grain sand, silt; good smoothing; good firing.

2. Semi-fine category; exterior color: brick-like; interior color: brick-like; temper: sand, mica; good smoothing; good firing.

3. Rough category; exterior color: light brown; interior color: dark brown; temper: sand, pebbles, silt, ochre; poor smoothing; good firing.

4.Semi-fine category; exterior color: light brown; interior color: dark brown; temper: large grain sand, pebbles, ochre; good smoothing; good firing; decoration: impressions on the rim.

\section{Plate X}

1. Rough category; exterior color: light brown; interior color: light brown; temper: large grain sand, pebbles, silt; good smoothing; good firing.

2. Rough category; exterior color: light brown; interior color: light brown; temper: large grain sand, pebbles, silt; good smoothing; good firing.

3. Rough category; exterior color: light brown; interior color: dark brown; temper: large grain sand, pebbles; good smoothing; poor firing.

4. Rough category; exterior color: dark brown; interior color: greyish brown; temper: large grain sand, pebbles, mica; good smoothing; good firing.

\section{Plate XI}

1. Rough category; exterior color: brick-like; interior color: brick-like; temper: large grain sand, silt, mica; good smoothing; good firing.

2. Rough category; exterior color: brick-like; interior color: brick-like; temper: large grain sand, pebbles, ochre; good smoothing; good firing.

3. Rough category; exterior color: brick-like; interior color: light brown; temper: large grain sand, silt, ochre; good smoothing; good firing.

4. Rough category; exterior color: brick-like; interior color: brick-like; temper: large grain sand, pebbles, silt; poor smoothing; good firing.

\section{Plate XII}

1. Rough category; exterior color: brick-like; interior color: brick-like; temper: large grain sand, pebbles, silt; good smoothing; good firing.

2. Rough category; exterior color: brick-like; interior color: brick-like; temper: large grain sand, silt; good smoothing; good firing.

3. Rough category; exterior color: light brown; interior color: light brown; temper: large grain sand; good smoothing; good firing.

4. Rough category; exterior color: coffee-like; interior color: coffee-like; temper: large grain sand, pebbles, silt; good smoothing; good firing. 
5. Rough category; exterior color: greyish brown; interior color: greyish brown; temper: large grain sand, pebbles, silt, ochre; good smoothing; good firing.

6. Rough category; exterior color: greyish brown; interior color: brick-like; temper: large grain sand, pebbles, ochre, mica; poor smoothing; good firing.

7. Rough category; exterior color: greyish brown; interior color: coffee-like; temper: large grain sand, pebbles, silt, ochre; good smoothing; good firing.

\section{Plate XIII}

1. Rough category; exterior color: brick-like; interior color: brick-like; temper: large grain sand, pebbles, silt; good smoothing; good firing.

2. Rough category; exterior color: greyish brown; interior color: reddish-brown; temper: large grain sand, pebbles, mica; good smoothing; good firing.

3. Rough category; exterior color: light brown; interior color: light brown; temper: large grain sand, pebbles, silt, ochre; poor smoothing; good firing.

4. Rough category; exterior color: brick-like; interior color: brick-like; temper: large grain sand, pebbles, silt, ochre; good smoothing; good firing.

\section{Plate XIV}

1. Fine category; exterior color: coffee-like; interior color: whitish-coffee-like; temper: fine sand, silt, mica; very good smoothing; good firing.

2. Rough category; exterior color: brick-like; interior color: brick-like; temper: large grain sand, pebbles, ochre; good smoothing; good firing.

3. Rough category; exterior color: light brown; interior color: light brown; temper: large grain sand, pebbles, silt; poor smoothing; good firing.

4. Rough category; exterior color: reddish in the lower part with dark-greyish in the upper part (blacktopped); interior color: greyish; temper: large grain sand, pebbles, mica; poor smoothing; good firing.

5. Rough category; exterior color: light brown; interior color: light brown; temper: large grain sand, pebbles; good smoothing; good firing.

6. Rough category; exterior color: light brown; interior color: brick-like; temper: large grain sand, pebbles, silt; good smoothing; good firing.

\section{Plate XV}

1. Semi-fine category; exterior color: light brown; interior color: coffee-like; temper: pebbles, silt; good smoothing; good firing.

2. Rough category; exterior color: light brown; interior color: light brown; temper: large grain sand, pebbles, silt; poor smoothing; good firing.

3. Semi-fine category; exterior color: light brown; interior color: light brown; temper: pebbles, silt; good smoothing; good firing.

4. Semi-fine category; exterior color: light brown; interior color: coffee-like; temper: sand, silt, mica; good smoothing; good firing. 
5. Rough category; exterior color: light brown; interior color: dark brown; temper: large grain sand, pebbles, ochre; poor smoothing; good firing; decoration: small alveoli on the rim.

6. Rough category; exterior color: light brown; interior color: light brown; temper: large grain sand, pebbles, silt; good smoothing; good firing.

\section{Plate XVI}

1. Rough category; exterior color: greyish brown; interior color: light brown; temper: large grain sand, pebbles, silt; good smoothing; good firing.

2. Fine category; exterior color: brick-like; interior color: whitish-coffee-like; temper: fine sand, ochre, silt; good smoothing; good firing.

3. Rough category; exterior color: light brown; interior color: dark brown; temper: large grain sand, pebbles, ochre; good smoothing; good firing.

4. Rough category; exterior color: brick-like; interior color: brick-like; temper: large grain sand, silt, ochre; good smoothing; good firing.

\section{Plate XVII}

1. Rough category; exterior color: brick-like; interior color: reddish-brown; temper: sand, silt, mica; poor smoothing; poor firing.

2. Semi-fine category; exterior color: coffee-like; interior color: coffee-like; temper: sand, silt, mica; good smoothing; good firing.

3. Semi-fine category; exterior color: dark brown; interior color: coffee-like; temper: sand, silt, ochre; poor smoothing; poor firing.

4. Rough category; exterior color: light brown; interior color: dark brown; temper: large grain sand, ochre; good smoothing; good firing.

5. Rough category; exterior color: coffee-like; interior color: dark brown; temper: large grain sand, pebbles; poor smoothing; good firing.

6. Rough category; exterior color: greyish brown; interior color: light brown; temper: large grain sand, pebbles; good smoothing; good firing; decoration: impression made with an object.

7. Semi-fine category; exterior color: brick-like; interior color: light brown; temper: large grain sand, pebbles, silt; poor smoothing; good firing.

8. Rough category; exterior color: greyish brown; interior color: brick-like; temper: large grain sand, pebbles, silt; poor smoothing; good firing.

9. Semi-fine category; exterior color: reddish-brown; interior color: brick-like; temper: sand, silt, ochre; poor smoothing; good firing.

10. Rough category; exterior color: light brown; interior color: brick-like; temper: large grain sand, silt, ochre; poor smoothing; good firing.

\section{Plate XVIII}

1. Rough category; exterior color: brick-like; interior color: brick-like; temper: large grain sand, silt; good smoothing; good firing. 
2. Fine category; exterior color: light brown; interior color: light brown; temper: fine sand, silt, mica; good smoothing; good firing. (quadrilateral)

3. Rough category; exterior color: coffee-like; interior color: light brown; temper: large grain sand, pebbles; poor smoothing; good firing.

4. Rough category; exterior color: reddish-brown; interior color: dark brown; temper: large grain sand, pebbles; poor smoothing; poor firing.

5. Rough category; exterior color: reddish-brown; interior color: brick-like ; temper: large grain sand, pebbles, silt; poor smoothing; poor firing.

6. Semi-fine category; exterior color: brick-like in the lower part with dark brown in the upper part (blacktopped); interior color: whitish-coffee-like; temper: pebbles, silt; poor smoothing; good firing.

7. Rough category; exterior color: reddish-brown; interior color: light brown; temper: large grain sand, pebbles; good smoothing; good firing.

8. Semi-fine category; exterior color: reddish-brown; interior color: dark brown; temper: sand, pebbles, silt, ochre; poor smoothing; good firing.

\section{Plate XIX}

1. Rough category; exterior color: reddish-brown; interior color: reddish-brown; temper: large grain sand, pebbles, ochre; poor smoothing; good firing.

2. Rough category; exterior color: brick-like; interior color: brick-like; temper: large grain sand, pebbles, silt; good smoothing; good firing.

3. Rough category; exterior color: light brown; interior color: light brown; temper: large grain sand, pebbles, ochre; good smoothing; good firing.

4. Semi-fine category; exterior color: brick-like; interior color: brick-like; temper: sand, silt, mica; good smoothing; good firing.

5. Rough category; exterior color: brick-like; interior color: brick-like; temper: large grain sand, silt; good smoothing; good firing.

\section{Plate XX}

1. Rough category; exterior color: brick-like; interior color: light brown; temper: large grain sand, pebbles; good smoothing; good firing.

2. Semi-fine category; exterior color: light brown; interior color: coffee-like with black firing mark; temper: mica, large grain sand; poor smoothing; good firing.

3. Rough category; exterior color: light brown; interior color: light brown; temper: large grain sand, pebbles; poor smoothing; good firing.

4. Rough category; exterior color: brick-like; interior color: brick-like; temper: large grain sand, pebbles, ochre, mica; good smoothing; good firing.

5. Rough category; exterior color: brick-like; interior color: brick-like; temper: large grain sand, silt, pebbles, ochre; poor smoothing; good firing.

\section{Plate XXI}

1. Rough category; exterior color: greyish brown; interior color: brick-like; temper: large grain sand, silt; good smoothing; good firing. 
2. Fine category; exterior color: brick-like; interior color: black greyish; temper: fine sand, silt, mica; very good smoothing; good firing.

3. Rough category; exterior color: reddish-brown; interior color: brick-like; temper: large grain sand; poor smoothing; good firing.

4. Rough category; exterior color: brick-like; interior color: brick-like; temper: large grain sand, pebbles, silt; good smoothing; good firing.

5. Semi-fine category; exterior color: greyish; interior color: brick-like; temper: sand, silt, mica; very good smoothing; good firing.

\section{Plate XXII}

1. Semi-fine category; exterior color: reddish-brown; interior color: brick-like; temper: sand, silt ochre; good smoothing; good firing.

2. Rough category; exterior color: greyish brown; interior color: light brown; temper: large grain sand, pebbles, mica; poor smoothing; poor firing.

3. Rough category; exterior color: greyish; interior color: reddish-brown; temper: large grain sand, pebbles, ochre; good smoothing; good firing.

4. Semi-fine category; exterior color: brick-like; interior color: greyish brown; temper: large grain sand; poor smoothing; good firing.

5. Rough category; exterior color: light brown; interior color: greyish; temper: large grain sand, silt; poor smoothing; good firing.

6 . Fine category; exterior color: brick-like in the lower part with black greyish in the upper part (blacktopped); interior color: brick-like; temper: sand, silt, ochre; poor smoothing; good firing; decoration: lob and three impressions, under the rim.

7. Rough category; exterior color: light brown; interior color: dark brown; temper: large grain sand, pebbles; good smoothing; good firing.

\section{Plate XXIII}

1. Rough category; exterior color: reddish-brown; interior color: dark brown; temper: large grain sand, pebbles, silt; poor smoothing; good firing.

2. Rough category; exterior color: brick-like; interior color: brick-like; temper: large grain sand, silt; good smoothing; good firing.

3. Rough category; exterior color: light brown; interior color: light brown; temper: large grain sand, pebbles; poor smoothing; good firing.

4. Rough category; exterior color: reddish-brown; interior color: brick-like; temper: large grain sand, silt; good smoothing; good firing.

5. Rough category; exterior color: whitish-coffee-like; interior color: whitish-coffeelike; temper: large grain sand, silt, ochre; poor smoothing; good firing,

6 . Fine category; exterior color: light brown; interior color: brick-like; temper: fine sand, silt; poor smoothing; good firing.

7. Fine category; exterior color: light brown; interior color: light brown; temper: sand, silt; good smoothing; good firing, 
8. Rough category; exterior color: light brown; interior color: light brown; temper: large grain sand, silt; poor smoothing; good firing.

9. Rough category; exterior color: light brown with dark-greyish firing mark; interior color: black greyish; temper: large grain sand, pebbles; good smoothing; good firing. 10. Rough category; exterior color: light brown; interior color: light brown; temper: sand, silt, mica; good smoothing; good firing.

\section{Plate XXIV}

1. Rough category; exterior color: greyish brown; interior color: dark brown; temper: large grain sand; good smoothing; good firing.

2. Rough category; exterior color: dark brown; interior color: light brown; temper: large grain sand, silt; good smoothing; good firing.

3. Fine category; exterior color: brick-like; interior color: brick-like; temper: fine sand, silt, mica; poor smoothing; good firing.

4. Rough category; exterior color: light brown; interior color: light brown; temper: large grain sand, pebbles, ochre; good smoothing; good firing.

5. Rough category; exterior color: light brown; interior color: whitish-coffee-like; temper: large grain sand, silt; poor smoothing; good firing.

\section{Plate XXV}

1. Rough category; exterior color: brick-like; interior color: brick-like; temper: large grain sand, pebbles, ochre; good smoothing; good firing.

2. Rough category; exterior color: reddish-brown; interior color: dark brown; temper: large grain sand, pebbles; poor smoothing; poor firing.

3. Rough category; exterior color: brick-like; interior color: brick-like; temper: large grain sand, silt; good smoothing; good firing,

4. Rough category; exterior color: brick-like; interior color: greyish brown; temper: large grain sand, silt; poor smoothing; good firing.

5. Fine category; exterior color: coffee-like; interior color: coffee-like; temper: fine sand, silt; poor smoothing; good firing.

6. Rough category; exterior color: light brown; interior color: light brown; temper: large grain sand, ochre; good smoothing; good firing.

7. Rough category; exterior color: reddish-brown; interior color: light brown; temper: mica, large grain sand; good smoothing; good firing.

8. Rough category; exterior color: brick-like; interior color: greyish brown; temper: large grain sand, pebbles, silt; poor smoothing; good firing.

\section{Plate XXVI}

1. Semi-fine category; exterior color: reddish-brown; interior color: brick-like; temper: sand, silt; good smoothing; good firing.

2. Fine category; exterior color: brick-like; interior color: black greyish; temper: sand, silt, mica; good smoothing; good firing. 
3. Rough category; exterior color: light brown; interior color: dark brown; temper: large grain sand, pebbles, silt; poor smoothing; poor firing.

4. Fine category; exterior color: brick-like; interior color: black greyish; temper: fine sand, silt, mica; very good smoothing; very good firing.

5. Fine category; exterior color: coffee-like; interior color: whitish-coffee-like; temper: fine sand, silt, mica; very good smoothing; very good firing.

6. Semi-fine category; exterior color: brick-like; interior color: black greyish; temper: sand, silt; poor smoothing; good firing; decoration: incisions, short incisions.

7. Fine category; exterior color: brick-like; interior color: dark brown; temper: fine sand, ochre, silt; very good smoothing; very good firing.

8. Rough category; exterior color: brick-like; interior color: brick-like; temper: large grain sand, silt; poor smoothing; poor firing.

\section{Plate XXVII}

1. Semi-fine category; exterior color: light brown; interior color: light brown; temper: sand, silt; good smoothing; good firing; decoration: incisions.

2. Semi-fine category; exterior color: brick-like; interior color: brick-like; temper: sand, silt, mica; good smoothing; good firing; decoration: incisions, impressions (made with an object).

3. Fine category; exterior color: dark brown; interior color: black greyish; temper: sand, silt; good smoothing; good firing; decoration: incisions, elongated stitches, impressions (with an object).

4. Semi-fine category; exterior color: light brown; interior color: light brown; temper: sand, silt, mica; poor smoothing; good firing; decoration: incisions, elongated stitches, inlays (white).

5. Fine category; exterior color: brick-like; interior color: greyish; temper: fine sand, silt, mica; good smoothing; good firing; decoration: incisions, short incisions.

6. Fine category; exterior color: reddish-brown; interior color: reddish-brown; temper: fine sand, silt; good smoothing; good firing; decoration: incisions, stitches.

\section{Plate XXVIII}

1. Semi-fine category; exterior color: brick-like; interior color: dark brown; temper: sand, silt; good smoothing; good firing; decoration: incisions, stitches.

2. Semi-fine category; exterior color: light brown; interior color: light brown; temper: sand, silt; good smoothing; good firing; decoration: incisions.

3. Semi-fine category; exterior color: brick-like; interior color: coffee-like; temper: sand, silt; good smoothing; good firing; decoration: incisions.

4. Semi-fine category; exterior color: coffee-like; interior color: dark brown; temper: sand, silt; poor smoothing; good firing; decoration: incisions, impressions made with an object.

5. Semi-fine category; exterior color: light brown; interior color: coffee-like; temper: large grain sand, silt; good smoothing; good firing. 
6. Rough category; exterior color: light brown; interior color: dark brown; temper: large grain sand, pebbles; poor smoothing; good firing.

7. Fine category; exterior color: brick-like; interior color: brick-like; temper: fine sand, silt; good smoothing; good firing; decoration: incisions.

8. Rough category; exterior color: brick-like; interior color: greyish brown; temper: large grain sand, ochre; poor smoothing; poor firing.

9. Rough category; exterior color: brick-like; interior color: brick-like; temper: large grain sand, pebbles, silt; poor smoothing; good firing; decoration: incisions, stitches.

\section{Plate XXIX}

1. Semi-fine category; exterior color: light brown; interior color: light brown; temper: fine sand, silt; good smoothing; good firing.

2. Fine category; exterior color: brick-like; interior color: brick-like; temper: fine sand, silt, mica; good smoothing; good firing; decoration: incisions.

3. Semi-fine category; exterior color: light brown; interior color: dark brown; temper: sand, silt; good smoothing; good firing; decoration: incisions, stitches.

4. Fine category; exterior color: greyish brown; interior color: greyish brown; temper: sand, silt, mica; good smoothing; good firing; decoration: incisions.

5. Semi-fine category; exterior color: coffee-like; interior color: greyish; temper: sand, silt, mica; good smoothing; good firing; decoration: incisions.

6. Fine category; exterior color: light brown; interior color: brick-like; temper: sand, silt, mica; brown; good smoothing; good firing; decoration: incisions, elongated stitches.

7. Semi-fine category; exterior color: brick-like; interior color: brick-like; temper: sand, silt; good smoothing; good firing; decoration: incisions, stitches.

8. Fine category; exterior color: dark brown; interior color: dark brown; temper: fine sand, silt, mica; good smoothing; good firing; decoration: incisions.

9. Fine category; exterior color: dark brown; interior color: brick-like; temper: fine sand, silt, mica; good smoothing; good firing; decoration: incisions.

\section{Plate XXX}

1. Semi-fine category; exterior color: brick-like; interior color: brick-like; temper: large grain sand, silt, mica; good smoothing; good firing; decoration: incisions.

2. Fine category; exterior color: brick-like; interior color: brick-like; temper: fine sand, silt, mica; good smoothing; good firing.

3. Fine category; exterior color: brick-like; interior color: light brown; temper: fine sand, silt; poor smoothing; poor firing; decoration: incisions.

4. Semi-fine category; exterior color: reddish-brown; interior color: brick-like; temper: sand, silt; good smoothing; good firing; decoration: incisions, traces of reddish-brown painting.

5. Fine category; exterior color: brick-like; interior color: greyish brown; temper: fine sand, silt; very good smoothing, good firing. 


\section{Plate XXXI}

1. Semi-fine category; exterior color: brick-like; interior color: brick-like; temper: fine sand, silt; good smoothing; good firing; decoration: incisions, elongated stitches.

2. Fine category; exterior color: coffee-like; interior color: coffee-like; temper: fine sand, silt; good smoothing; poor firing; decoration: incisions, stitches.

3. Semi-fine category; exterior color: brick-like; interior color: brick-like; temper: sand, silt; good smoothing; good firing; decoration: incisions.

4. Fine category; exterior color: light brown; interior color: black greyish; temper: fine sand, silt; good smoothing; good firing; decoration: incisions, elongated stitches.

5. Semi-fine category; exterior color: light brown; interior color: brown; temper: sand, silt, ochre; good smoothing; good firing; decoration: incisions.

6. Semi-fine category; exterior color: brick-like; interior color: brick-like; temper: sand, silt; good smoothing; good firing; decoration: incisions.

7. Semi-fine category; exterior color: coffee-like; interior color: greyish; temper: large grain sand, silt; good smoothing; good firing; decoration: incisions, elongated stitches.

8. Fine category; exterior color: brick-like; interior color: brick-like; temper: sand, silt, mica; good smoothing; good firing; decoration: incisions.

9. Fine category; exterior color: coffee-like; interior color: light brown; temper: fine sand, silt; good smoothing; good firing; decoration: incisions.

10. Fine category; exterior color: greyish; interior color: dark brown; temper: fine sand, silt, mica, ochre; good smoothing; good firing; decoration: incisions.

11. Fine category; exterior color: light brown; interior color: coffee-like; temper: fine sand, silt, mica; good smoothing; good firing; decoration: incisions.

12. Fine category; exterior color: coffee-like; interior color: coffee-like; temper: fine sand, silt; very good smoothing; good firing; decoration: incisions, stitches.

13. Rough category; exterior color: brick-like; interior color: brick-like; temper: large grain sand, silt; poor smoothing; poor firing; decoration: incisions.

14. Semi-fine category; exterior color: greyish; interior color: greyish; temper: sand, mica; good smoothing; good firing; decoration: incisions, elongated stitches.

15. Fine category; exterior color: reddish-brown; interior color: dark brown; temper: fine sand, silt; good smoothing; good firing; decoration: incisions.

16. Rough category; exterior color: light brown; interior color: light brown; temper: large grain sand, pebbles, ochre; poor smoothing; good firing; decoration: incisions. 17. Fine category; exterior color: brick-like; interior color: brick-like; temper: sand, silt, mica; good smoothing; good firing; decoration: incisions, stitches.

\section{Plate XXXII}


1. Semi-fine category; exterior color: brick-like; interior color: brick-like; temper: sand, silt, mica; good smoothing; good firing; decoration: incisions.

2. Semi-fine category; exterior color: brick-like; interior color: brick-like; temper: sand, silt, mica; good smoothing; good firing; decoration: incisions.

3. Fine category; exterior color: brick-like; interior color: brick-like; temper: fine sand, silt, mica; very good smoothing; good firing; decoration: incisions.

4. Semi-fine category; exterior color: brick-like; interior color: brick-like; temper: sand, silt, mica; good smoothing; good firing; decoration: incisions, stitches.

5. Semi-fine category; exterior color: brick-like; interior color: brick-like; temper: sand, silt, mica; good smoothing; good firing; decoration: incisions.

6. Fine category; exterior color: brick-like; interior color: coffee-like; temper: fine sand, ochre, silt; good smoothing; poor smoothing; decoration: incisions.

7. Semi-fine category; exterior color: brick-like; interior color: brick-like; temper: sand, silt, mica; good smoothing; very good firing; decoration: incisions, elongated stitches.

8. Fine category; exterior color: coffee-like; interior color: coffee-like; temper: fine sand, ochre, silt; very good smoothing; good firing; decoration: incisions, elongated stitches.

\section{Plate XXXIII}

1. Semi-fine category; exterior color: brick-like; interior color: brick-like; temper: sand, silt; good smoothing; good firing; decoration: incisions.

2. Fine category; exterior color: brick-like; interior color: brick-like; temper: fine sand, silt; good smoothing; good firing; decoration: incisions.

3. Fine category; exterior color: brick-like; interior color: brick-like; temper: fine sand, silt, mica, ochre; good smoothing; good firing; decoration: incisions, elongated stitches.

4. Semi-fine category; exterior color: brick-like; interior color: brick-like; temper: large grain sand, silt; good smoothing; poor firing; decoration: incisions.

5. Fine category; exterior color: coffee-like; interior color: coffee-like; temper: fine sand, silt, mica; very good smoothing; good firing; decoration: incisions.

6. Fine category; exterior color: light brown; interior color: brick-like; temper: sand, silt; very good smoothing; good firing; decoration: incisions.

7. Fine category; exterior color: brick-like; interior color: brick-like; temper: fine sand, silt; very good smoothing; very good firing; decoration: incisions.

8. Semi-fine category; exterior color: brick-like; interior color: coffee-like; temper: sand, silt, mica; good smoothing; good firing; decoration: incisions.

\section{Some conclusions}

This paper was made to present some aspects captured during the preventive excavation at Turdaș-Luncă carried out in 2011, on the occasion of the construction of the Deva-Orăștie highway sector. Among these aspects is the analysis of the 
feature 959 but also its relationship to the structures (structure 9, 12-14, 21-22) around it.

From a technological point of view, the identified pottery falls within the Neolithic patterns, being made of coils, more precisely within phase III of Turdaș culture (but also with rare older elements).

All this analysis provided us with the predominant colors of the ceramics in this feature, namely light colors such as: brick-like, light brown, brown, reddish, and less often darker colors such as dark brown, black greyish.

From the temper graphic (Graphic 7) we observe three main categories of temper (sand and silt; large grain sand, pebbles, and silt; fine sand, silt and mica) practically being the combinations that give us the three types of ceramic categories (fine, semi-fine and rough) from where we notice the presence of the silt to a large extent.

Regarding ornamentation (Graphic 5), $72 \%$ of the material present in feature 959 is unornamented. The remaining $28 \%$ are from this point of view in the register of ornaments of the Turdaș culture.

Related to the dotted-incised strip, a diversification is observed, with strips filled with stitches which become longer and wider.

As mention above, feature 959 is surrounded by several dwelling structures, together forming a group composed of:

- structure 9 (C. 902a-e; C. 903a-e; C. 947; C. 948; C. 949; C. 951b-g; C. 953; C. 956; C.957; C. 957b; C. 958);

- structure 12 (C. 968; C. 969a-f; C. 970b-f; C. 971a-c; C. 986a);

- structure 13 (C. 972a-b; C. 983a, c, e, g, i; C. 984a, b, d, e);

- structure 14 (C. 955; C. 965a-d; C. 966-a; C. 967a-d);

- structure 21 (C. 960a-h; C. 961a-f; C. 1454; C. 1455);

- structure 22 (C. 973a-d; C. 973f; C. 973i; C. 973j; C. 1350; C. 1351; C. 1352; C. 1359; C. 1360; C. 1361);

In Plans 3-4 we have a proposal for the grouping of structures, as we observed it. From what we see in the plan, we can conclude that in sector $\mathrm{C}$ we encounter - at a moment - a systematization of the area, on" neighborhoods/markets" or - why not - on family groups, all being part of a possible prehistoric city with several moments - certain - of inhabitation. 


\section{Illustration list}

\section{Plans}

Plan 1. Sectors of the Turdaş site and the fortification system - the yellow lines represent approximations.

Plan 2. Turdaș-Luncă. 2011 campaign. Sector C. Feature 959. Turdaș culture III. Identifying the feature within the sector.

Plan 3. Turdaș-Luncă. 2011 campaign. Sector C. Feature 959. Turdaş culture III grouping of structures (with purple).

Plan 4. Turdaș-Luncă. 2011 campaign. Sector C. Grouping of structures (9, 12-14, 21-22).

\section{Photos}

Photo 1. Turdaș-Luncă. 2011 campaign. Sector C. Feature 959. Turdaș culture, phase III - section view.

Photo 2. Turdaș-Luncă. 2011 campaign. Sector C. Feature 959. Turdaș culture, phase III - image after emptying.

\section{Drawings}

Drawing 1. Turdaș-Luncă. 2011 campaign. Sector C. Feature 959. Turdaș culture, phase III - drawing after emptying.

Drawing 2. Turdaș-Luncă. 2011 campaign. Sector C. Feature 959. Turdaș culture, phase III - drawing with section view.

\section{Graphics}

Graphic 1. Turdaș-Luncă. 2011 campaign. Sector C. Feature 959. Turdaș culture, phase III. Graphic with percentage analysis of ceramic categories.

Graphic 2. Turdaș-Luncă. 2011 campaign. Sector C. Feature 959. Turdaș culture, phase III. Graphic with percentage analysis of firing categories.

Graphic 3. Turdaș-Luncă. 2011 campaign. Sector C. Feature 959. Turdaș culture, phase III. Graphic with percentage analysis of exterior color of the ceramic materials.

Graphic 4. Turdaș-Luncă. 2011 campaign. Sector C. Feature 959. Turdaș culture, phase III. Graphic with percentage analysis of interior color of the ceramic materials.

Graphic 5. Turdaș-Luncă. 2011 campaign. Sector C. Feature 959. Turdaș culture, phase III. Graphic with percentage analysis of decoration of the ceramic materials.

Graphic 6. Turdaș-Luncă. 2011 campaign. Sector C. Feature 959. Turdaș culture, phase III. Graphic with percentage analysis of smoothing of the ceramic materials.

Graphic 7. Turdaș-Luncă. 2011 campaign. Sector C. Feature 959. Turdaș culture, phase III. Graphic with percentage analysis of temper. 


\section{Maps}

Map 1. Settlement from Turdaş-Luncă. Perimeter of the researched surface (Josephin map).

Map 2. Settlement from Turdaș-Luncă. Overview of the area researched in 2011.

\section{Plates}

Pl. I. Turdaș-Luncă. 2011 campaign. Sector C. Feature 959. Pottery. Turdaș culture, phase III.

PI. II. Turdaș-Luncă. 2011 campaign. Sector C. Feature 959. Pottery. Turdaș culture, phase III.

Pl. III. Turdaș-Luncă. 2011 campaign. Sector C. Feature 959. Pottery. Turdaș culture, phase III.

Pl. IV. Turdaş-Luncă. 2011 campaign. Sector C. Feature 959. Pottery. Turdaș culture, phase III.

Pl. V. Turdaș-Luncă 2011 campaign. Sector C. Feature 959. Pottery. Turdaș culture, phase III.

Pl. VI. Turdaş-Luncă. 2011 campaign. Sector C. Feature 959. Pottery. Turdaş culture, phase III.

Pl. VII. Turdaș-Luncă. 2011 campaign. Sector C. Feature 959. Pottery. Turdaș culture, phase III.

Pl. VIII. Turdaș-Luncă. 2011 campaign. Sector C. Feature 959. Pottery. Turdaș culture, phase III.

Pl. IX. Turdaş-Luncă. 2011 campaign. Sector C. Feature 959. Pottery. Turdaș culture, phase III.

Pl. X. Turdaș-Luncă. 2011 campaign. Sector C. Feature 959. Pottery. Turdaș culture, phase III.

Pl. XI. Turdaş-Luncă. 2011 campaign. Sector C. Feature 959. Pottery. Turdaș culture, phase III.

Pl. XII. Turdaș-Luncă. 2011 campaign. Sector C. Feature 959. Pottery. Turdaș culture, phase III.

Pl. XIII. Turdaș-Luncă. 2011 campaign. Sector C. Feature 959. Pottery. Turdaș culture, phase III.

Pl. XIV. Turdaș-Luncă. 2011 campaign. Sector C. Feature 959. Pottery. Turdaș culture, phase III.

Pl. XV. Turdaș-Luncă. 2011 campaign. Sector C. Feature 959. Pottery. Turdaș culture, phase III.

PI. XVI. Turdaș-Luncă. 2011 campaign. Sector C. Feature 959. Pottery. Turdaș culture, phase III.

Pl. XVII. Turdaș-Luncă. 2011 campaign. Sector C. Feature 959. Pottery. Turdaș culture, phase III.

Pl. XVIII. Turdaș-Luncă. 2011 campaign. Sector C. Feature 959. Pottery. Turdaș culture, phase III. 
Pl. XIX. Turdaș-Luncă. 2011 campaign. Sector C. Feature 959. Pottery. Turdaș culture, phase III.

Pl. XX. Turdaș-Luncă. 2011 campaign. Sector C. Feature 959. Pottery. Turdaș culture, phase III.

PI. XXI. Turdaș-Luncă. 2011 campaign. Sector C. Feature 959. Pottery. Turdaș culture, phase III.

Pl. XXII. Turdaș-Luncă. 2011 campaign. Sector C. Feature 959. Pottery. Turdaș culture, phase III.

PI. XXIII. Turdaș-Luncă. 2011 campaign. Sector C. Feature 959. Pottery. Turdaș culture, phase III.

PI. XXIV. Turdaș-Luncă. 2011 campaign. Sector C. Feature 959. Pottery. Turdaș culture, phase III.

Pl. XXV. Turdaș-Luncă. 2011 campaign. Sector C. Feature 959. Pottery. Turdaș culture, phase III.

PI. XXVI. Turdaș-Luncă. 2011 campaign. Sector C. Feature 959. Pottery. Turdaș culture, phase III.

Pl. XXVII. Turdaș-Luncă. 2011 campaign. Sector C. Feature 959. Pottery. Turdaș culture, phase III.

PI. XXVIII. Turdaș-Luncă. 2011 campaign. Sector C. Feature 959. Pottery. Turdaș culture, phase III.

PI. XXIX. Turdaș-Luncă. 2011 campaign. Sector C. Feature 959. Pottery. Turdaș culture, phase III.

PI. XXX. Turdaș-Luncă. 2011 campaign. Sector C. Feature 959. Pottery. Turdaş culture, phase III.

PI. XXXI. Turdaș-Luncă. 2011 campaign. Sector C. Feature 959. Pottery. Turdaș culture, phase III.

Pl. XXXII. Turdaș-Luncă. 2011 campaign. Sector C. Feature 959. Pottery. Turdaș culture, phase III.

PI. XXXIII. Turdaș-Luncă. 2011 campaign. Sector C. Feature 959. Pottery. Turdaș culture, phase III. 


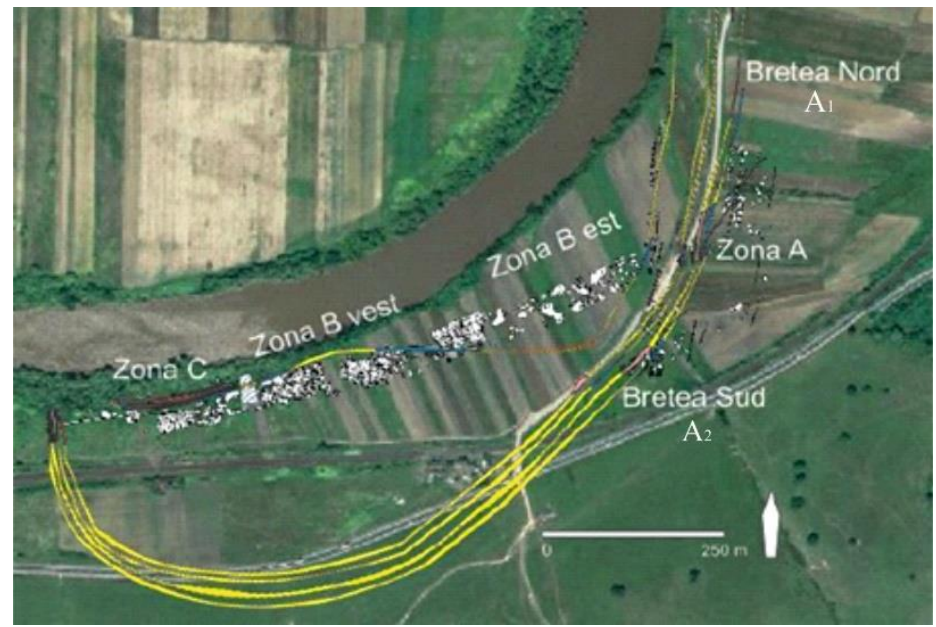

Plan 1. Sectors of the Turdaș site and the fortification system - the yellow lines represent approximations (Luca 2012, 33, Foto 3; Luca, Suciu 2015, 43, Photo 1; Palaghie 2020 (manuscript)).

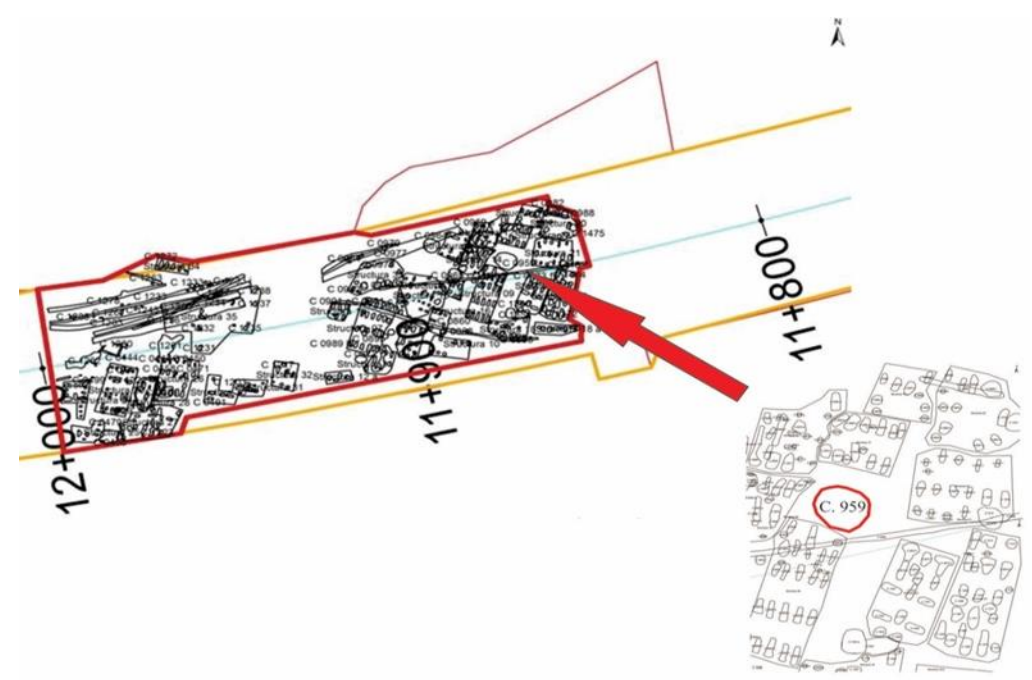

Plan 2. Turdaș-Luncă. 2011 campaign. Sector C. Feature 959. Turdaș culture III. Identifying the feature within the sector. 


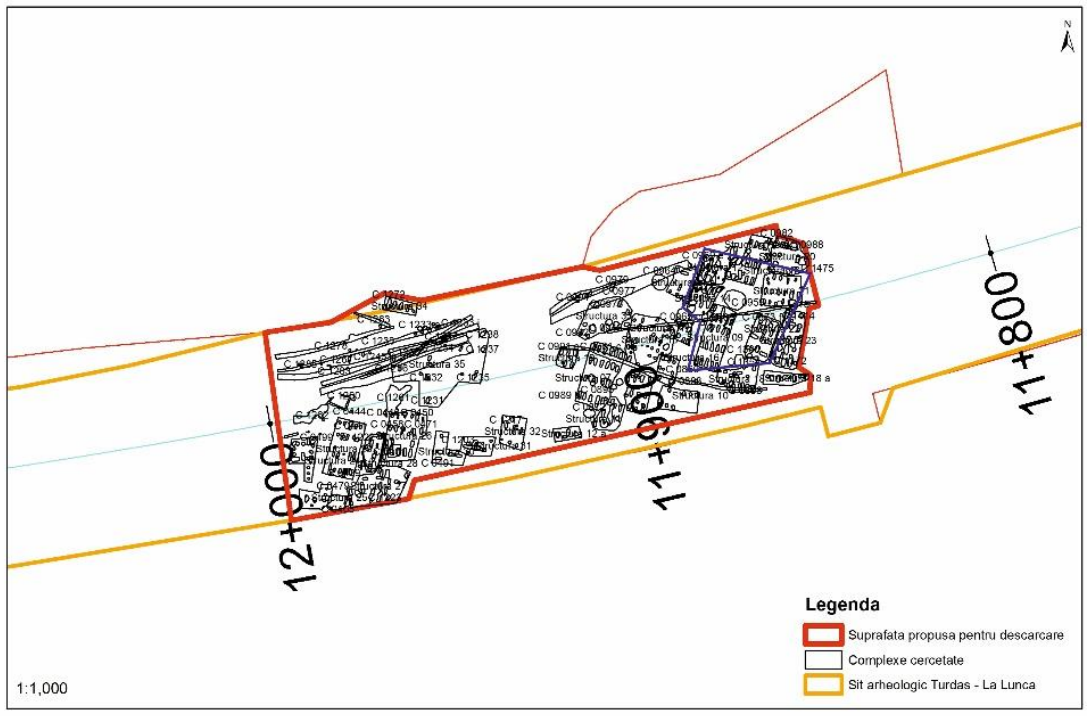

Plan 3. Turdaș-Luncă. 2011 campaign. Sector C. Feature 959. Turdaș culture, phase III - grouping of structures (with purple).

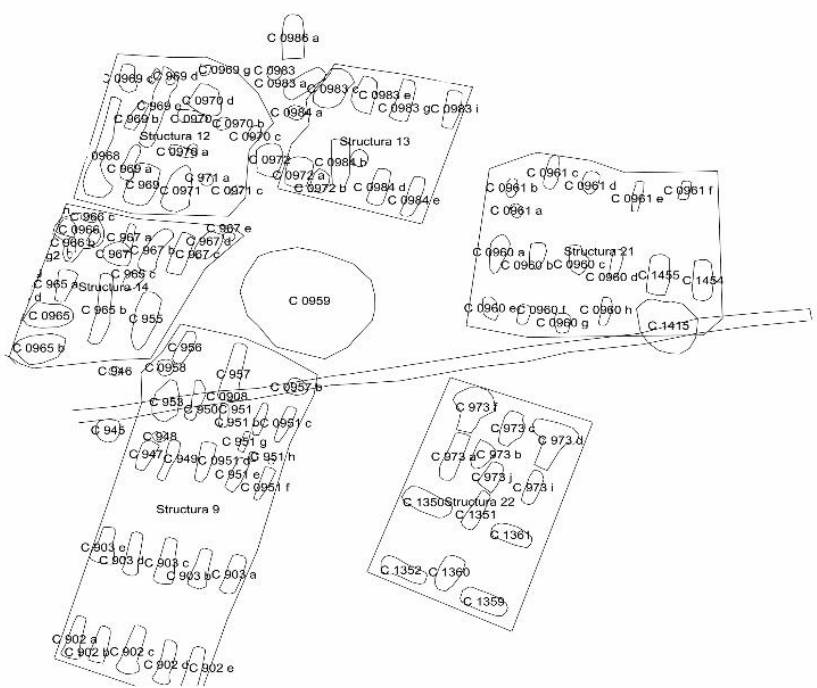

Plan 4. Turdaș-Luncă 2011 campaign. Sector C. Grouping of structures (9, 12-14, 2122). 


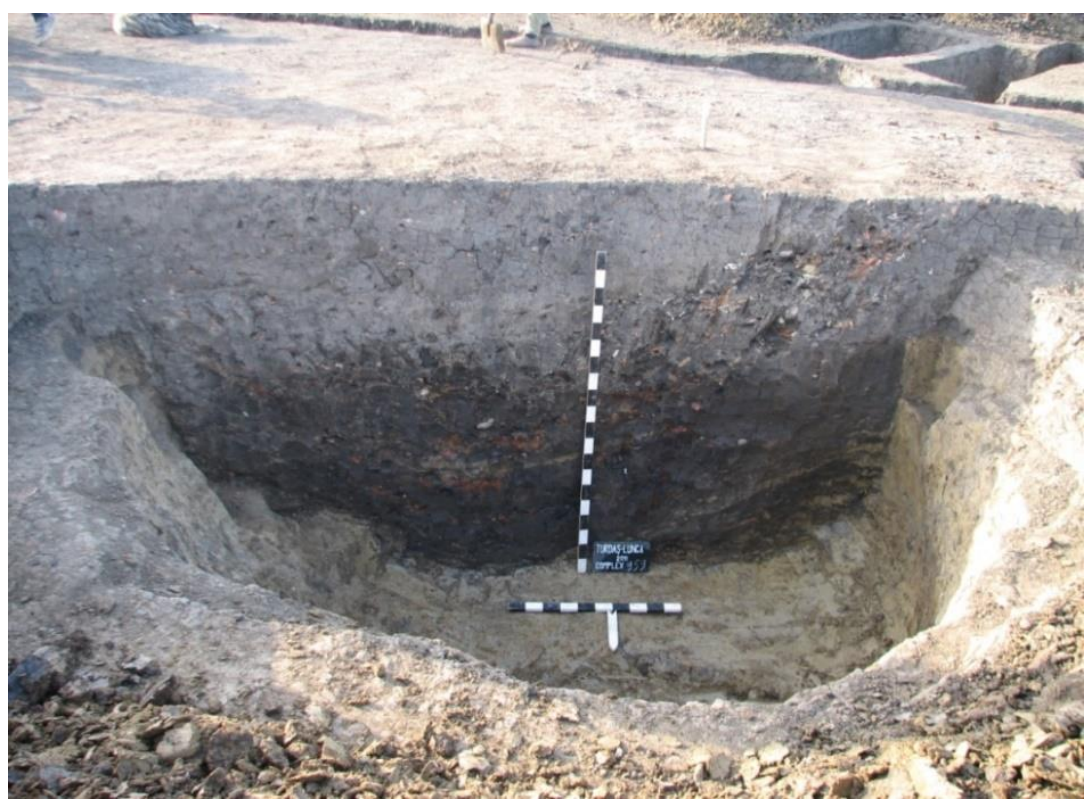

Photo 1. Turdaș-Luncă. 2011 campaign. Sector C. Feature 959. Turdaș culture, phase III - section view.

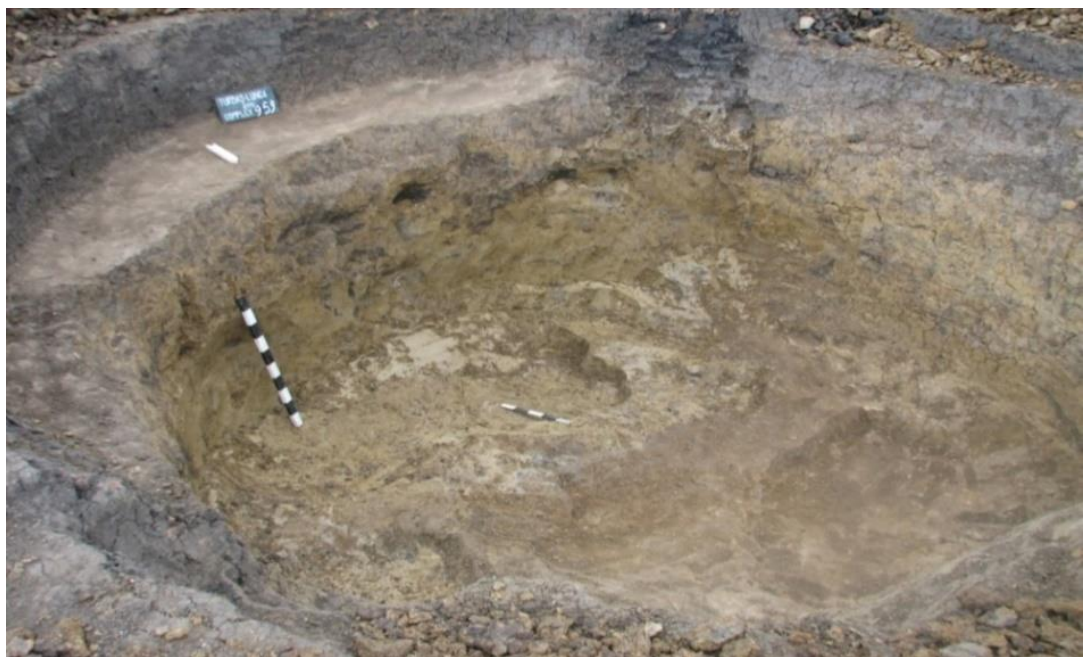

Photo 2. Turdaș-Luncă. 2011 campaign. Sector C. Feature 959. Turdaș culture, phase III - image after emptying. 


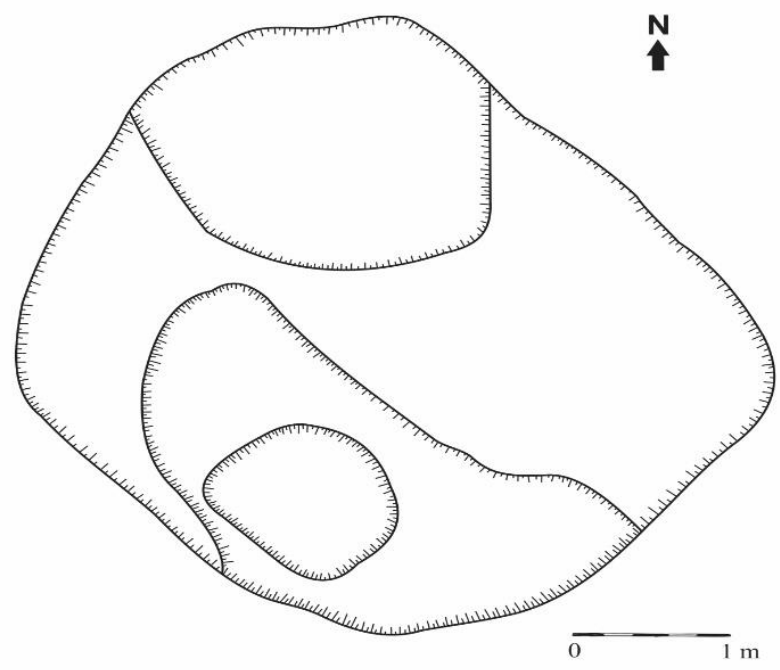

Drawing 1. Turdaș-Luncă. 2011 campaign. Sector C. Feature 959. Turdaș culture, phase III - drawing after emptying.

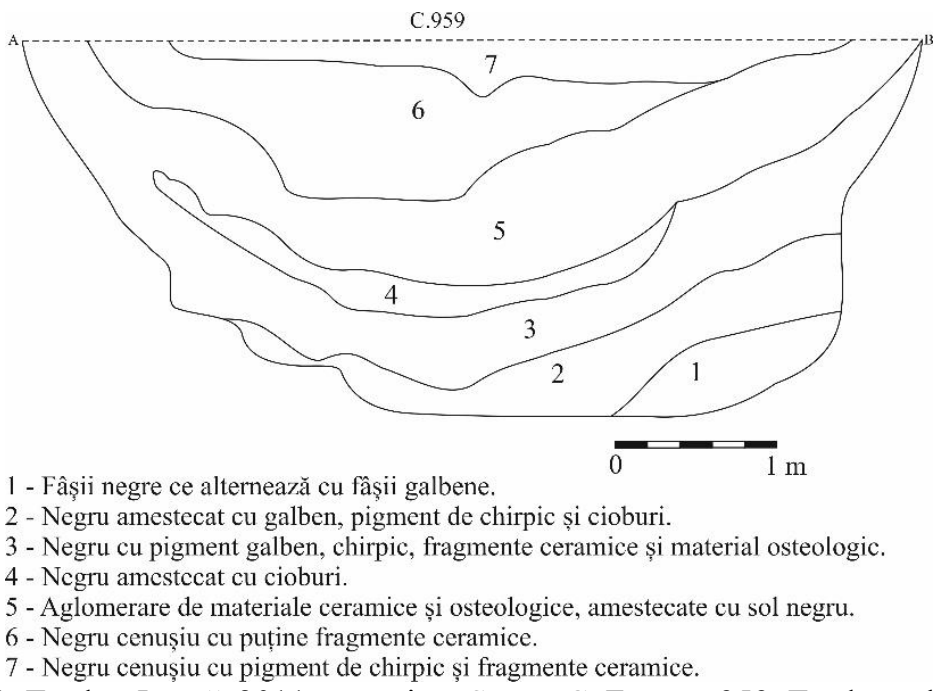

Drawing 2. Turdaş-Luncă. 2011 campaign. Sector C. Feature 959. Turdaș culture, phase III - drawing with section view. 


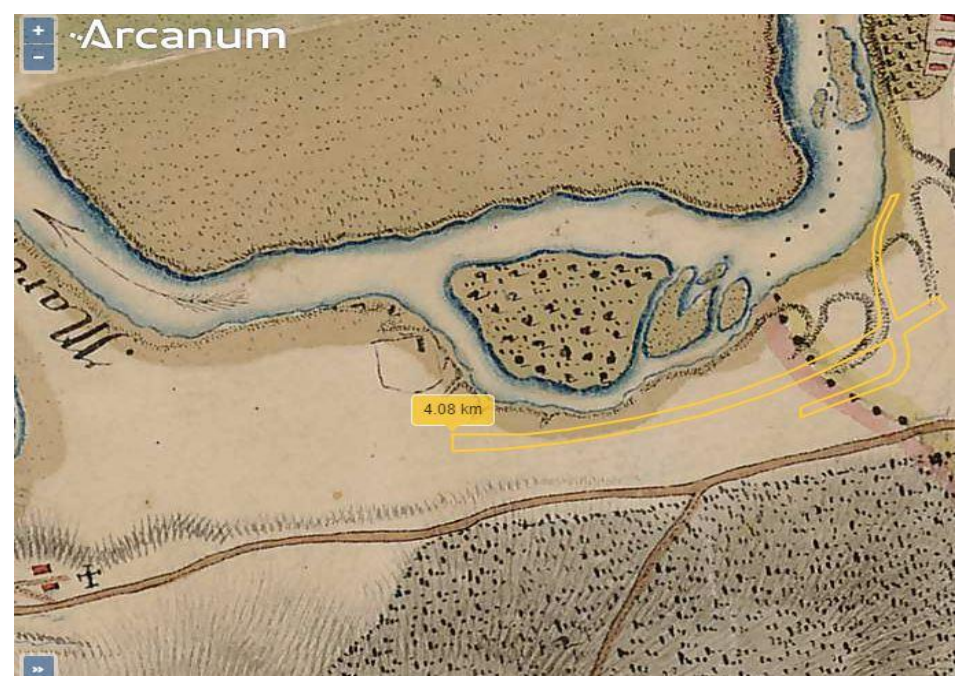

Map 1. Settlement from Turdaș-Luncă. Perimeter of the researched surface (Josephin map; http://mapire.eu/en/map/firstsurvey/?bbox $=2570934.3677172074 \% 2 \mathrm{C} 5755015.524158083 \% 2 \mathrm{C} 2577460.1790$ 070543\%2C5757815.030319028, accesed at 29-11-2019, time 21:28.).

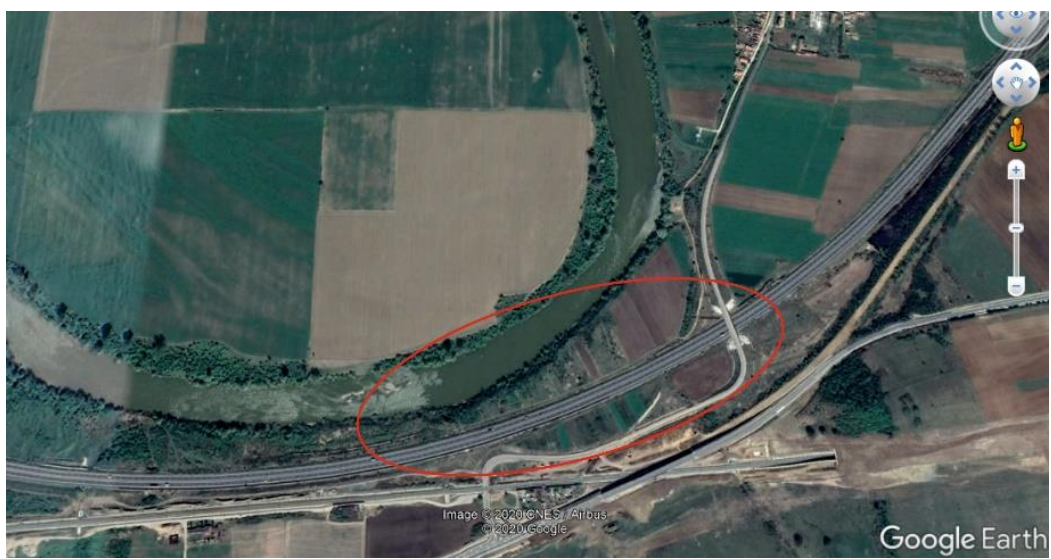

Map 2. Settlement from Turdaș-Luncă. Overview of the area researched in 2011 (Google Earth Pro, accesed at 2-09-2020, ora 15:16 (the presented photo was made from satellite in the $23^{\text {rd }}$ of April, 2020)). 

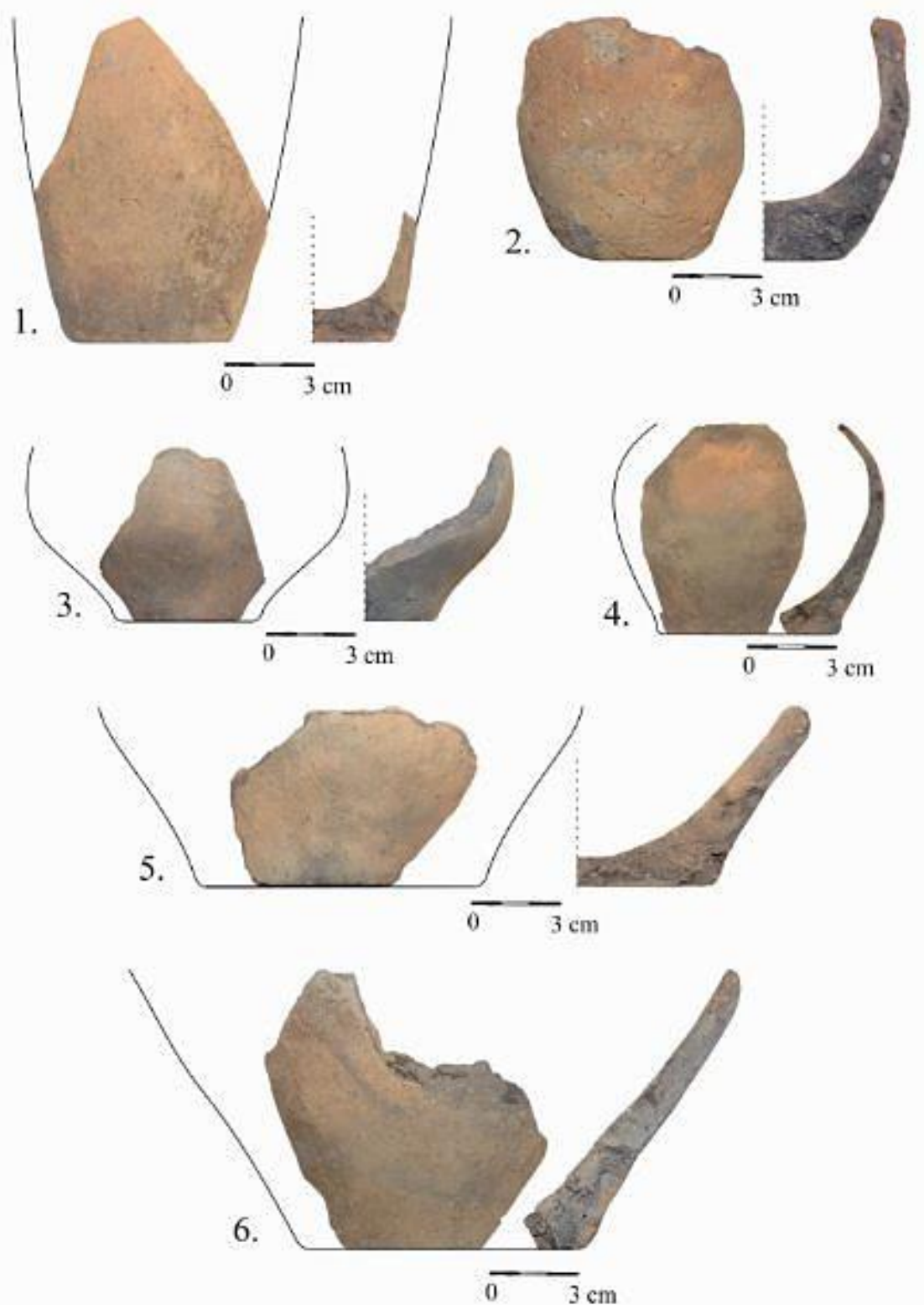

PI. I. Turdaș-Luncă. 2011 campaign. Sector C. Feature 959. Pottery. Turdaș culture, phase III. 


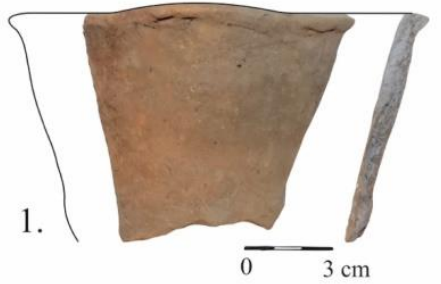

2.
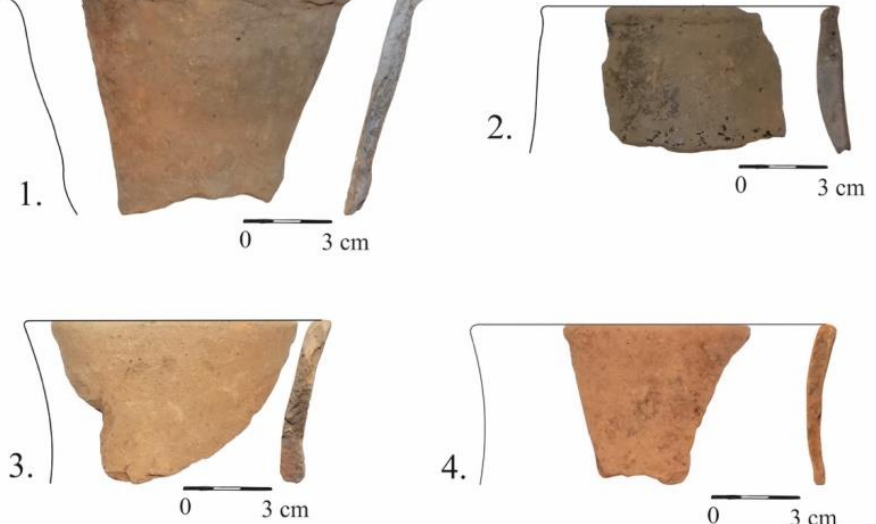

4.
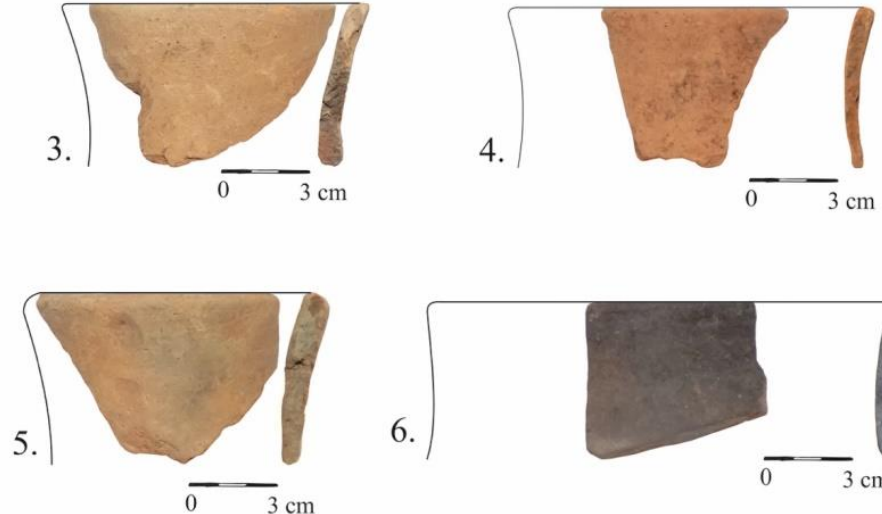

6.
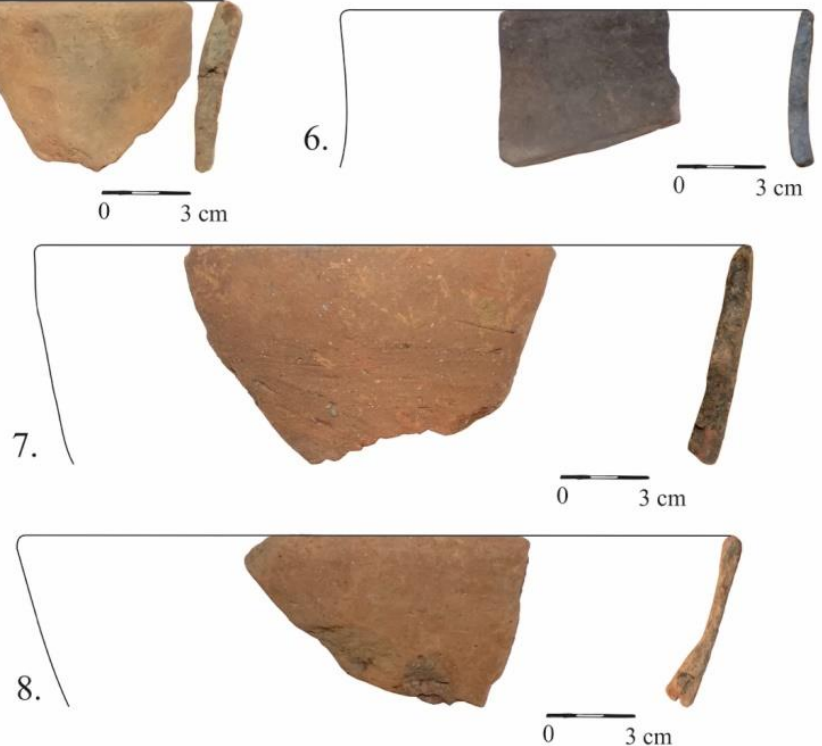

PI. II. Turdaș-Luncă. 2011 campaign. Sector C. Feature 959. Pottery. Turdaș culture, phase III. 

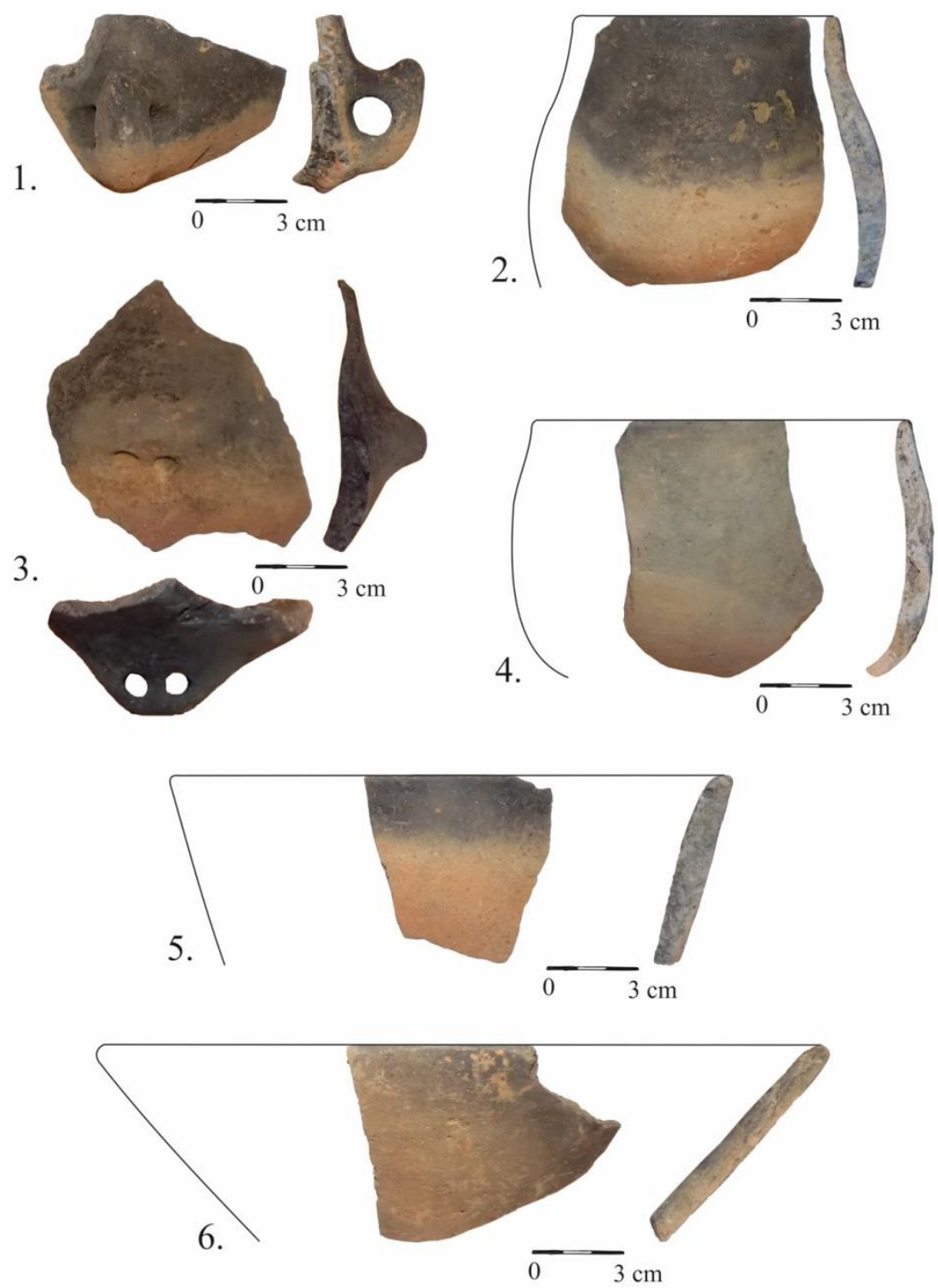

PI. III. Turdaș-Luncă. 2011 campaign. Sector C. Feature 959. Pottery. Turdaș culture, phase III. 

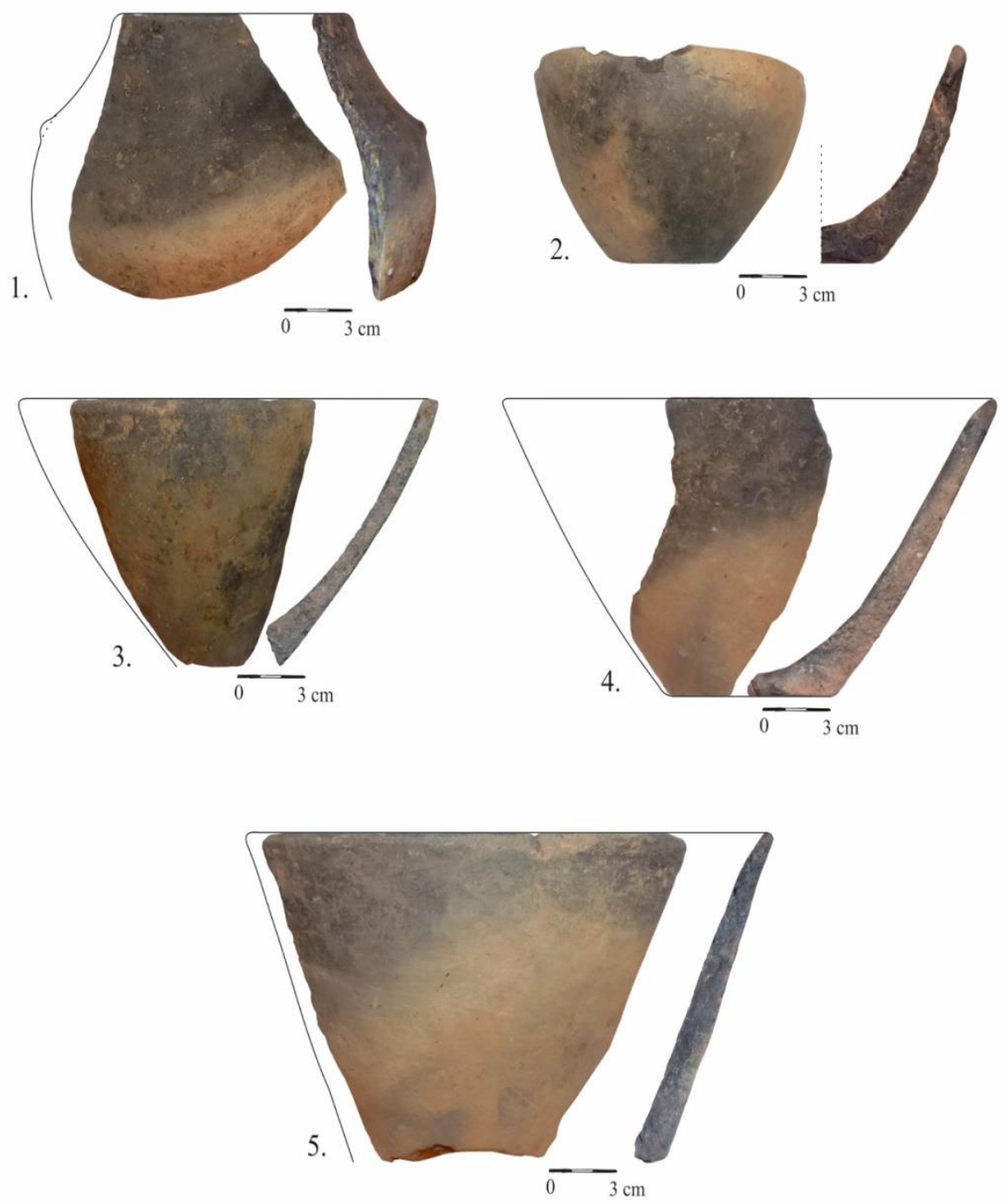

Pl. IV. Turdaș-Luncă. 2011 campaign. Sector C. Feature 959. Pottery. Turdaș culture, phase III. 

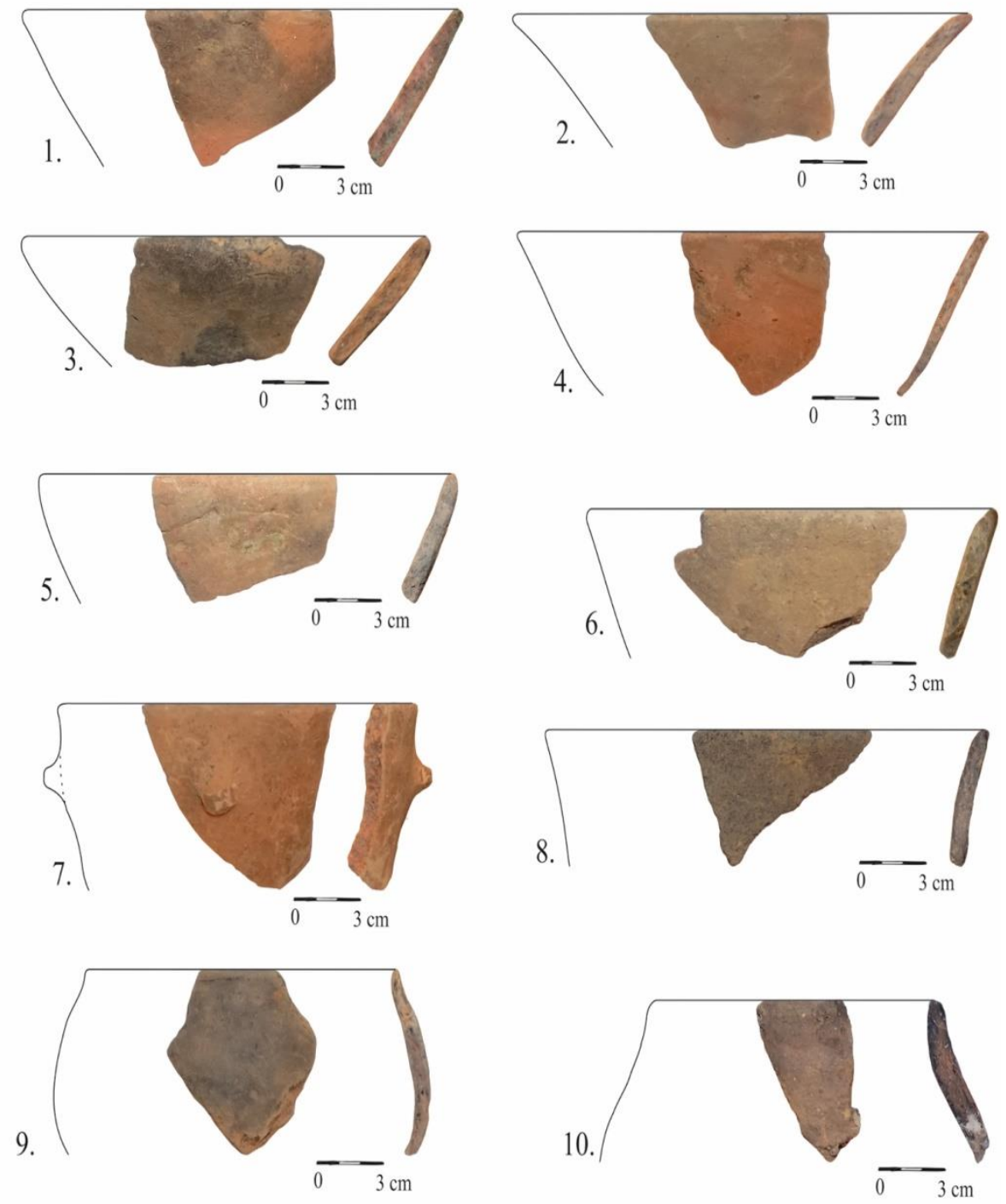

PI. V. Turdaș-Luncă. 2011 campaign. Sector C. Feature 959. Pottery. Turdaș culture, phase III. 

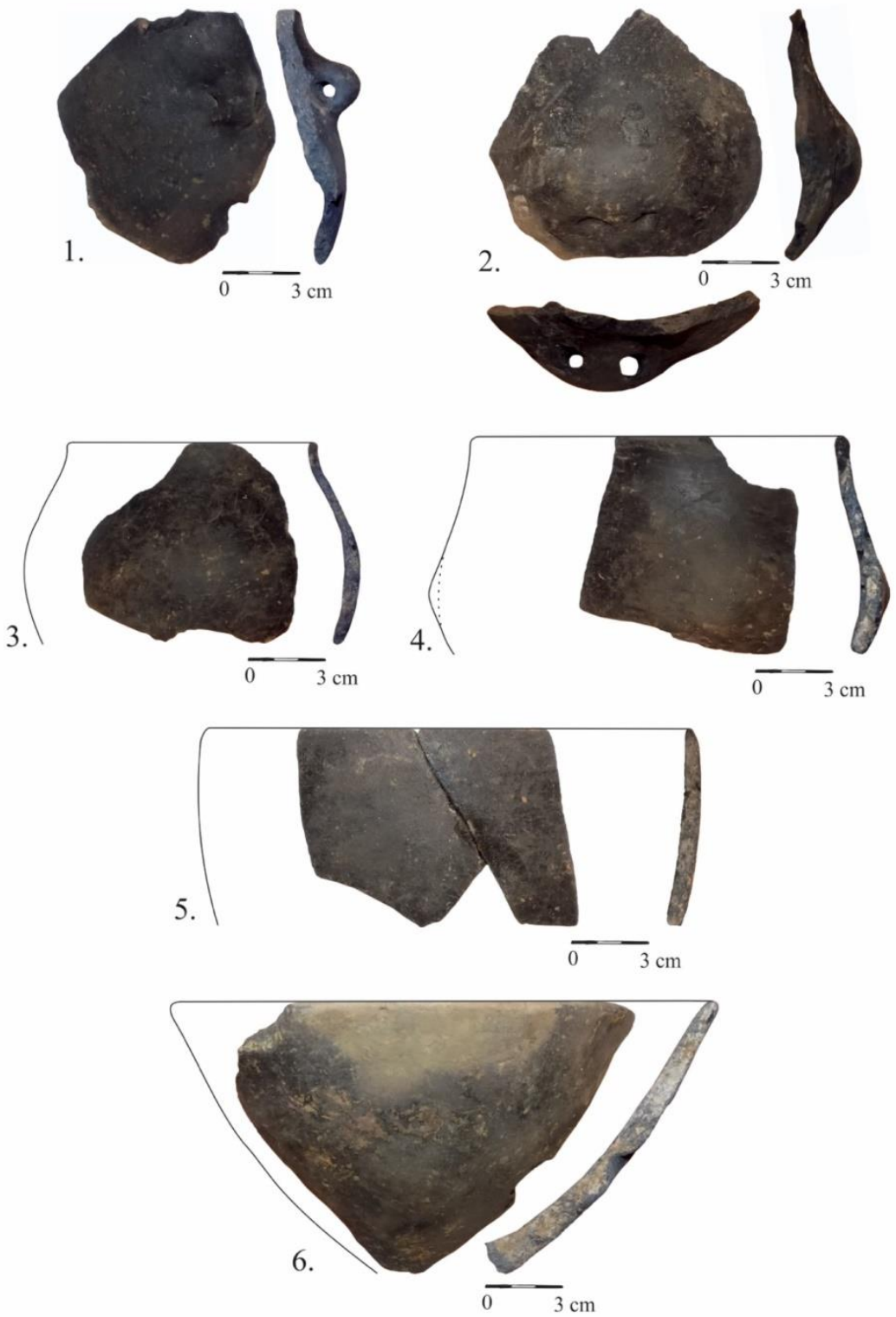

PI. VI. Turdaș-Luncă. 2011 campaign. Sector C. Feature 959. Pottery. Turdaș culture, phase III. 

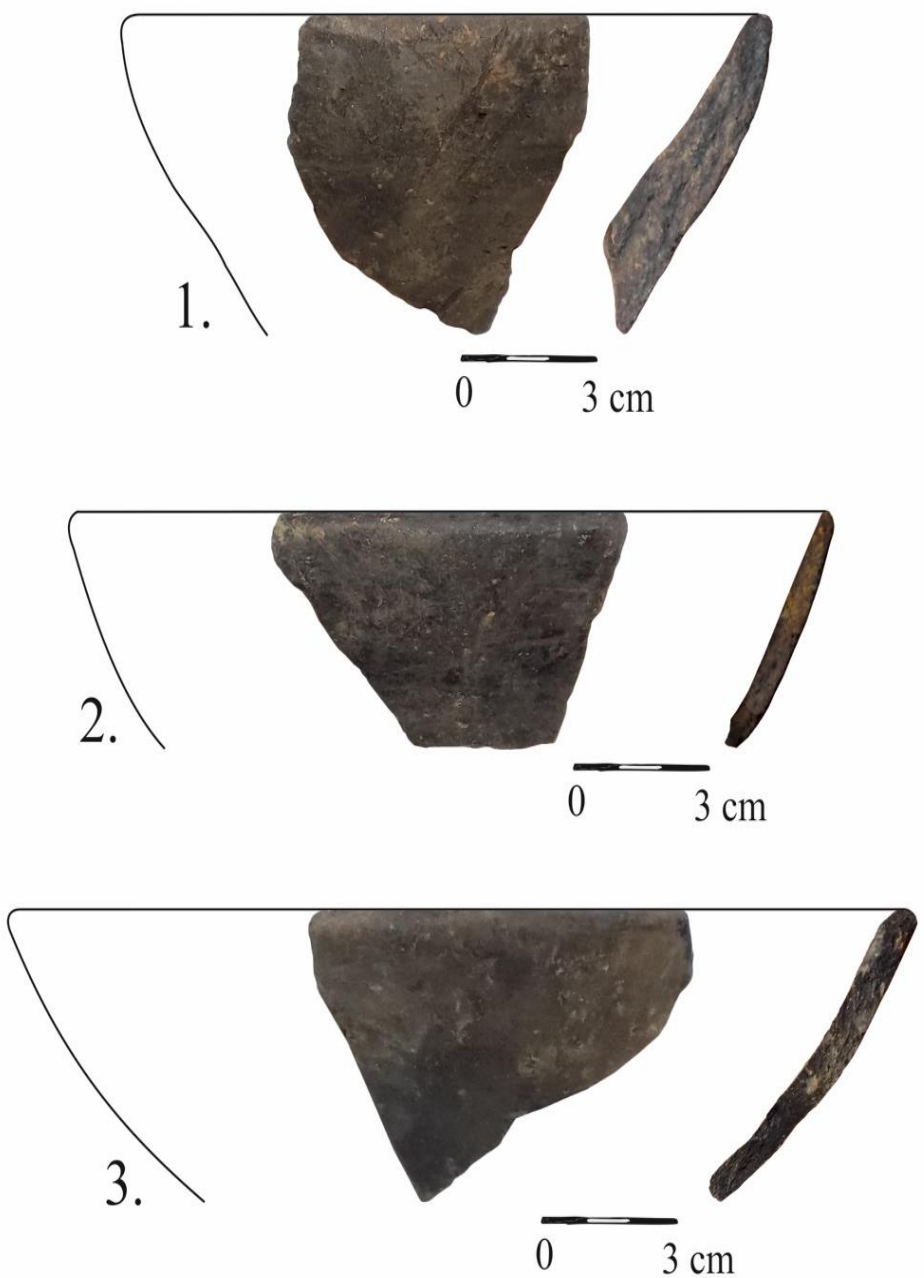

PI. VII. Turdaș-Luncă. 2011 campaign. Sector C. Feature 959. Pottery. Turdaș culture, phase III. 

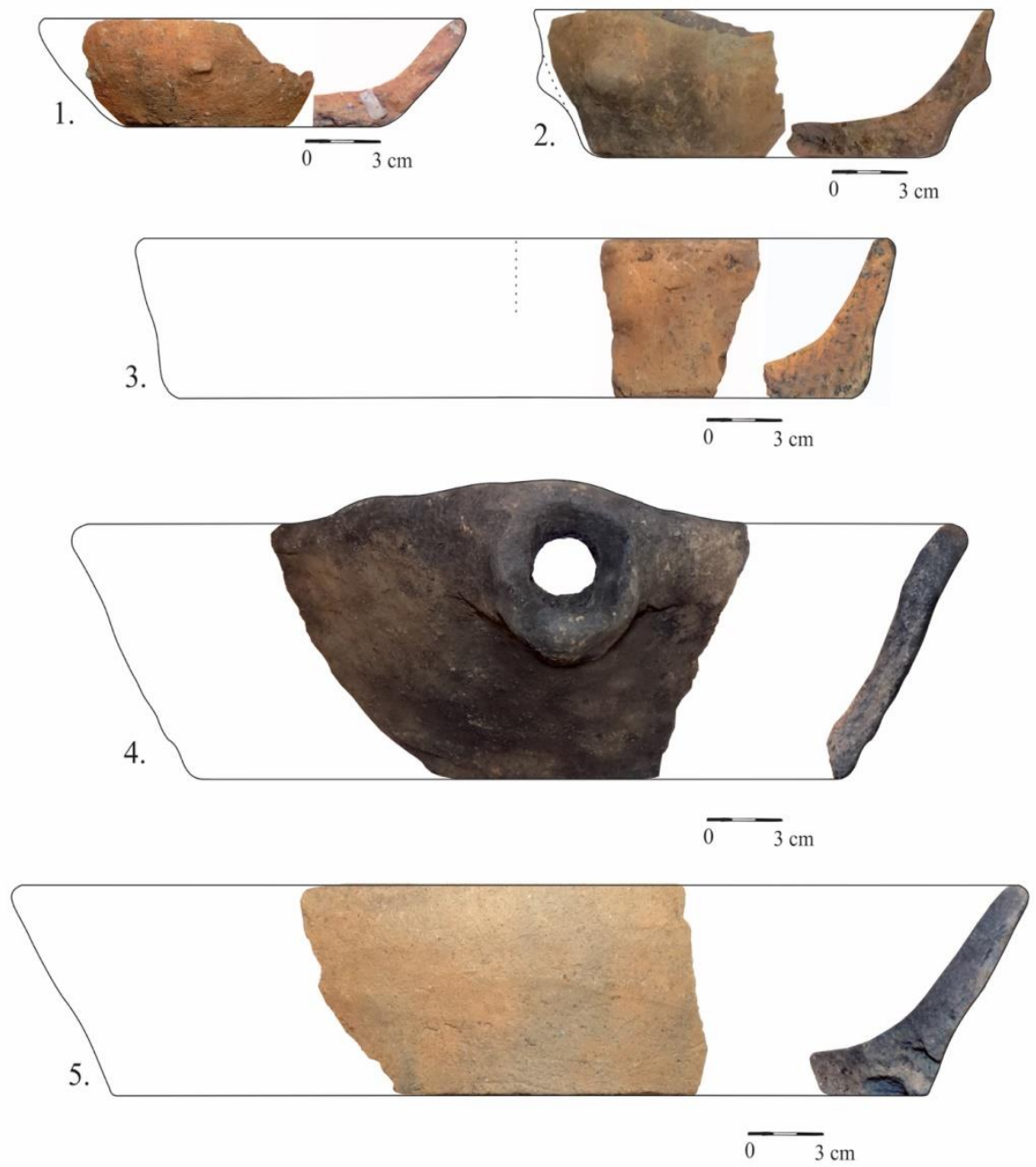

PI. VIII. Turdaș-Luncă. 2011 campaign. Sector C. Feature 959. Pottery. Turdaș culture, phase III. 

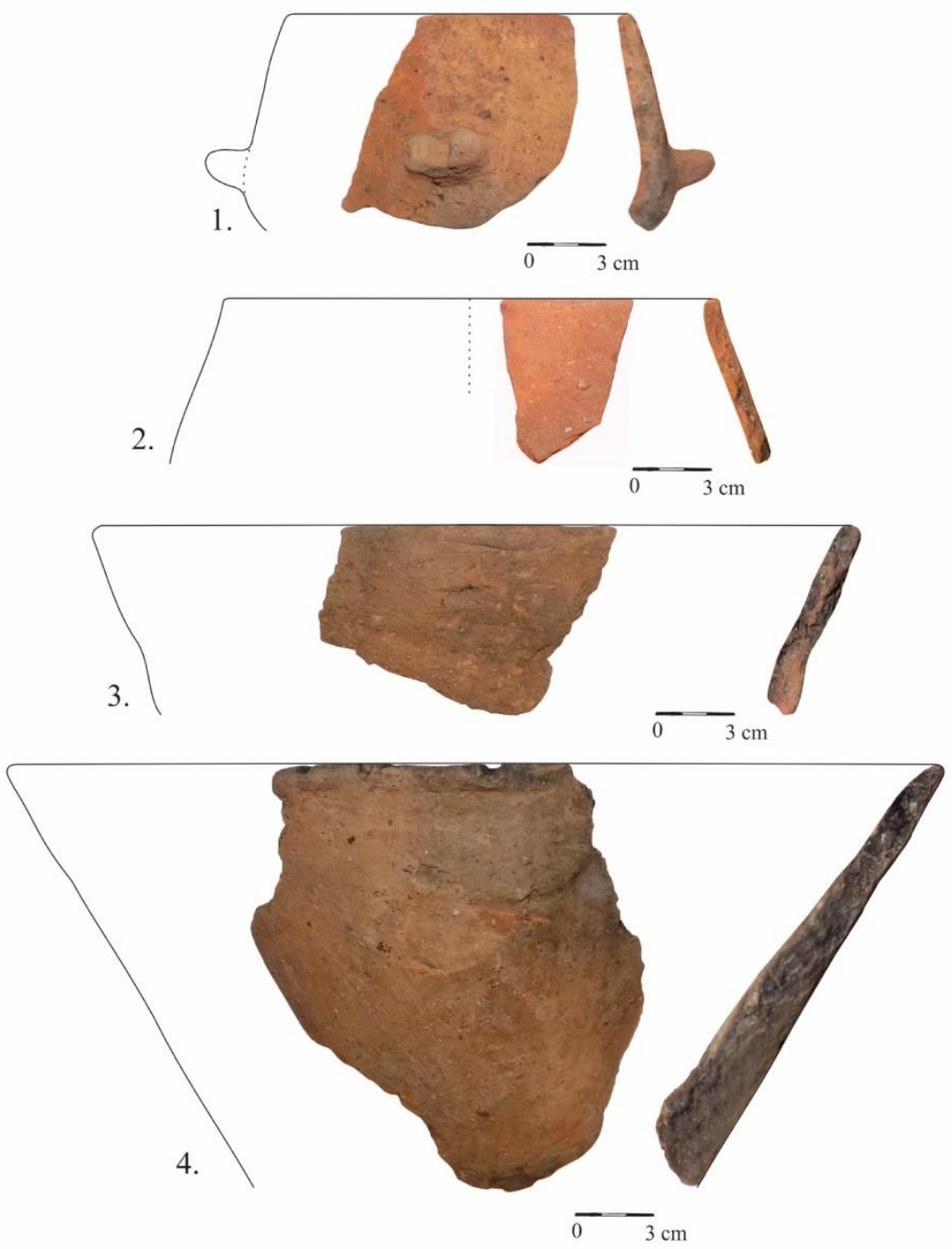

PI. IX. Turdaș-Luncă. 2011 campaign. Sector C. Feature 959. Pottery. Turdaș culture, phase III. 

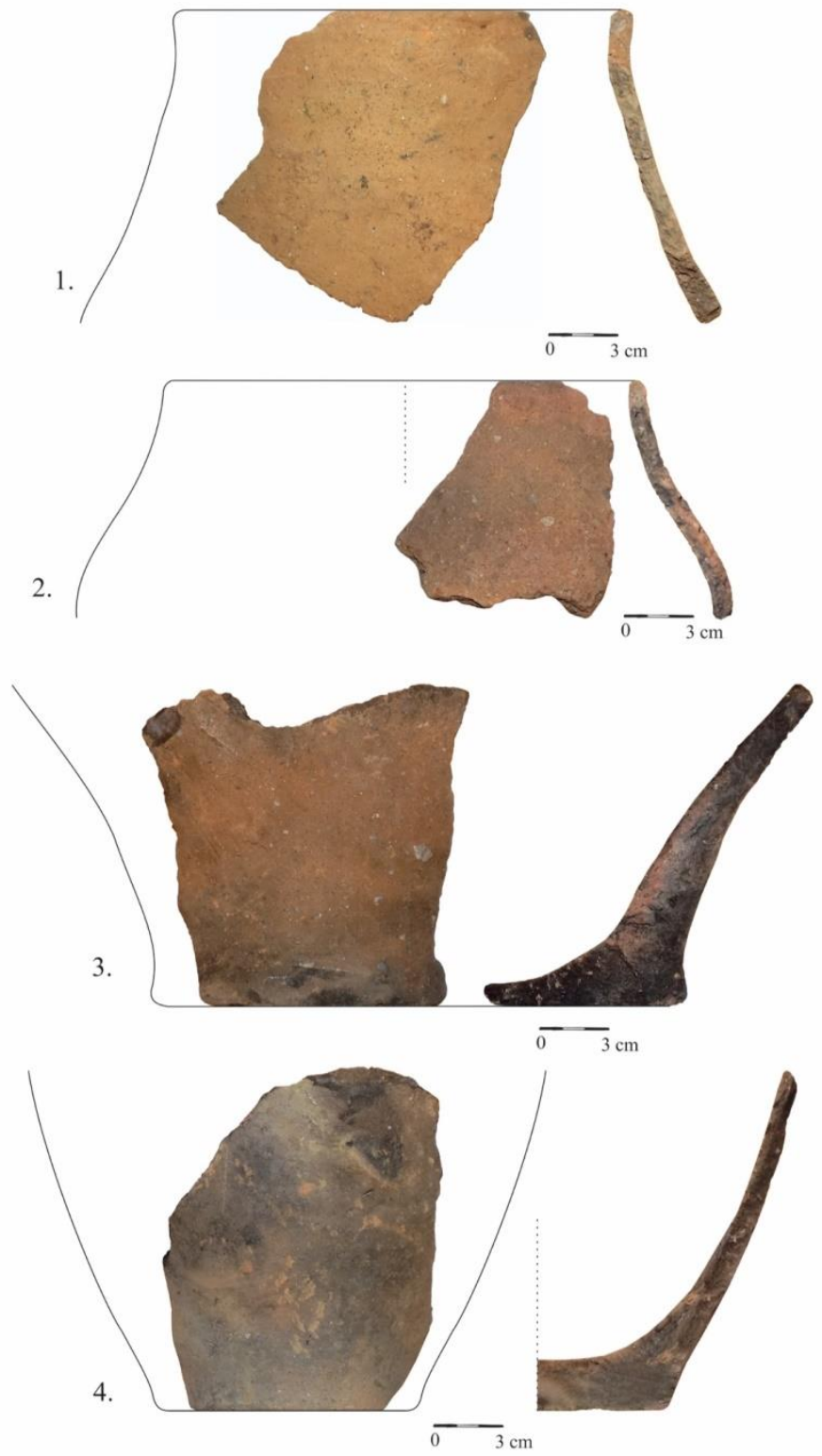

Pl. X. Turdaș-Luncă. 2011 campaign. Sector C. Feature 959. Pottery. Turdaș culture, phase III. 

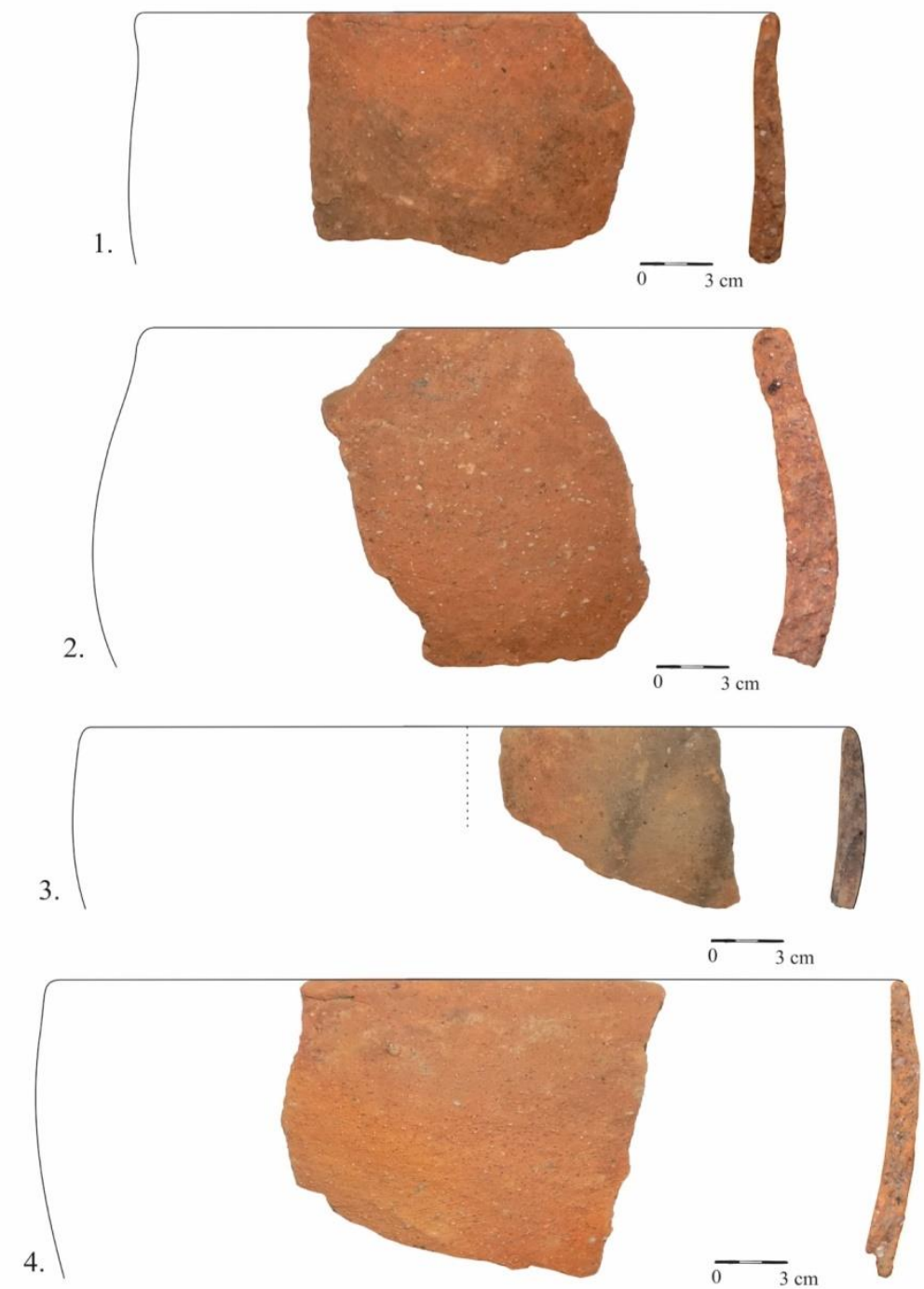

PI. XI. Turdaș-Luncă. 2011 campaign. Sector C. Feature 959. Pottery. Turdaș culture, phase III. 

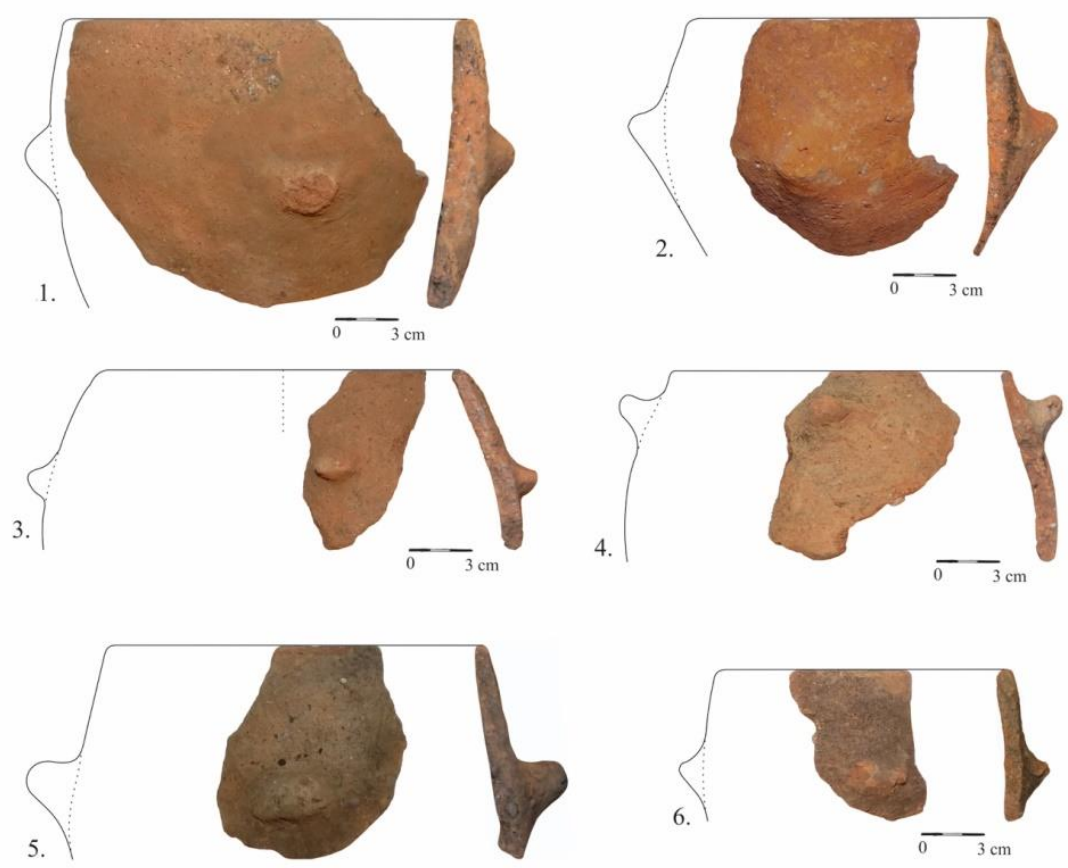

$\overline{0}-\overline{c m}$

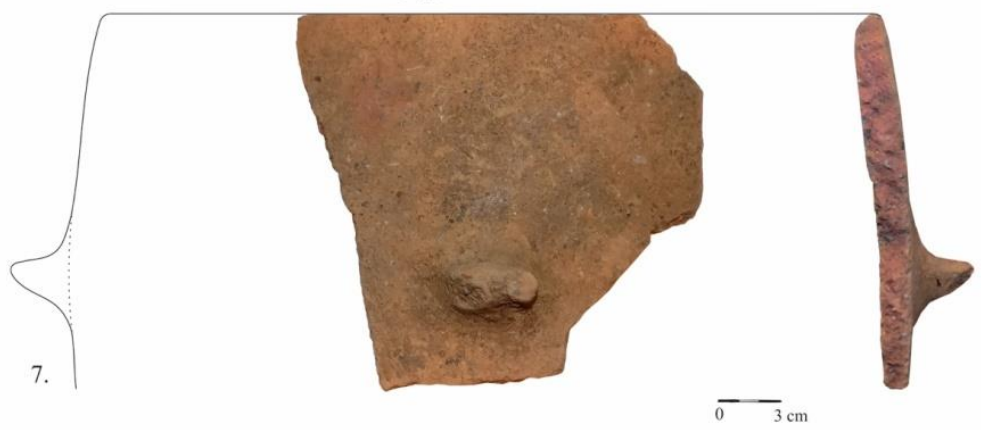

PI. XII. Turdaș-Luncă. 2011 campaign. Sector C. Feature 959. Pottery. Turdaș culture, phase III. 

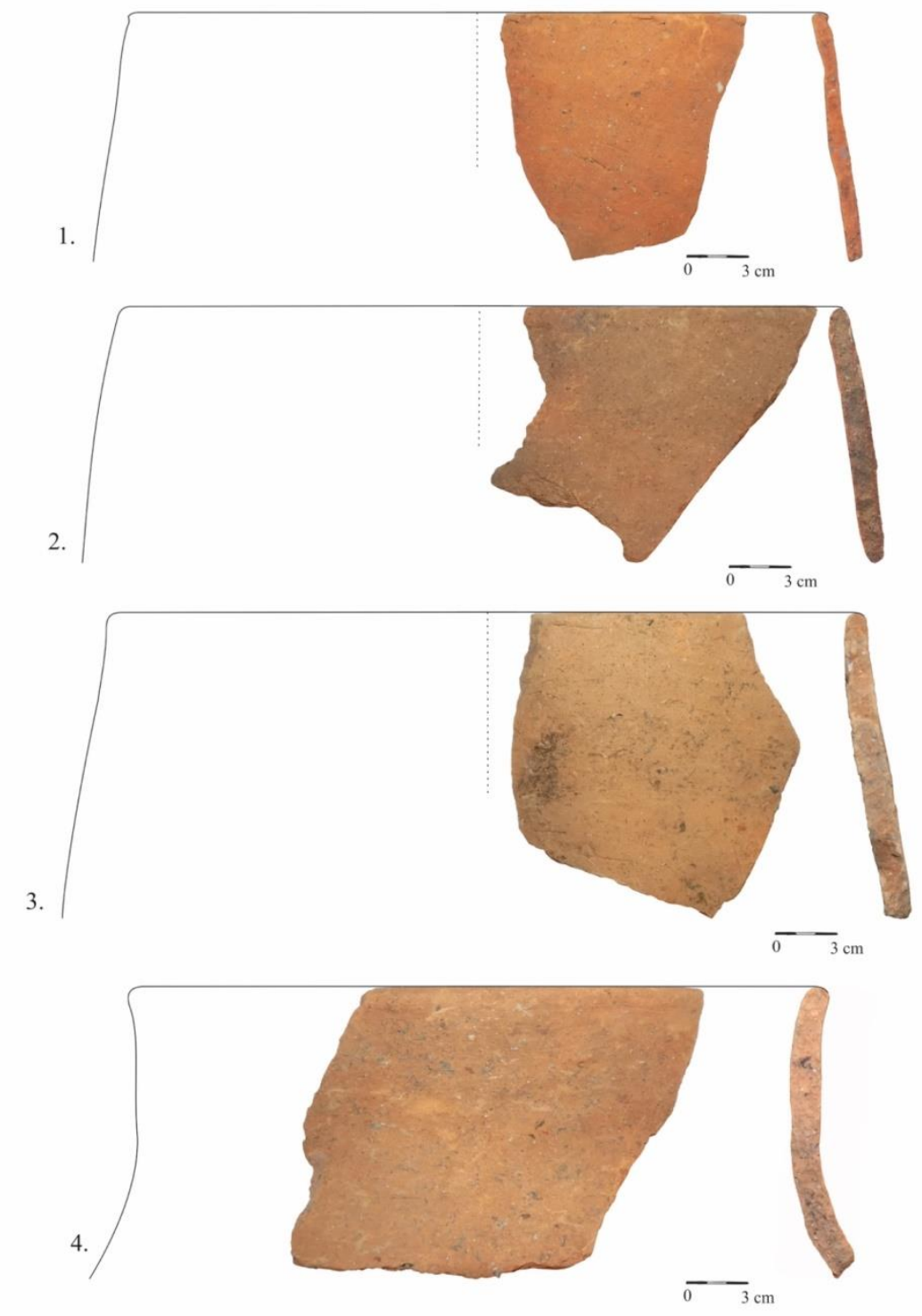

PI. XIII. Turdaș-Luncă. 2011 campaign. Sector C. Feature 959. Pottery. Turdaș culture, phase III. 
The Central Area of a "Square"

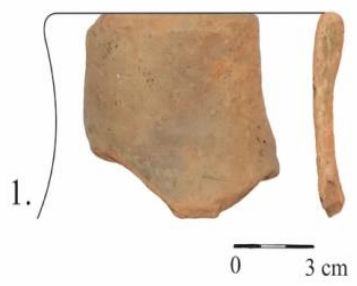

2.
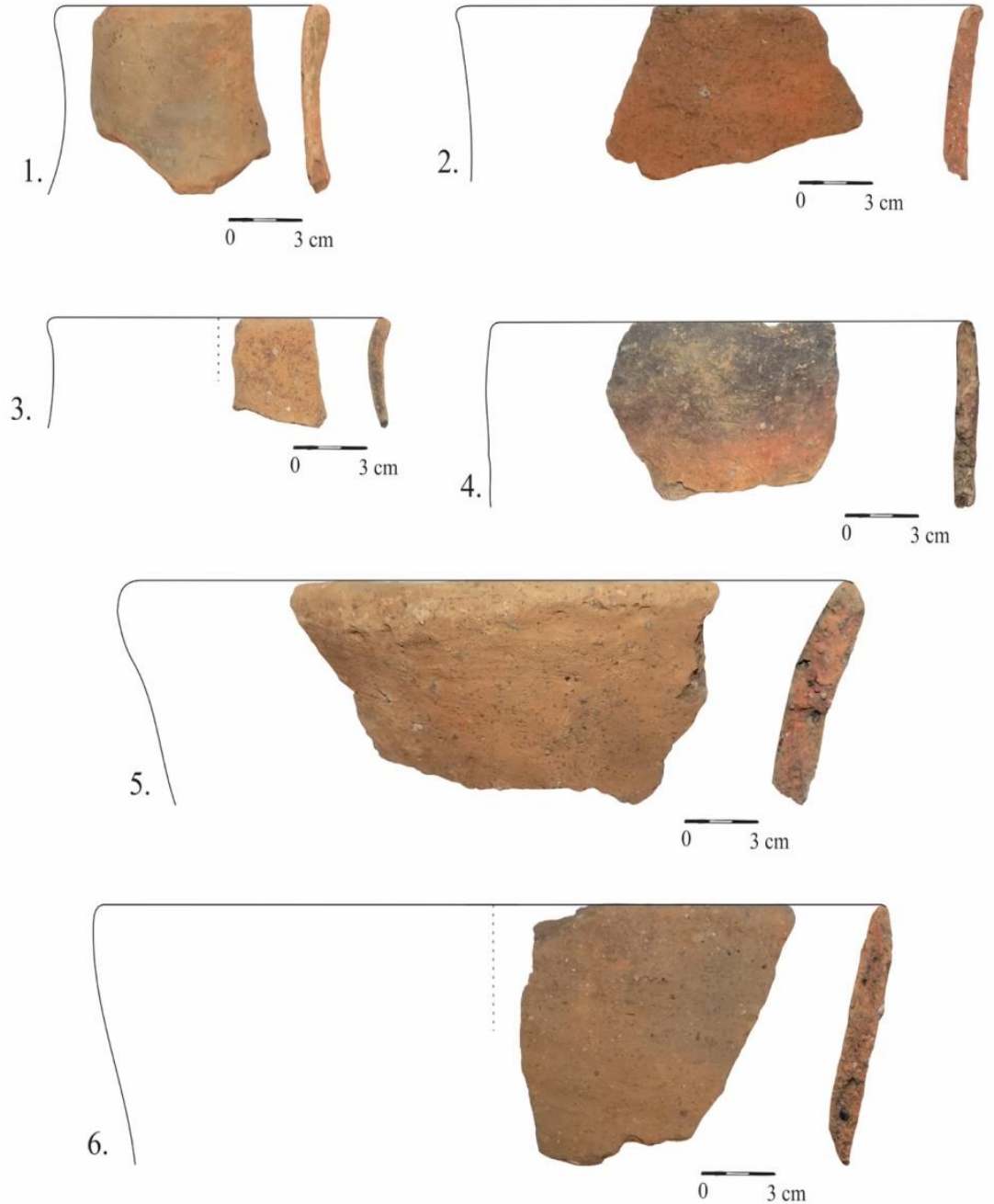

PI. XIV. Turdaș-Luncă. 2011 campaign. Sector C. Feature 959. Pottery. Turdaș culture, phase III. 

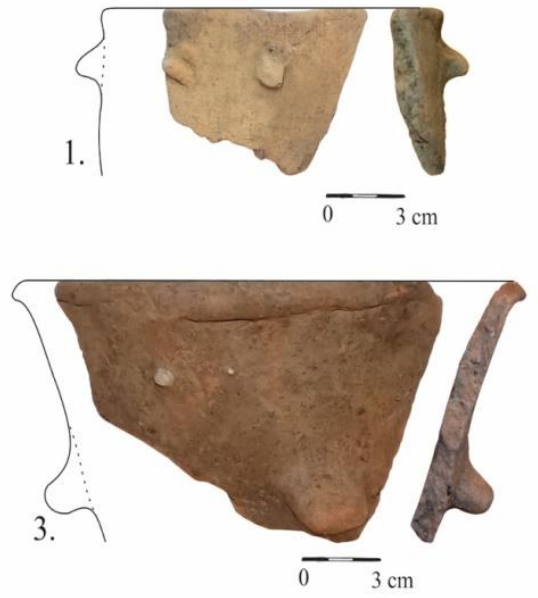
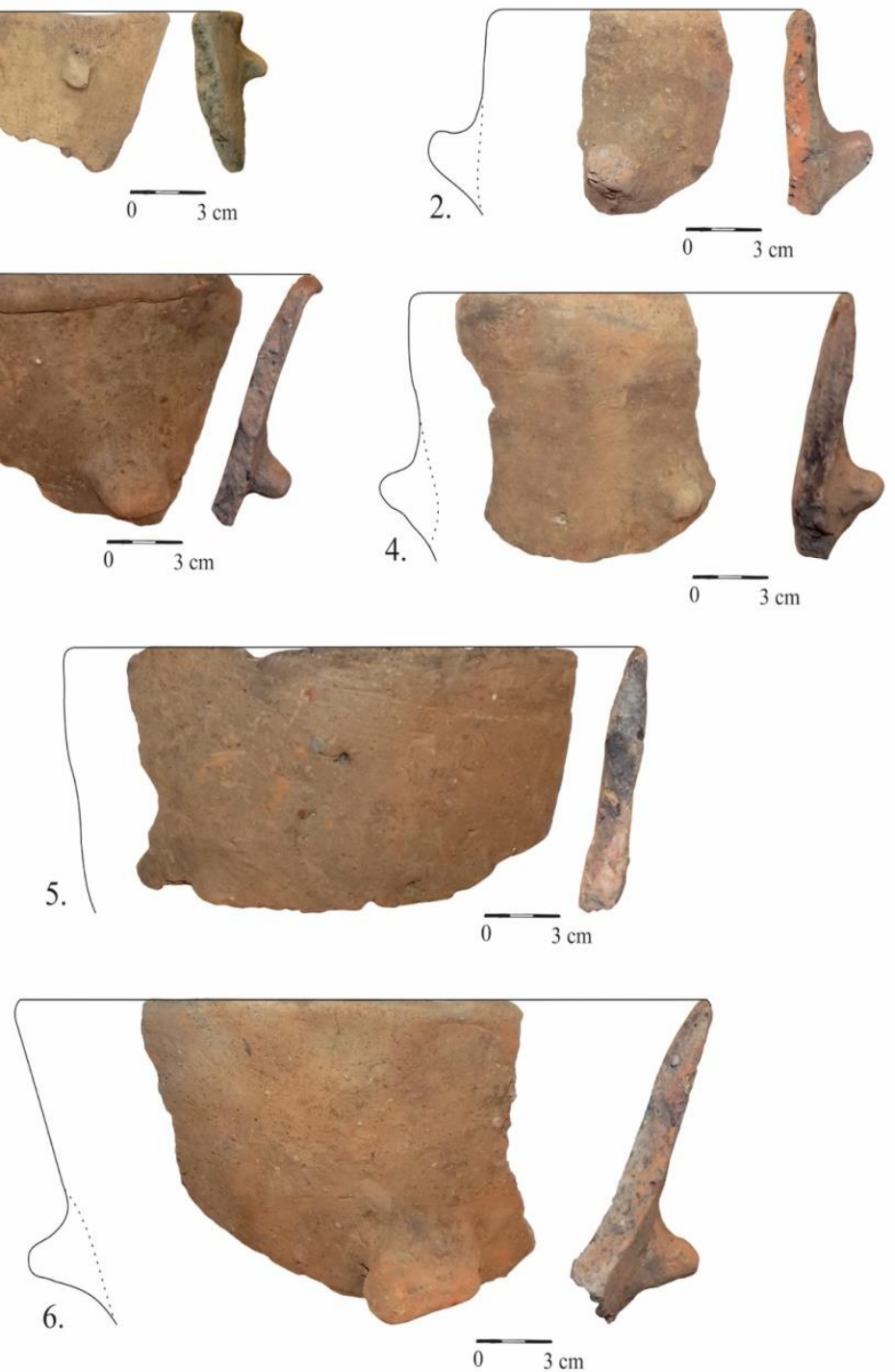

PI. XV. Turdaș-Luncă. 2011 campaign. Sector C. Feature 959. Pottery. Turdaș culture, phase III. 

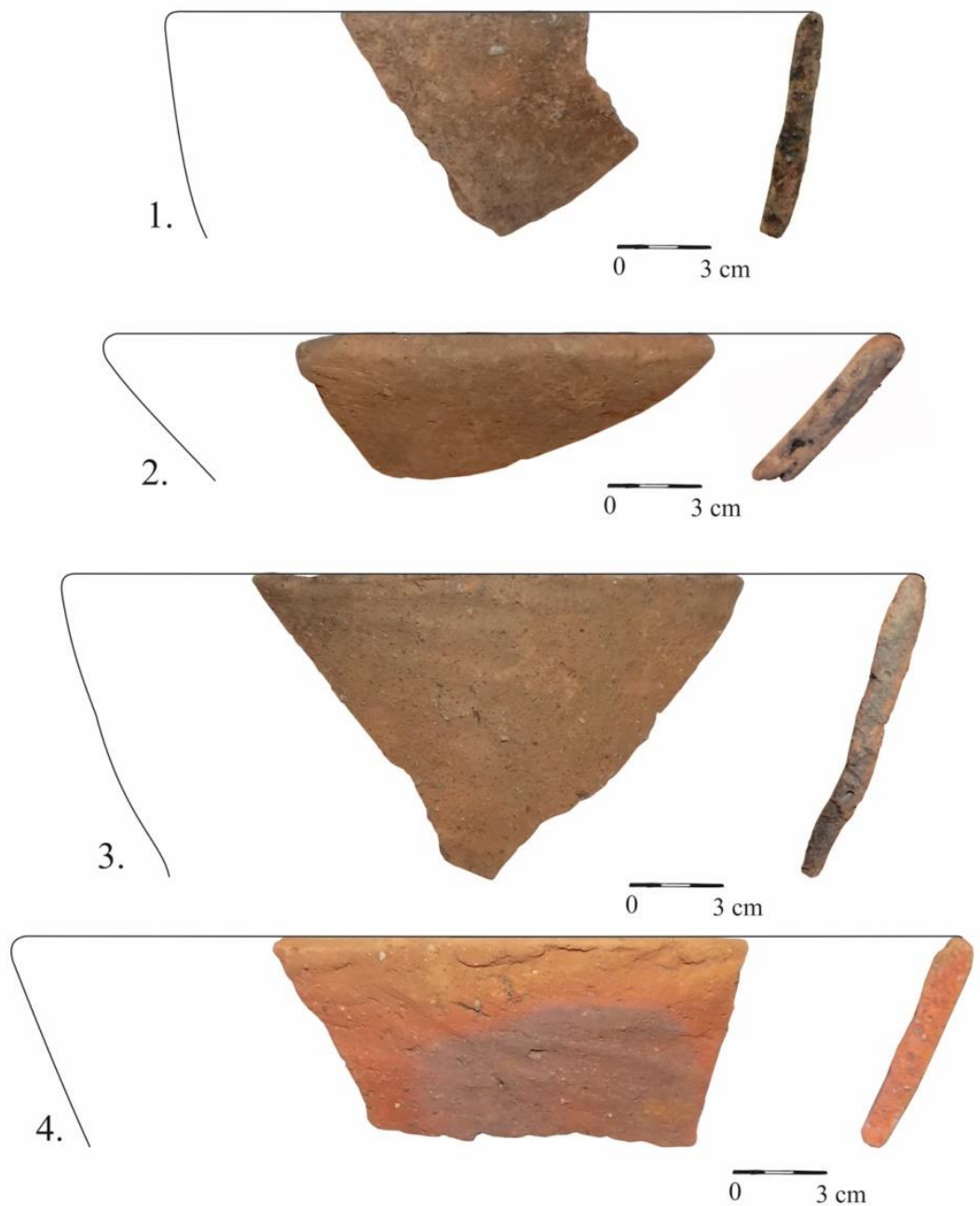

PI. XVI. Turdaș-Luncă. 2011 campaign. Sector C. Feature 959. Pottery. Turdaș culture, phase III. 

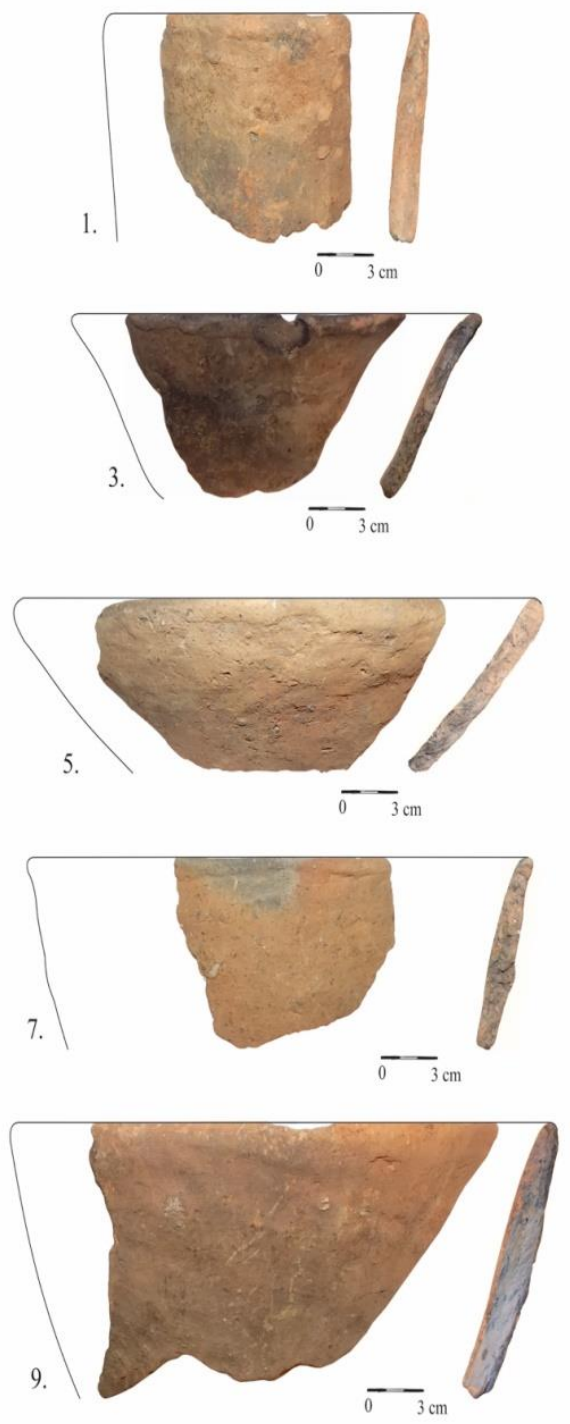
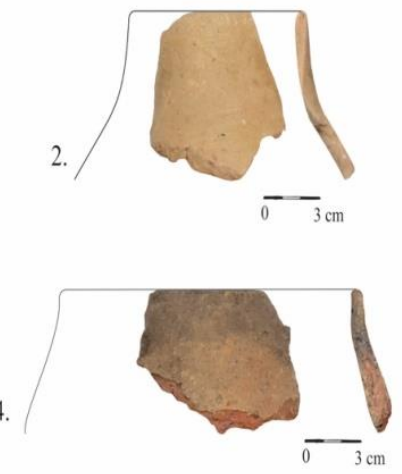

6.

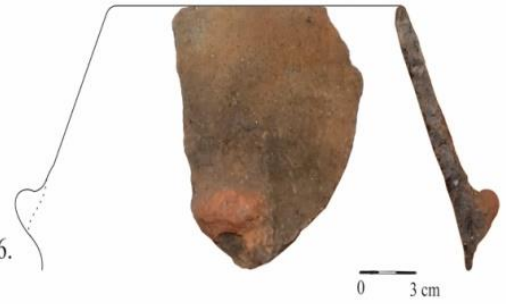

8.

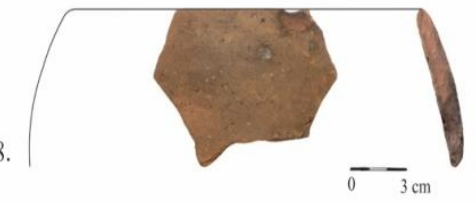

10.

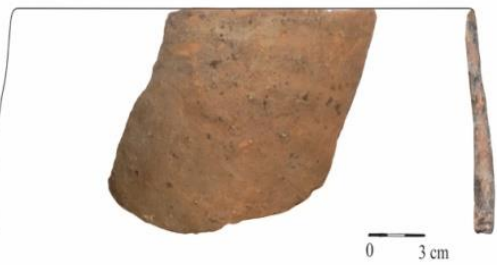

Pl. XVII. Turdaș-Luncă. 2011 campaign. Sector C. Feature 959. Pottery. Turdaș culture, phase III. 

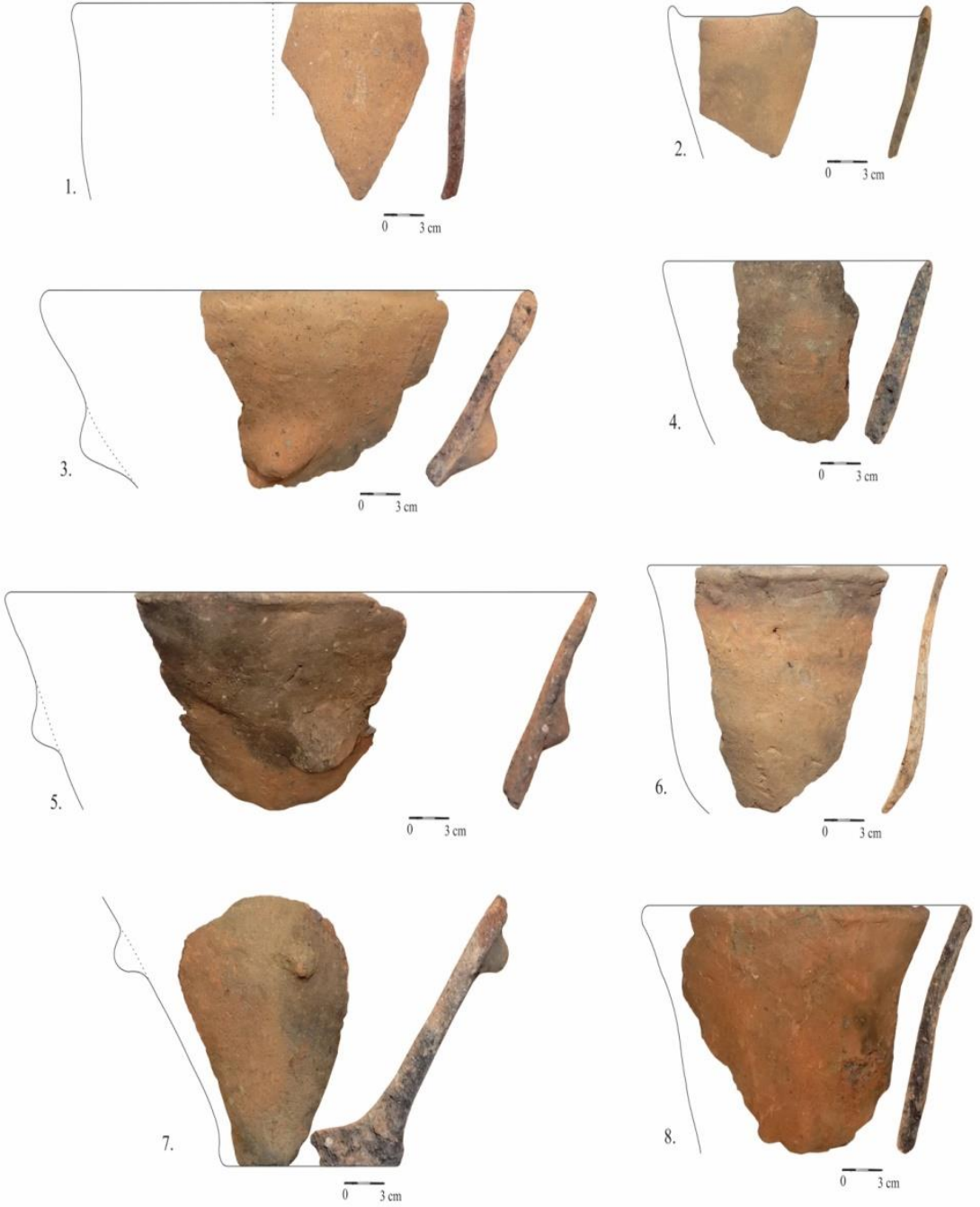

PI. XVIII. Turdaș-Luncă. 2011 campaign. Sector C. Feature 959. Pottery. Turdaş

Pl. XVII. Turdaș-Luncă. 2011 campaign. Sector
culture, phase III.

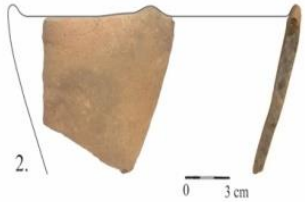

4.

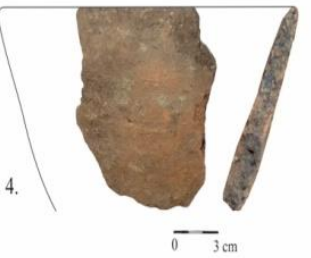

6.

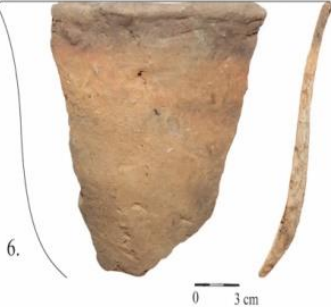



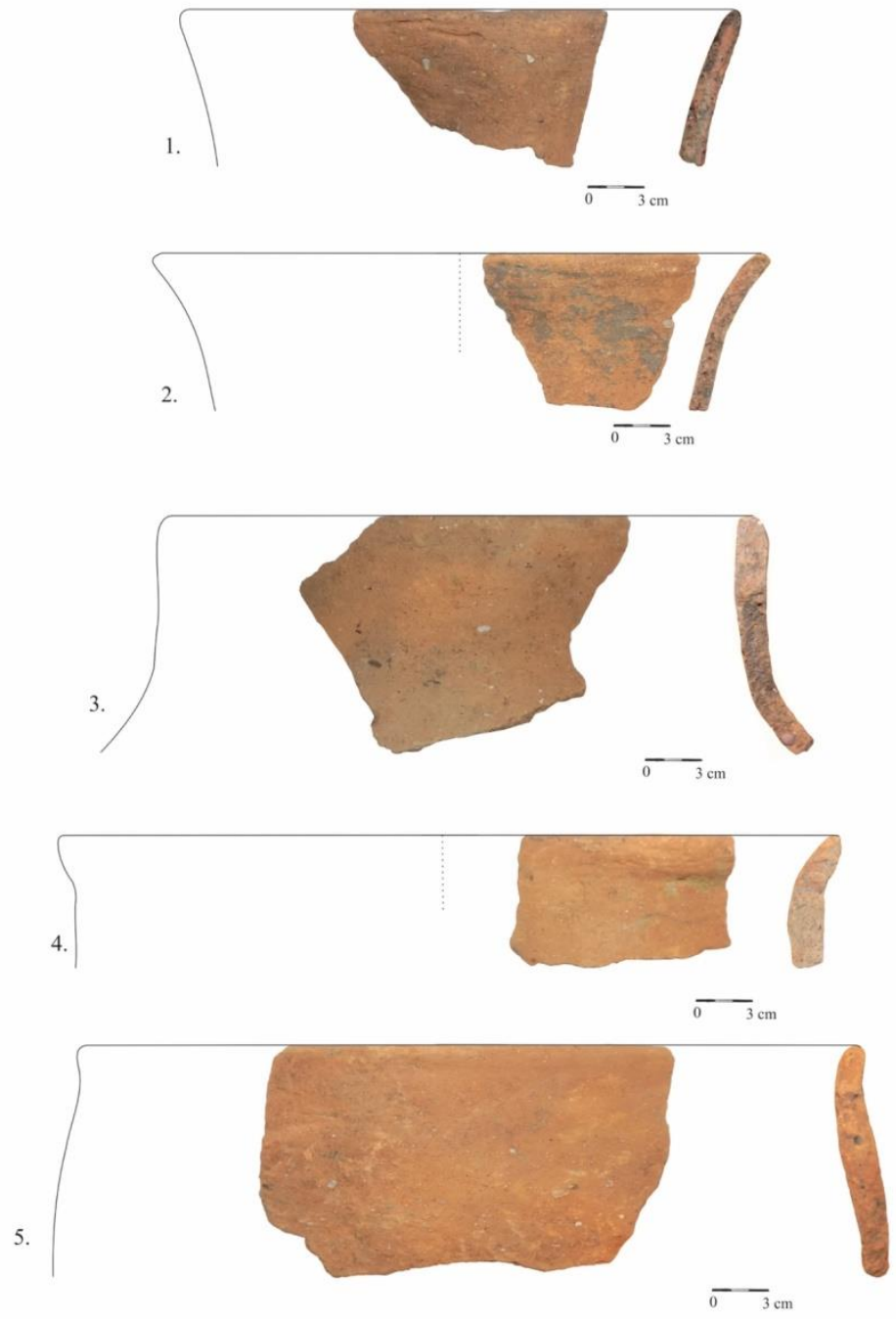

PI. XIX. Turdaş-Luncă. 2011 campaign. Sector C. Feature 959. Pottery. Turdaș culture, phase III. 
The Central Area of a "Square"

1.

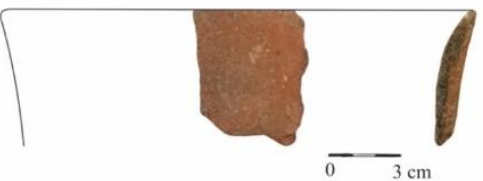

2.

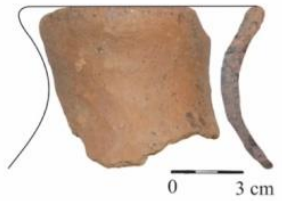

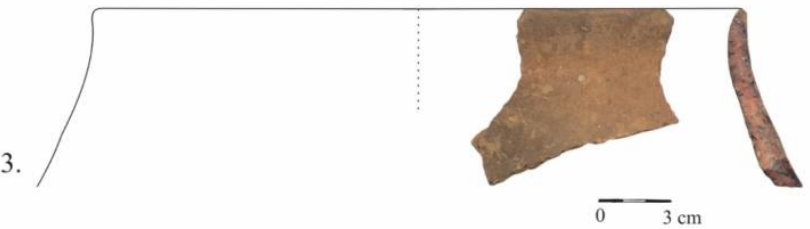
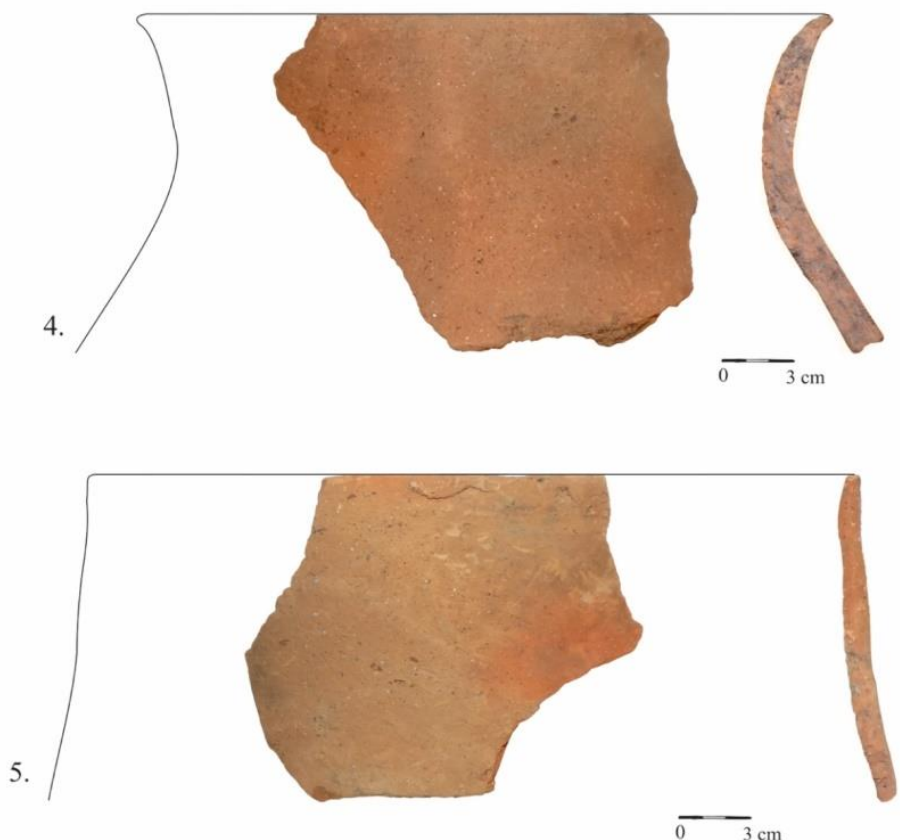

PI. XX. Turdaș-Luncă. 2011 campaign. Sector C. Feature 959. Pottery. Turdaș culture, phase III. 


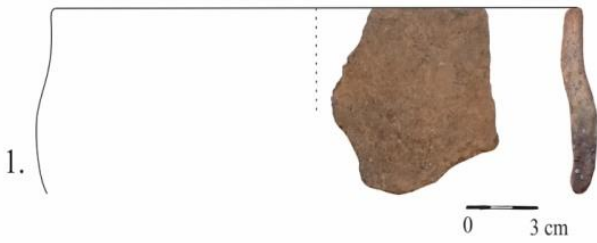

2.
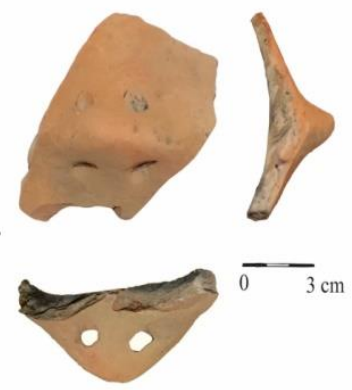

3.

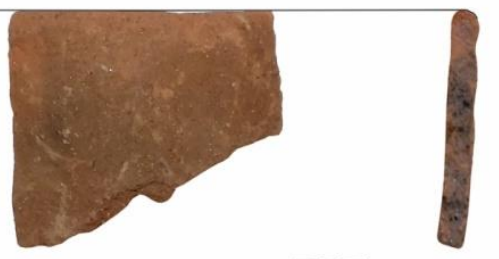

$\overline{0}-3 \mathrm{~cm}$

4.
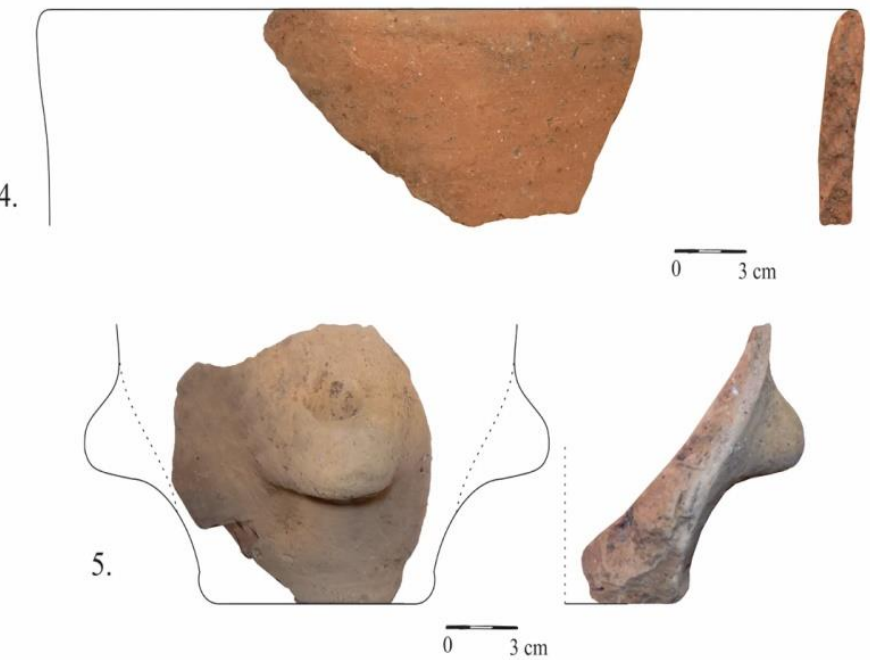

Pl. XXI. Turdaș-Luncă. 2011 campaign. Sector C. Feature 959. Pottery. Turdaș culture, phase III. 

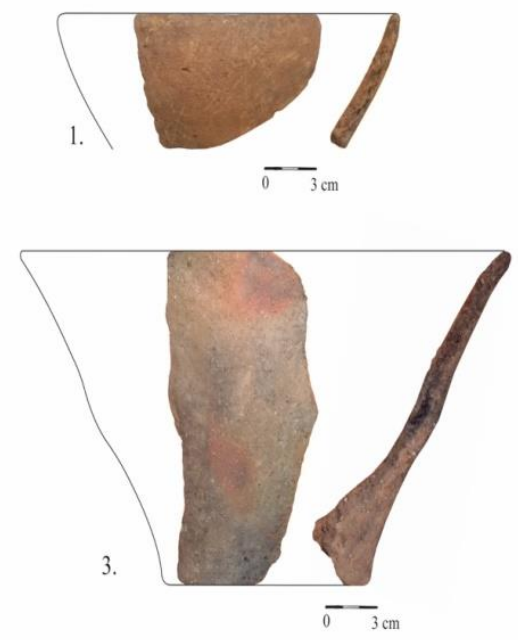
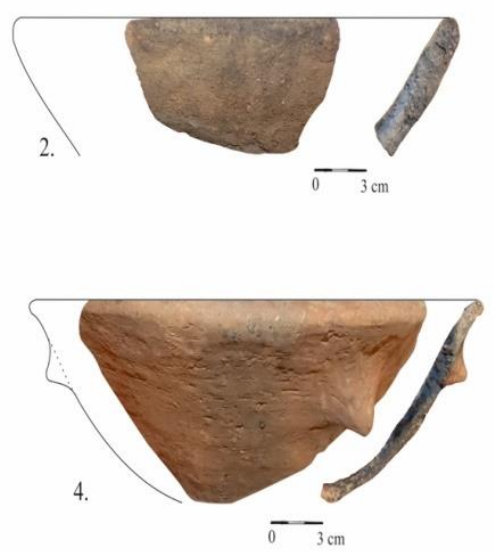

6.
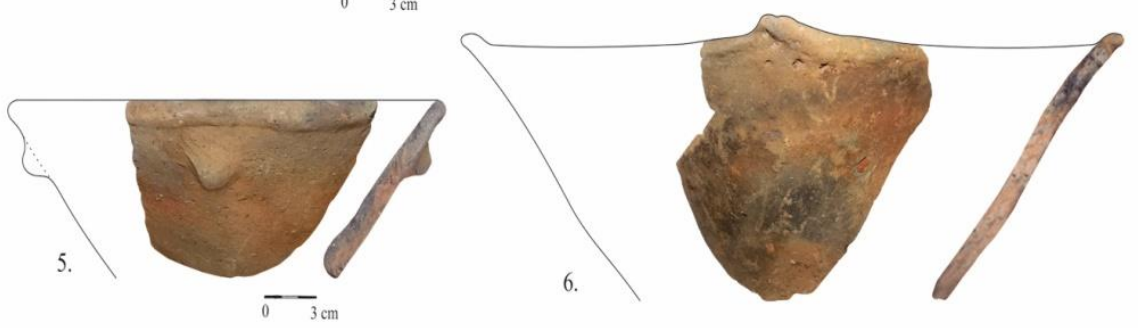

$\overline{0}-\overline{c m}$

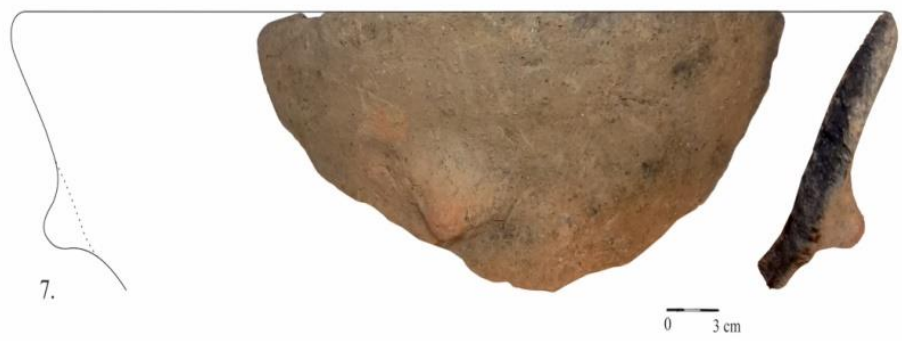

PI. XXII. Turdaș-Luncă. 2011 campaign. Sector C. Feature 959. Pottery. Turdaș culture, phase III. 

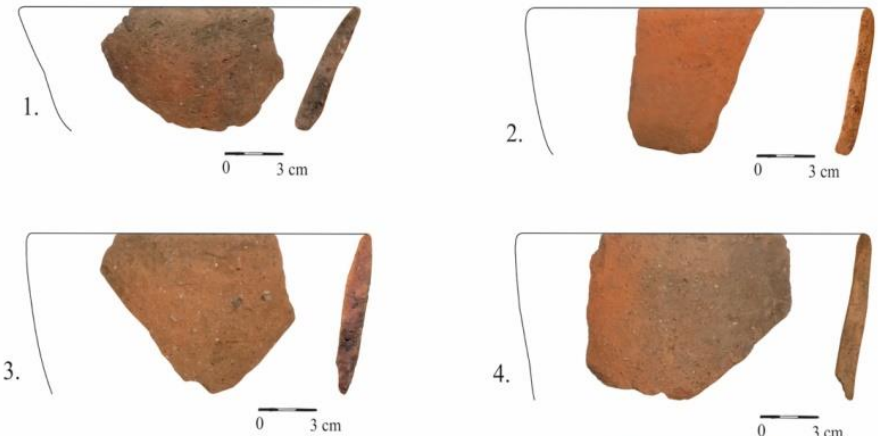

4.
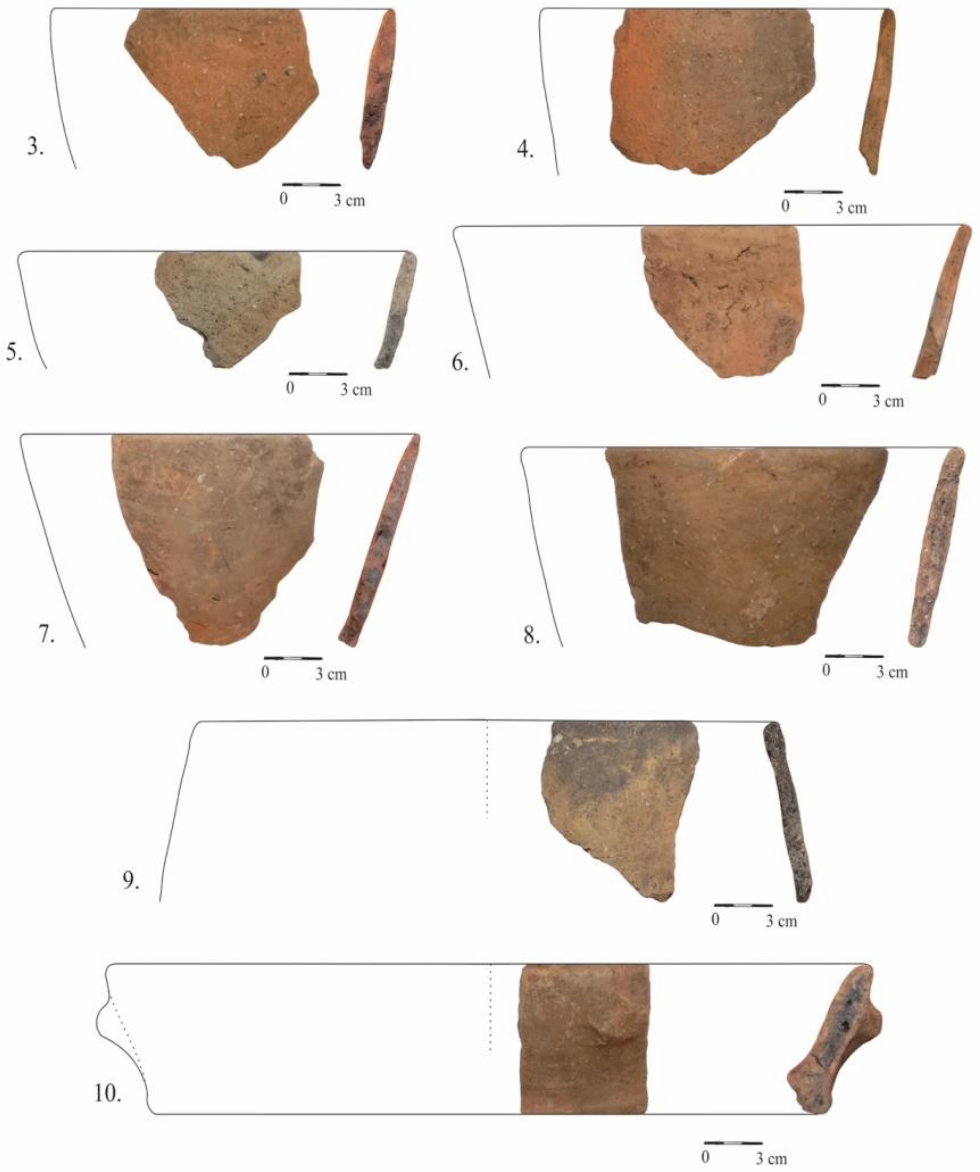

PI. XXIII. Turdaș-Luncă. 2011 campaign. Sector C. Feature 959. Pottery. Turdaș culture, phase III. 

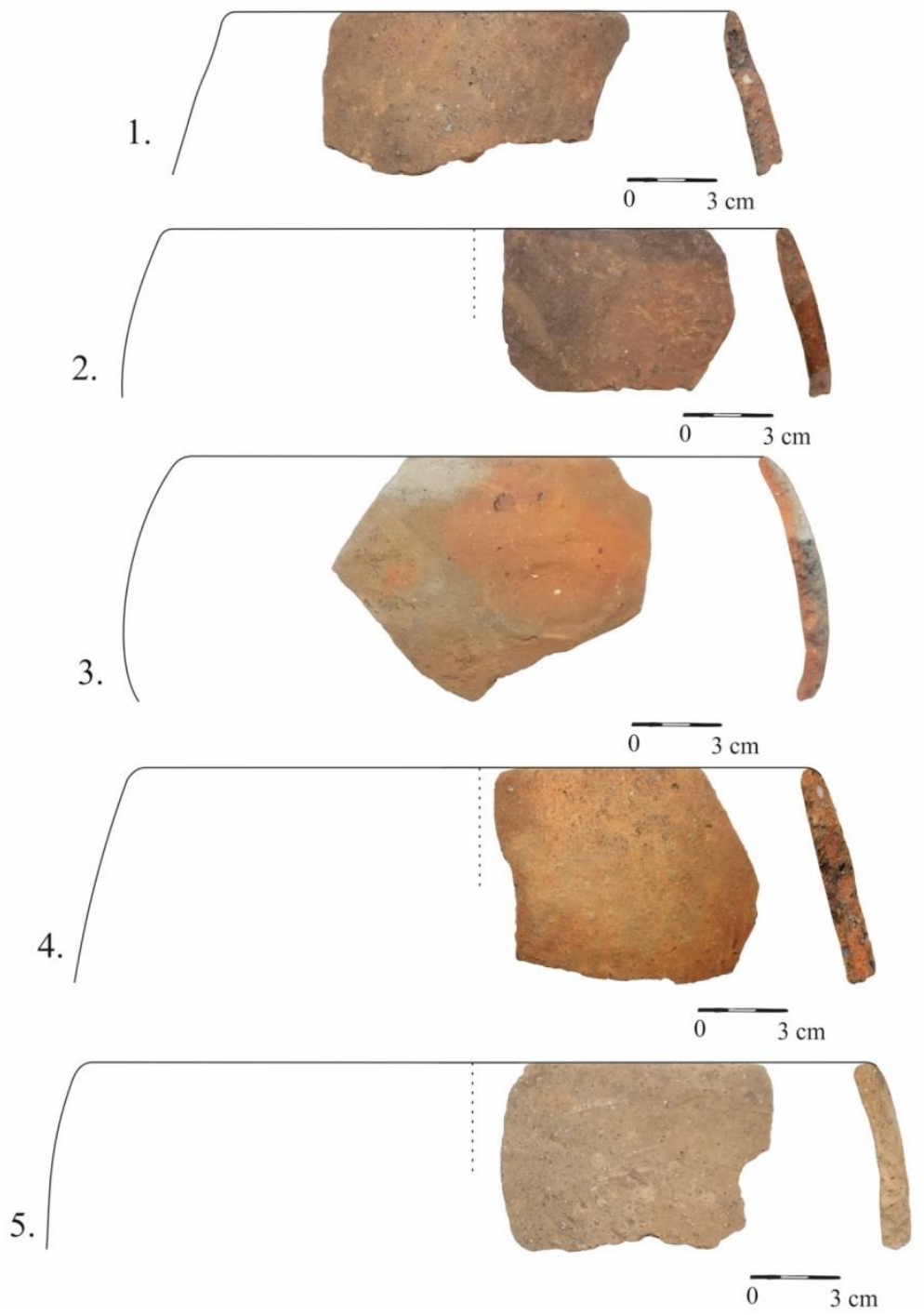

Pl. XXIV. Turdaș-Luncă. 2011 campaign. Sector C. Feature 959. Pottery. Turdaș culture, phase III. 

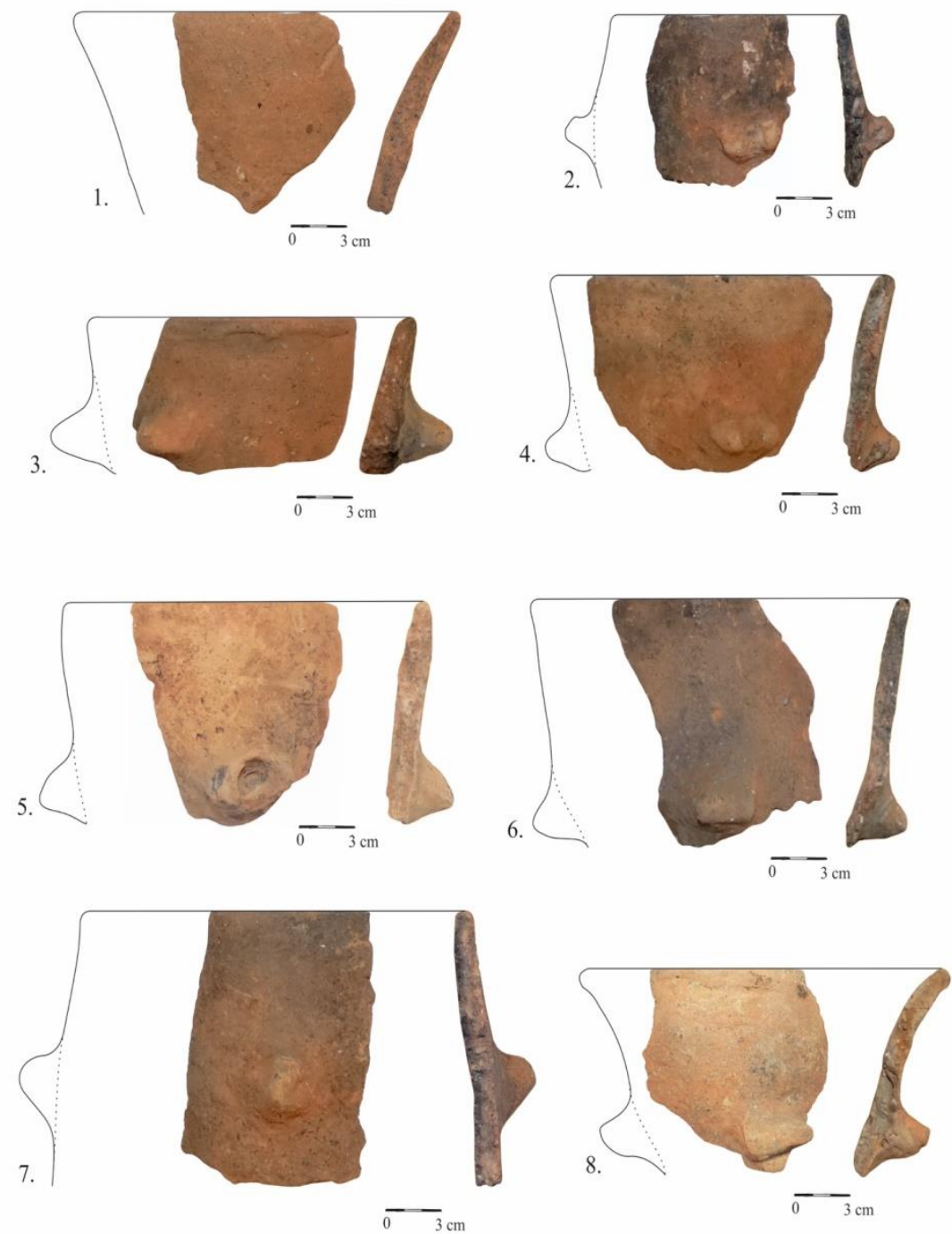

PI. XXV. Turdaș-Luncă. 2011 campaign. Sector C. Feature 959. Pottery. Turdaș culture, phase III. 

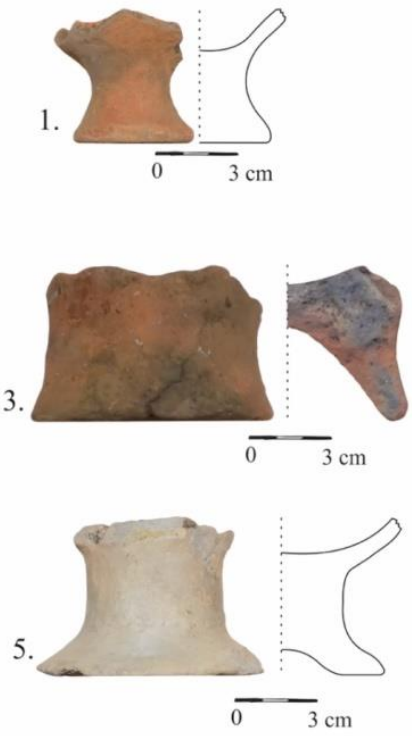

2.
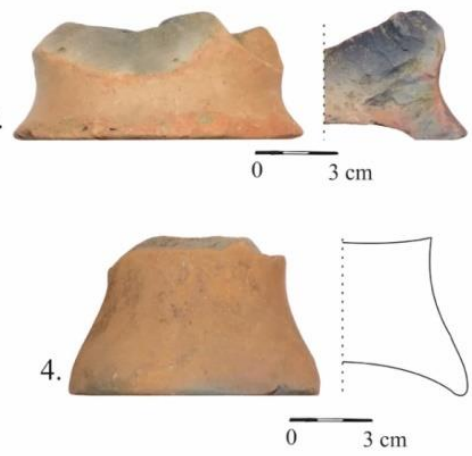

6.
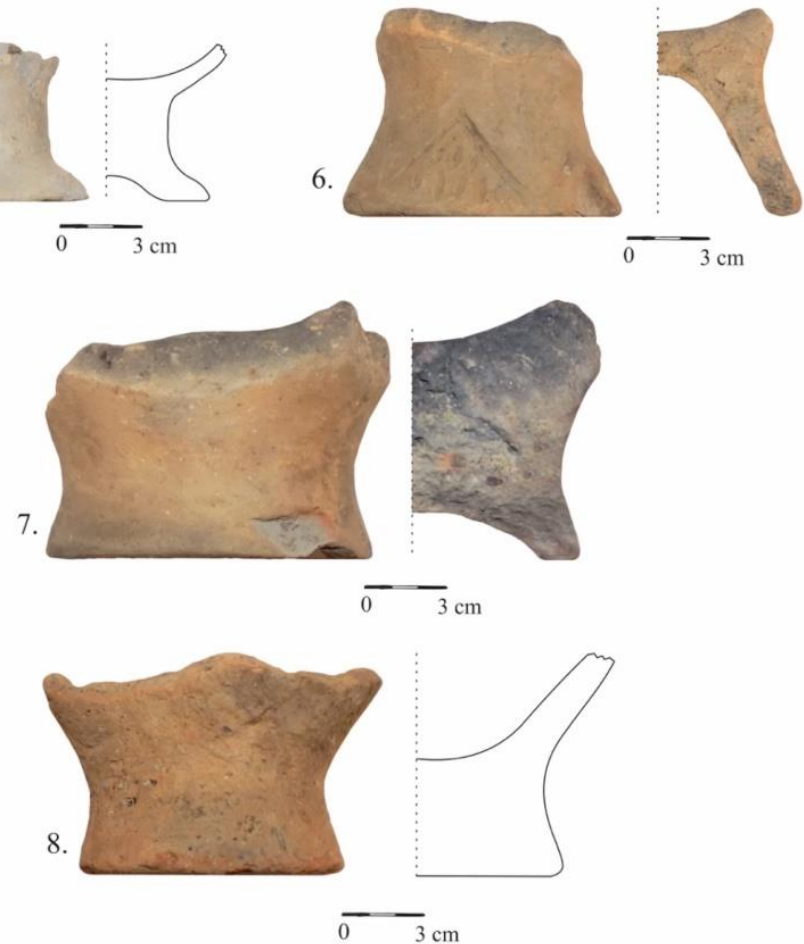

PI. XXVI. Turdaș-Luncă. 2011 campaign. Sector C. Feature 959. Pottery. Turdaș culture, phase III. 

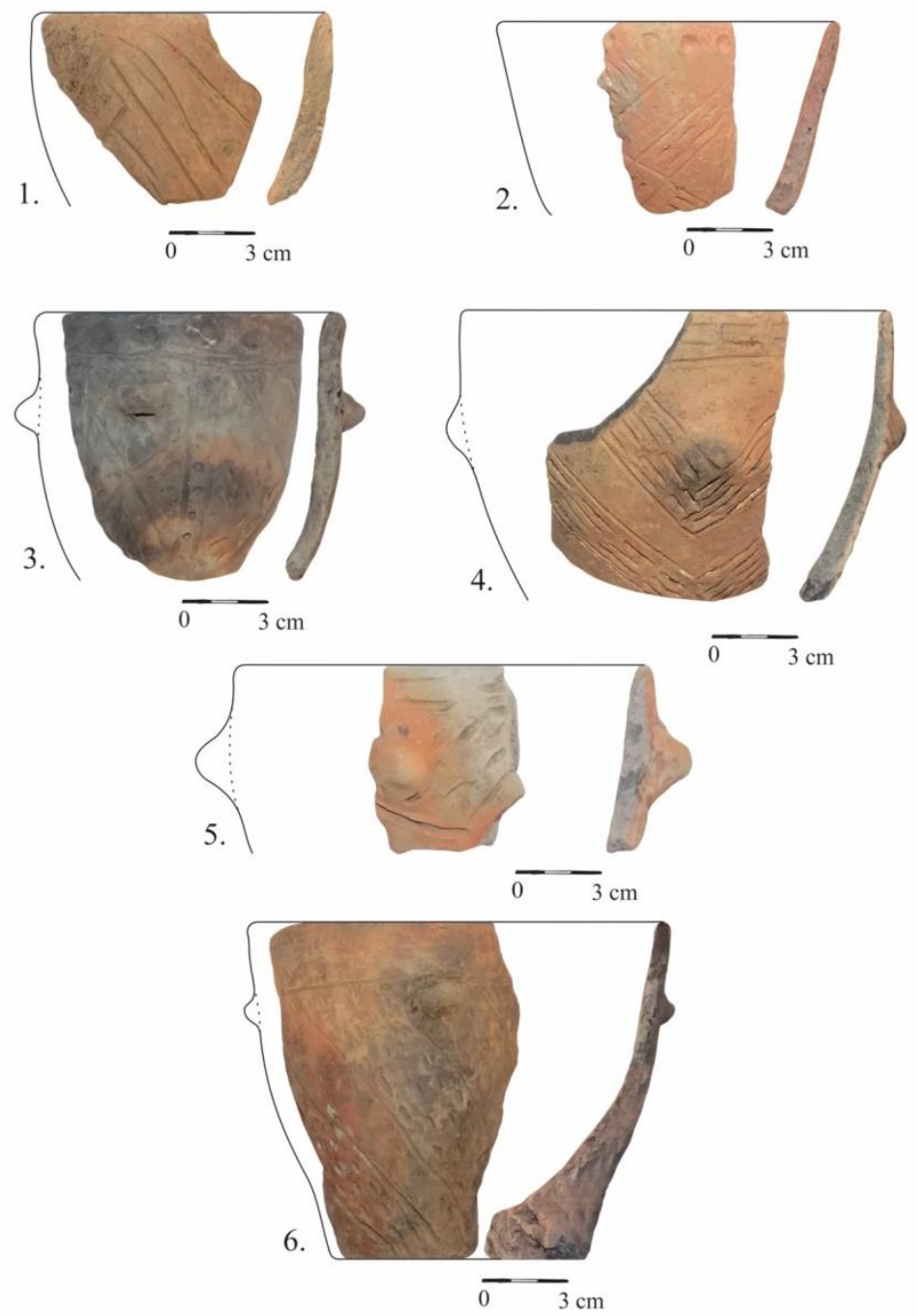

PI. XXVII. Turdaș-Luncă. 2011 campaign. Sector C. Feature 959. Pottery. Turdaș culture, phase III. 

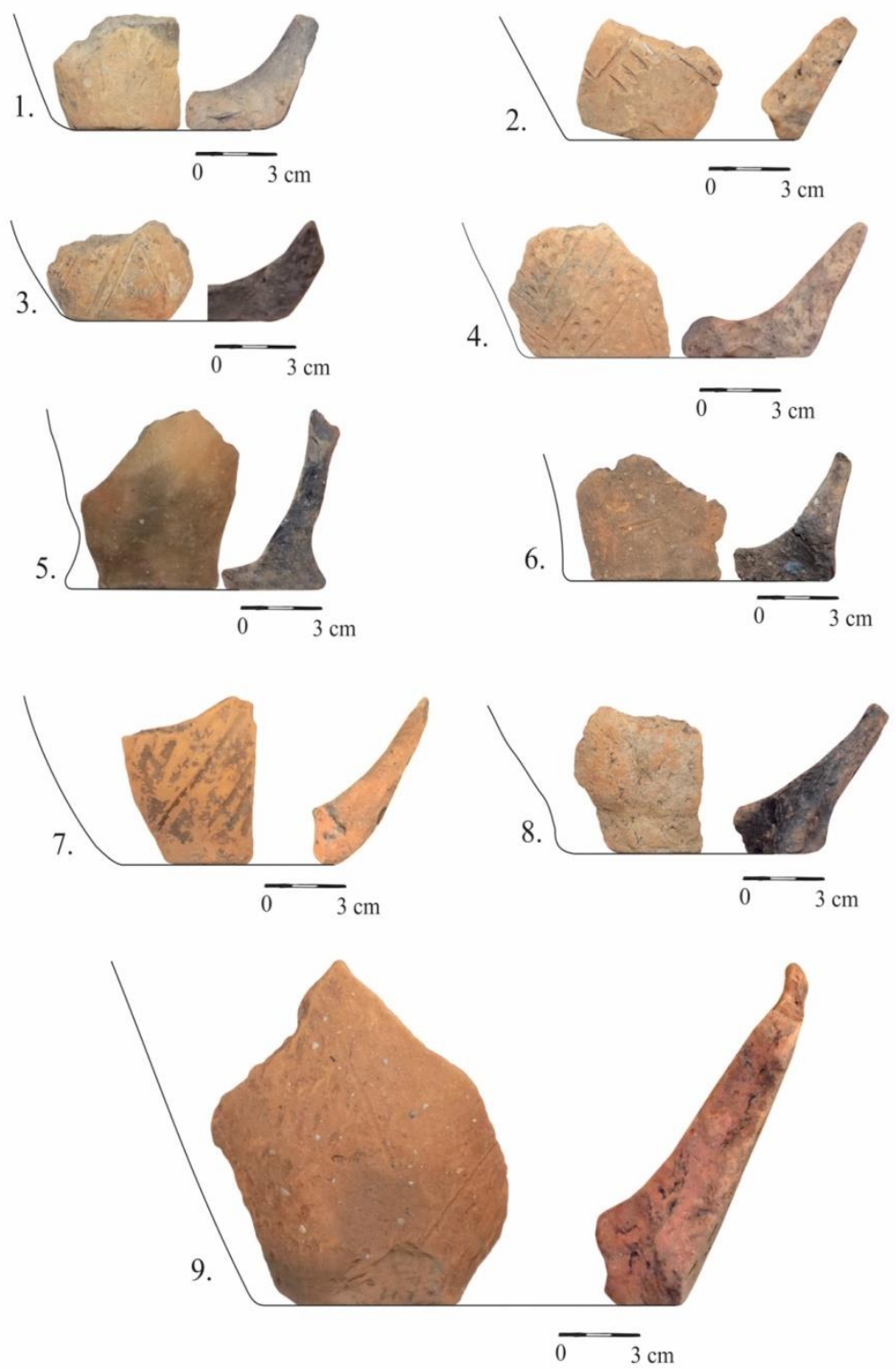

PI. XXVIII. Turdaș-Luncă. 2011 campaign. Sector C. Feature 959. Pottery. Turdaș culture, phase III. 


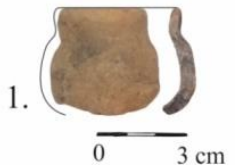

3.

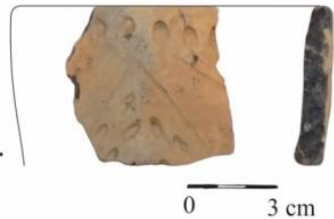

2.

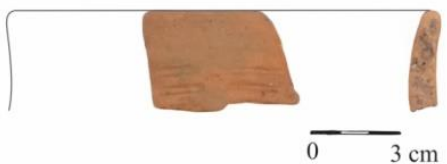

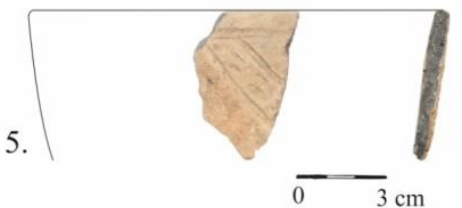

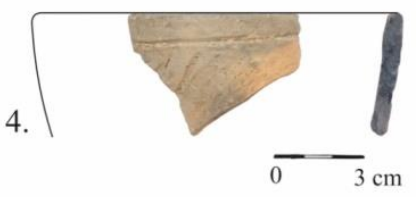

6.

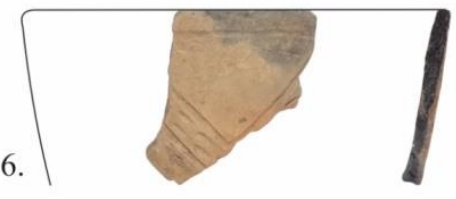

$$
\overline{0}-3 \mathrm{~cm}
$$
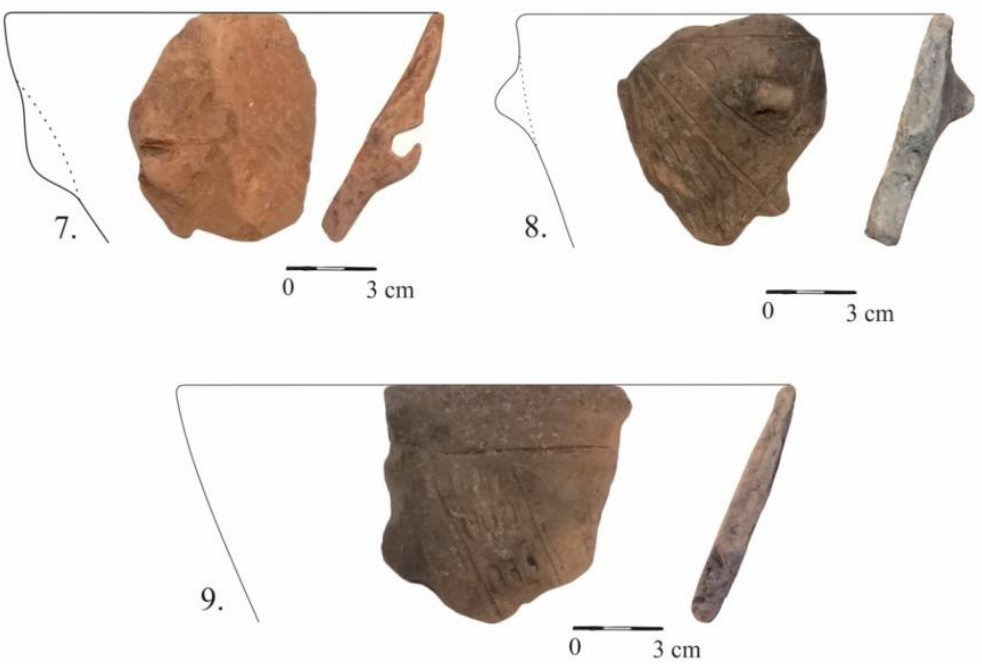

PI. XXIX. Turdaș-Luncă. 2011 campaign. Sector C. Feature 959. Pottery. Turdaș culture, phase III. 
1.

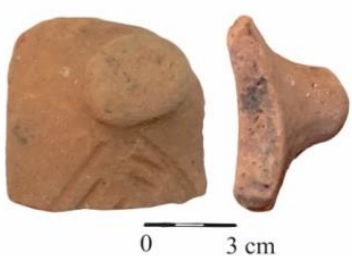

3.

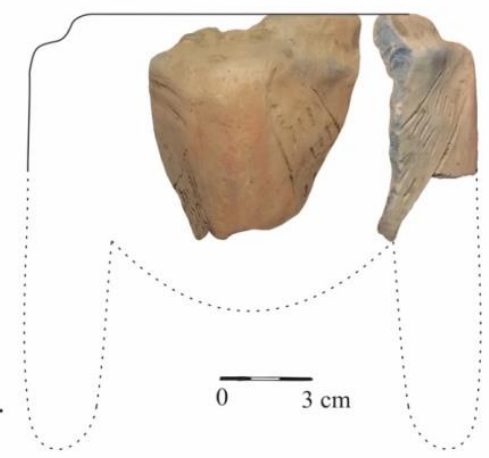

2.

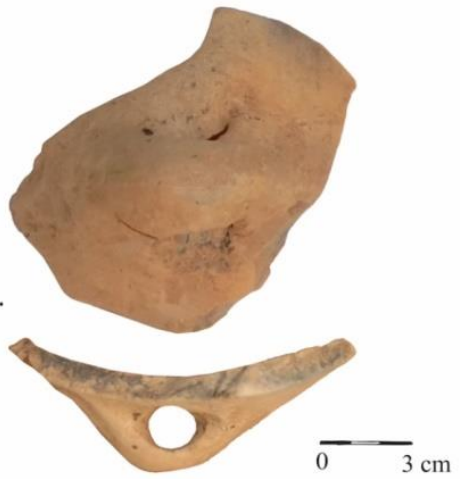

4.

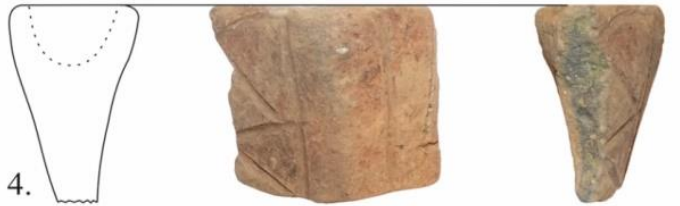

5.
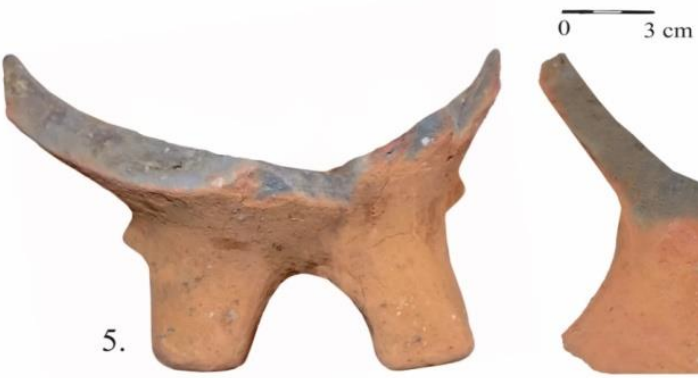

$3 \mathrm{~cm}$

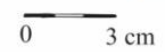

PI. XXX. Turdaș-Luncă. 2011 campaign. Sector C. Feature 959. Pottery. Turdaș culture, phase III. 
1.

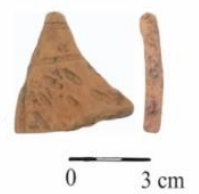

2.

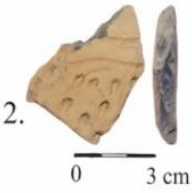

3.

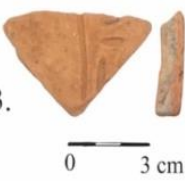

4.
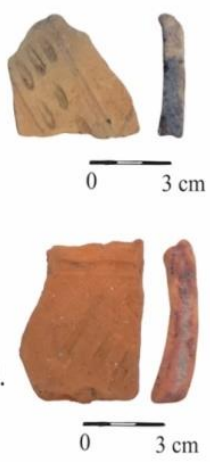

9.

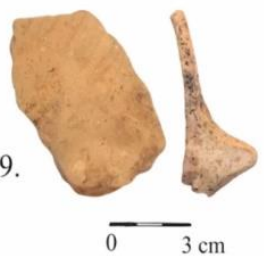

12.

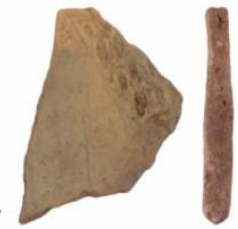

$\overline{0}-3 \mathrm{~cm}$

15.

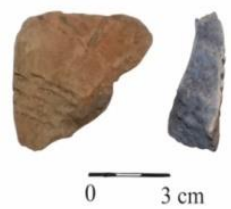

6.

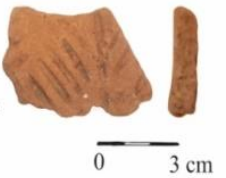

7.

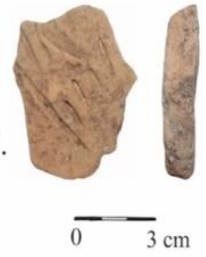

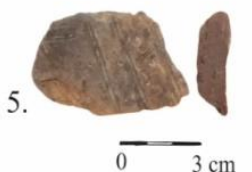
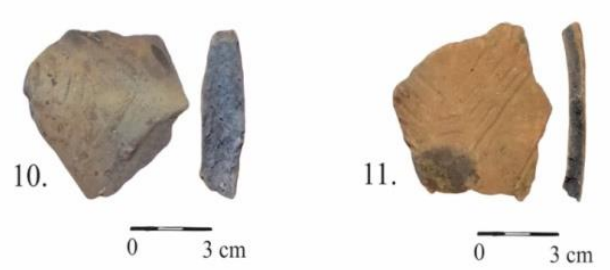

13.
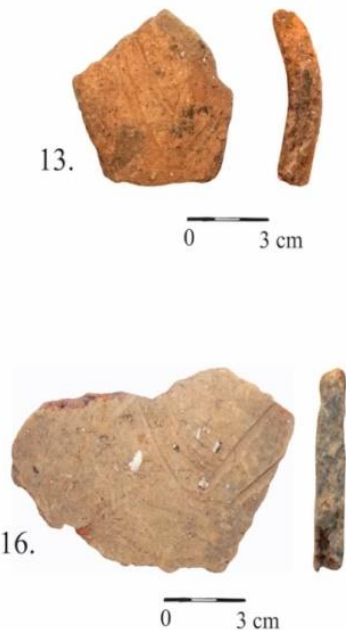

14.

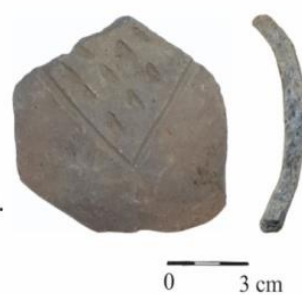

17.

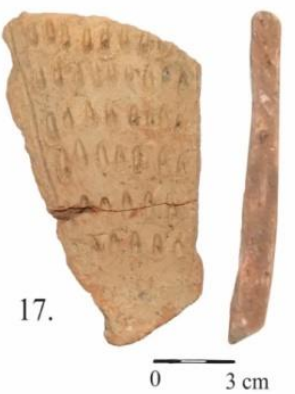

PI. XXXI. Turdaş-Luncă. 2011 campaign. Sector C. Feature 959. Pottery. Turdaş culture, phase III. 
1.
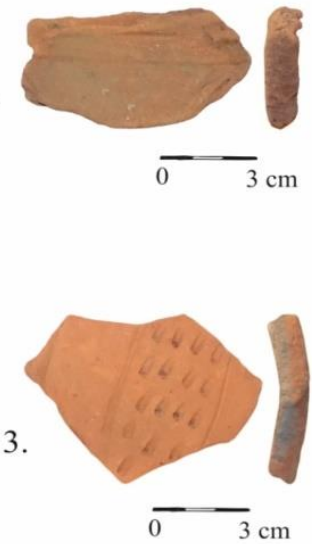

5.

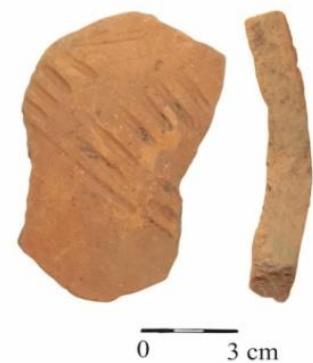

7.

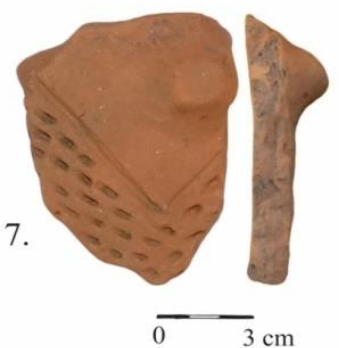

2.

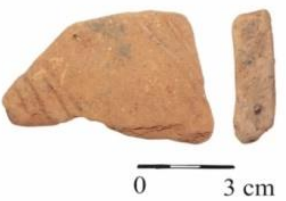

4.

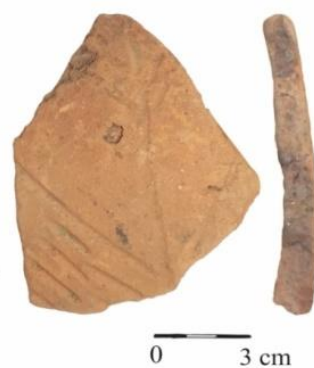

6.

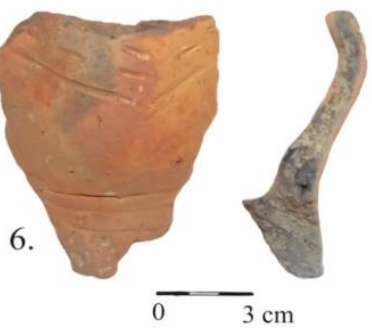

8.
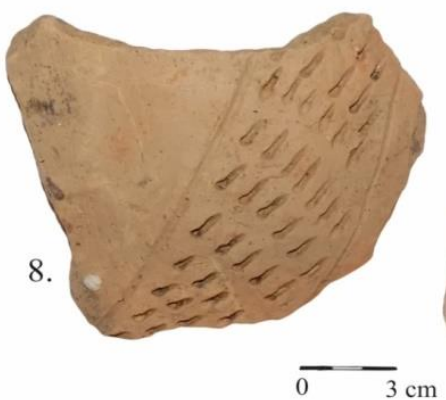

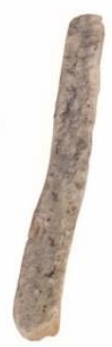

PI. XXXII. Turdaș-Luncă. 2011 campaign. Sector C. Feature 959. Pottery. Turdaș culture III. 
1.

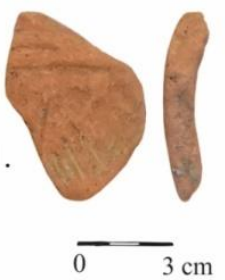

3.

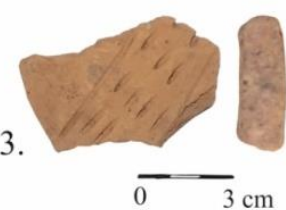

5.

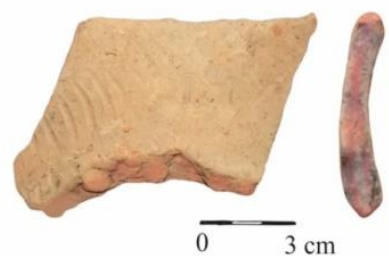

7.

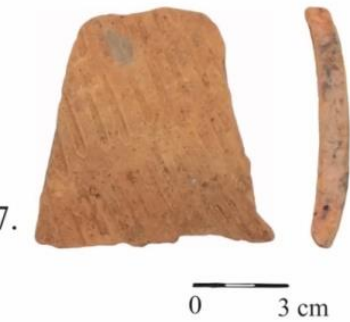

2.

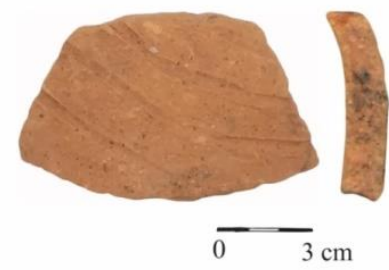

4.

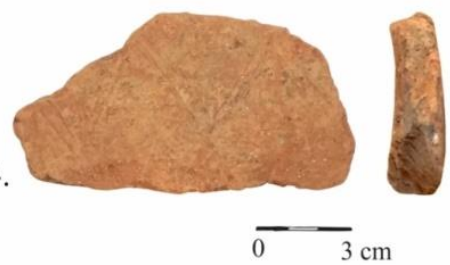

6.

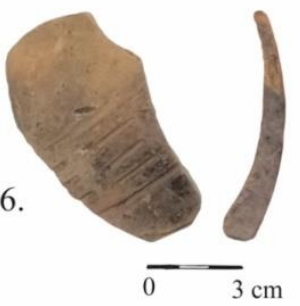

8.

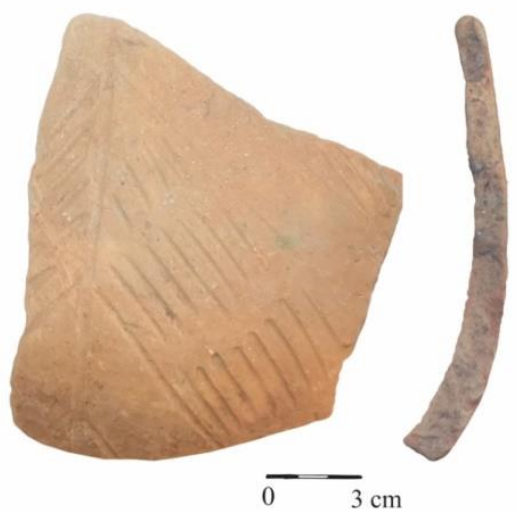

PI. XXXIII. Turdaș-Luncă. 2011 campaign. Sector C. Feature 959. Pottery. Turdaș culture III. 